\title{
Performance Study of Five Different Cabin Air Filters in The Laboratory and On-Road Drive
}

\author{
Fahad Alqahtani \\ falqaht1@mix.wvu.edu
}

Follow this and additional works at: https://researchrepository.wvu.edu/etd

Part of the Industrial Engineering Commons, Occupational Health and Industrial Hygiene Commons, and the Other Engineering Commons

\section{Recommended Citation}

Alqahtani, Fahad, "Performance Study of Five Different Cabin Air Filters in The Laboratory and On-Road Drive" (2020). Graduate Theses, Dissertations, and Problem Reports. 7950.

https://researchrepository.wvu.edu/etd/7950

This Dissertation is protected by copyright and/or related rights. It has been brought to you by the The Research Repository @ WVU with permission from the rights-holder(s). You are free to use this Dissertation in any way that is permitted by the copyright and related rights legislation that applies to your use. For other uses you must obtain permission from the rights-holder(s) directly, unless additional rights are indicated by a Creative Commons license in the record and/ or on the work itself. This Dissertation has been accepted for inclusion in WVU Graduate Theses, Dissertations, and Problem Reports collection by an authorized administrator of The Research Repository @ WVU.

For more information, please contact researchrepository@mail.wvu.edu. 


\title{
Performance Study of Five Different Cabin Air Filters in The Laboratory and On-Road Drive
}

\author{
FAHAD ALQAHTANI \\ Dissertation submitted to \\ Benjamin M. Statler College of Engineering and Mineral Resources \\ at West Virginia University \\ in partial fulfillment of the requirements for the degree of \\ Doctor of Philosophy \\ in \\ Industrial Engineering \\ Warren Myers, Ph.D., Chair \\ Gary Winn, Ph.D. \\ Kenneth Currie, Ph.D. \\ Ziqing Zhuang, Ph.D. \\ Anna Allen, MD. \\ Department of Industrial and Management Systems Engineering
}

\section{Morgantown, West Virginia}

2020

Keywords: Cabin Air Filters, $\mathrm{PM}_{2.5}, \mathrm{PM}_{10}$, Laboratory Performance, On-road Performance, Optical Particle Sizer (OPS).

Copyright 2020 Fahad Alqahtani 


\section{Abstract \\ Performance Study of Five Different Cabin Air Filters in The Laboratory and On-Road Drive}

\section{Fahad Alqahtani}

One of the aims of installing ventilation filters in a car is to prevent vehicle occupants from inhaling potentially harmful aerosols emanating from the environment. Vehicle cabin filters are essential in ensuring that a vehicle's air conditioning system provides clean air to its occupants. The purpose of the cabin filter is to improve air quality inside the car to provide better comfort and better protect occupants from experiencing unwanted respiratory problems. Using cabin filters in air conditioning systems is a common practice in modern vehicle manufacturing. Scientists and engineers are continually seeking new ways of improving the efficiency and effectiveness of cabin filters.

First, a laboratory experiment was conducted to test the mean efficiency for five different types of cabin air filters, which were separated into two groups based on the average surface area of each group. Each group was tested under three different concentrations $(40,000,60,000$ 80,000) particles/ $\mathrm{cm}^{3}$ as well as three different face velocities $(4.3,8.8,13.3) \mathrm{cm} / \mathrm{s}$ for group one and face velocities $(2.6,5.3,7.9) \mathrm{cm} / \mathrm{s}$ for group two, respectively. The purpose of this study was to evaluate the filtration efficiency of car air conditioning filters as a function of aerosol concentration and challenge face velocity. In addition, this study was also to simulate construction applications, since most construction equipment have cabins that should isolate workers from dust that the construction equipment makes. A three-way ANOVA was analyzed in JMP Software. The analysis showed that the types of filter, particle concentrations, and face velocities significantly $(p<0.05)$ effected the mean efficiency for both groups. The results for each group indicated that the highest mean efficiency across all filter types occurred at the lowest face velocity and the lowest mean efficiency was at the highest face velocity. Further, the mean efficiencies always decreased when the face velocities and concentration increased.

Finally, a second study, Study II, was conducted to evaluate the filtration efficiency of the five car air conditioning filters during city and highway driving. Test conditions during city or highway driving included seven ventilation fans setting and two different car speeds (50 and 70 $\mathrm{mph}$ ). This study investigated the efficiency of current car cabin filters and their effectiveness in filtering out particles in the air such as viruses, especially COVID-19. In addition, the major application areas that challenge COVID-19 are school buses, personal cars, taxis via different platforms such as Uber, and industrial vehicles. Study II sought to provide an insight to the combined operational efficiency of five types of cabin filters from particles ranging of 10 to 10,000 nanometer in normal operating conditions. The results from this investigation may be considered for development of standards to improve cabin air filters in future. 


\section{Acknowledgements}

I would like to express my deepest gratitude to my advisor Dr. Warren Myers for his continuous support, encouragement, and guidance, and for having confidence in me. His guidance helped me in all the time of research and writing of this dissertation. I was lucky to work with him and learn from his experience and skills in my field of research.

I wish to extend my thanks to my committee members, Dr. Gary Winn, Dr. Kenneth Currie, Dr. Ziqing Zhuang, and Dr. Anna Allen, for their time and efforts to review this research, and their precious suggestions and comments. I would thank Dr. Xinjian (Kevin) He for his academic support and help during my research development and writing. I greatly appreciate all the faculty members from the Department of Industrial and Management Systems Engineering for their help and encouragement.

Also, my thanks and appreciations go to my parents for their support, encouragement, and wise counsel. I would also like to thank my brothers and sisters, whom without their support this would have not been possible. I also appreciate all the support I received from the rest of my family.

Finally, to my wife, Majidah, and my two lovely children, Saad and Deem: your love and understanding helped me through my studies. Without you believing in me, I never would have made it. It is time to celebrate; you earned this degree right along with me. 


\section{Table of Contents}

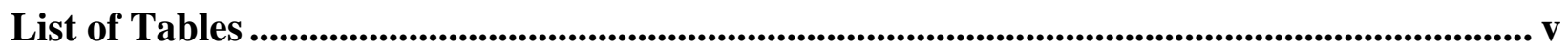

List of Figures...................................................................................................................... vi

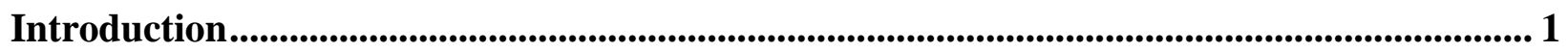

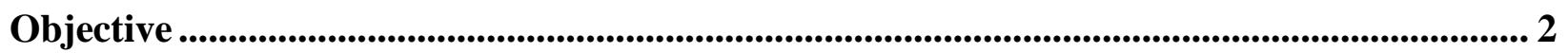

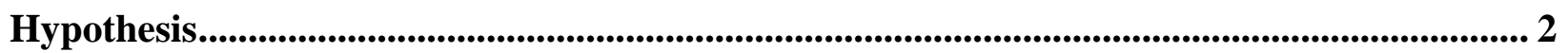

The first hypothesis: ......................................................................................................................... 2

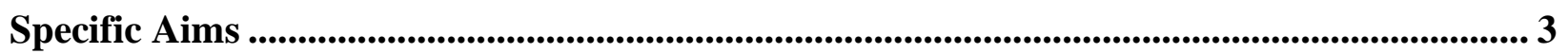

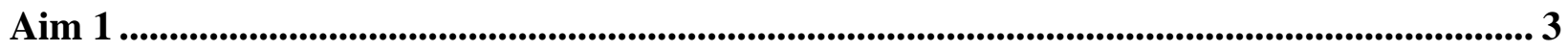

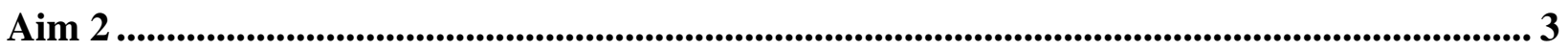

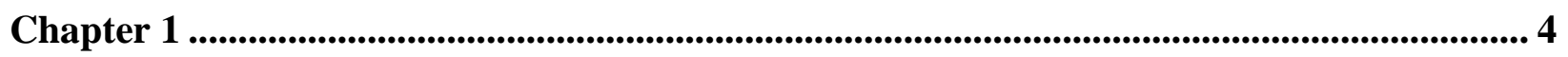

Introduction................................................................................................................................. 4

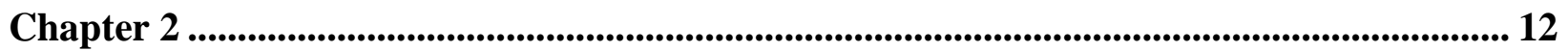

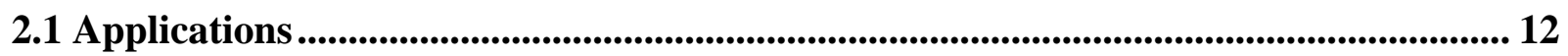

2.2 Equipment and Variables .............................................................................................. 14

2.3 Data Collection ......................................................................................................... 20

2.4 Data analysis................................................................................................................................ 22

2.5 Results and Discussion.................................................................................................................. 23

2.6 Conclusion ................................................................................................................................... 34

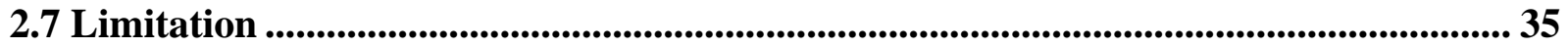

Chapter 3 .............................................................................................................................................. 36

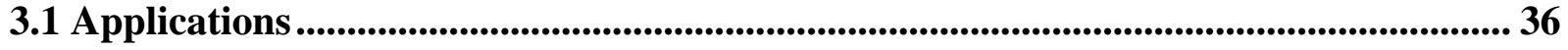

3.2 Equipment and Variables ....................................................................................................... 37

3.3 Experimental Setup ................................................................................................................... 41

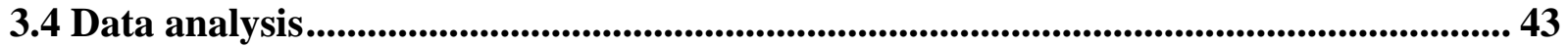

3.5 Results and Discussion............................................................................................................ 44

3.5.1 NanoScan Results for Midpoint Particle Size Range from $11.5 \mathrm{~nm}$ to $273.8 \mathrm{~nm}$....... 44

3.5.2 OPS Results for Midpoint Particle Size Range from $335 \mathrm{~nm}$ to 8,962.1 nm ............. 52

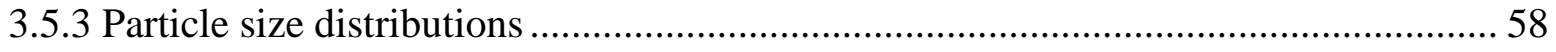

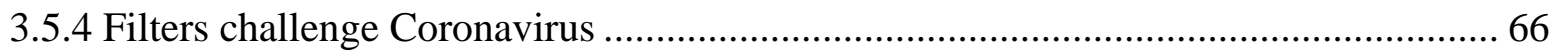

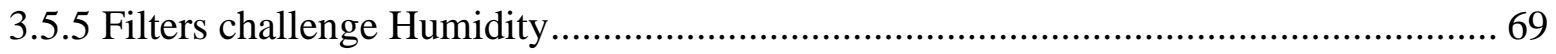

3.6 Conclusion ............................................................................................................................. 72

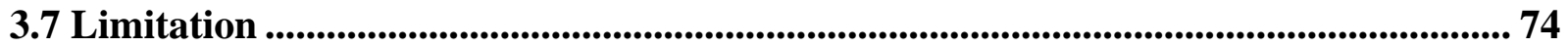




\section{List of Tables}

Table 2. 1 Flow rates required to achieve desired filter face velocities (Group one) …............................19

Table 2. 2 Flow rates required to achieve desired filter face velocities (Group two) ............................... 19

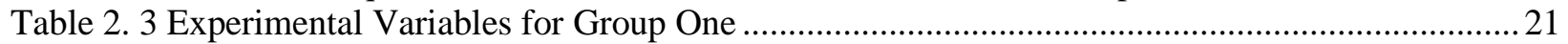

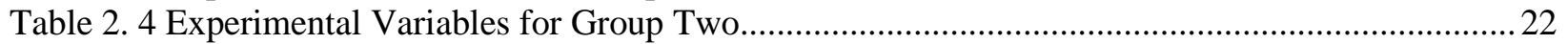

Table 2. 5 Average efficiency \% of the three cabin air filters (Group one) (............................................23

Table 2. 6 Average efficiency \% of the two cabin air filters (Group Two) ...........................................2 24

Table 2. 7 Three-way ANOVA results for filter efficiency as a function of air filter type, face velocity, and particle challenge concentration (Group one) ….......................................................................29

Table 2. 8 Three-way ANOVA results for filter efficiency as a function of air filter type, face velocity,

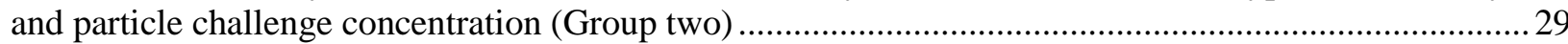

Table 2. 9 Pairwise multiple comparisons: mean efficiency\% among type of filters, face velocities and

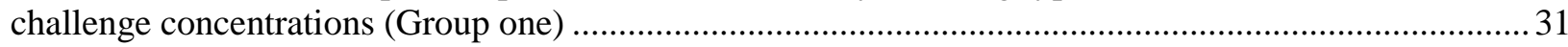

Table 2. 10 Pairwise multiple comparisons: mean efficiency\% among type of filters, face velocities and

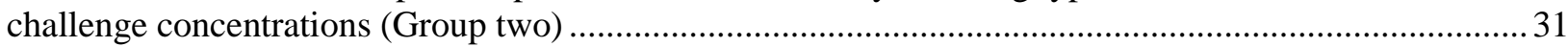

Table 2. 11 Mean efficiency\% among two way interaction between type of filters and challenge face

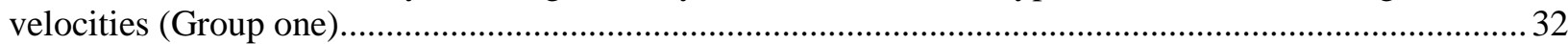

Table 2. 12 Mean efficiency\% among two-way interaction between type of filters and face velocities

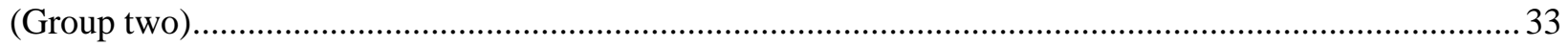

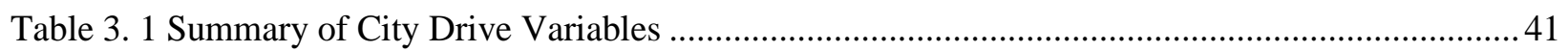

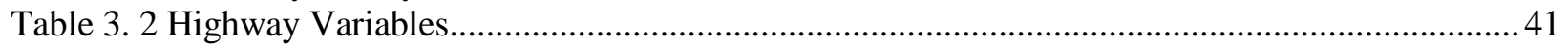

Table 3. 3 Mean Efficiency \% for the particle size range from 11.5 to $273.8 \mathrm{~nm}$................................ 45

Table 3. 4 Three-way ANOVA results for the Efficiency of particle size range from 11.5 to $273.8 \mathrm{~nm}$ as a function of type of cabin air filter, fan speeds (recirculation mode), and driving conditions ....................47 Table 3. 5 Pairwise multiple comparisons: Mean efficiency\% for particle size from 11.5 to $273.8 \mathrm{~nm}$ among type of filters, recirculation mode, and driving conditions .........................................................48

Table 3. 6 Mean efficiency\% among two-way interaction between type of filters and fan speeds

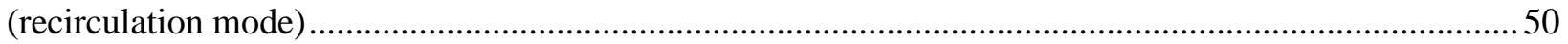

Table 3. 7 Mean efficiency\% among two-way interaction between type of filters and driving conditions 51

Table 3. 8 Mean Efficiency \% for the particle size range from 335 to 8,962.1 nm ...............................53

Table 3. 9 Three-way ANOVA results for the Efficiency of midpoint particle size range (335 - 8,962.1 $\mathrm{nm}$ ) as a function of type of cabin air filter, fan speeds (recirculation mode), and driving conditions ...... 55 Table 3. 10 Pairwise multiple comparisons: Mean efficiency\% for the particle size from 335 to 8,962.1 $\mathrm{nm}$ among type of filters, fan speeds (recirculation mode), and driving conditions .................................56 Table 3. 11 Mean efficiency\% among two way interaction between type of filters and driving conditions

Table 3. 12 Mean Filter Efficiency\% for Particles Ranging from 11.5 to 273.8 nanometers Under

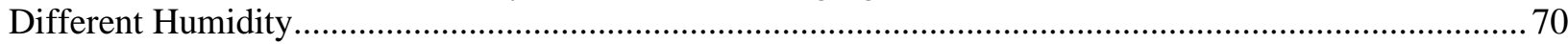

Table 3. 13 Three-way ANOVA results for the mean Efficiency for particles ranging from 11.5 to 273.8 nanometers as a function of type of cabin air filter, fan speeds (recirculation mode), and humidity .........70 Table 3. 14 Pairwise multiple comparisons: Mean efficiency for particles ranging from 11.5 to 273.8

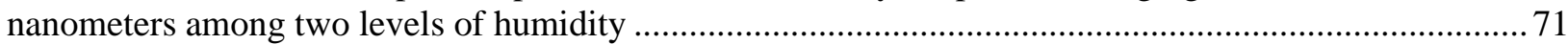

Table 3. 15 Mean Efficiency for Particles Ranging from 335 to 8,962.1 nanometers Under Different Humidity Under Different Humidity ......................................................................................... 71 
Table 3. 16 Three-way ANOVA results for the Filter Efficiency of 335-8,962.1 Nanometer Particles as a function of type of cabin air filter, fan speeds, and humidity 72 Table 3. 17 Pairwise multiple comparisons: Mean efficiency of 335-8,962.1 Nanometer Particles among two levels of humidity

\section{List of Figures}

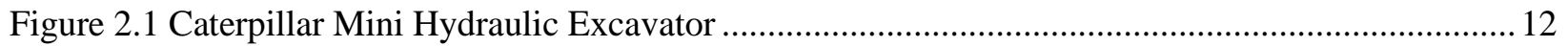

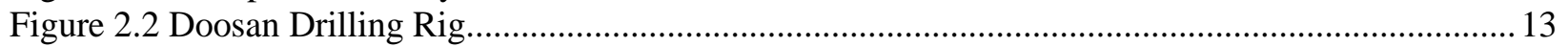

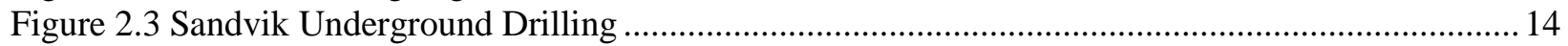

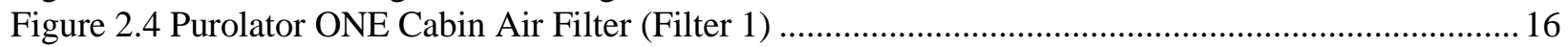

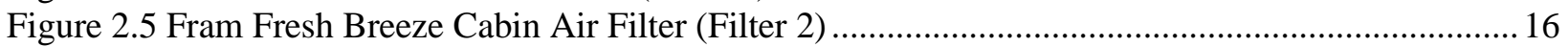

Figure 2.6 Beck/Arnley Paper Cabin Air Filter (Filter 3) .............................................................. 16

Figure 2.7 Purolator Premium with Febreze Freshness (Filter 4) ...................................................... 17

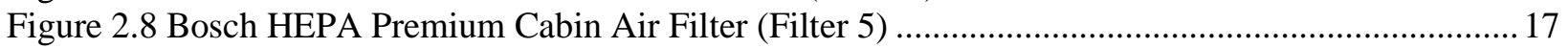

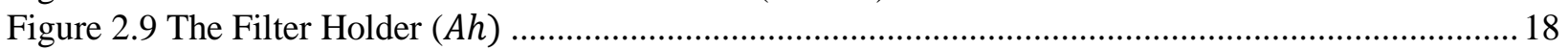

Figure 2.10 Experimental Setup (modified from He et al., 2013) .....................................................20

Figure 2.11 Filter efficiency at a challenge concentration of 40,000 particles $/ \mathrm{cm}^{3}$ versus face velocities

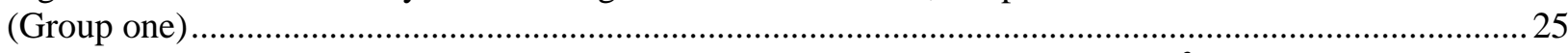

Figure 2.12 Filter efficiency at a challenge concentration of 40,000 particles $/ \mathrm{cm}^{3}$ versus face velocities

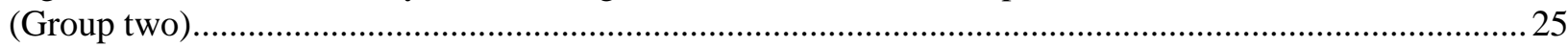

Figure 2.13 Filter efficiency at a challenge concentration of 80,000 particles $/ \mathrm{cm}^{3}$ versus face velocities

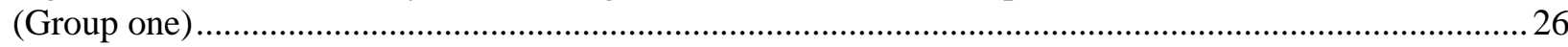

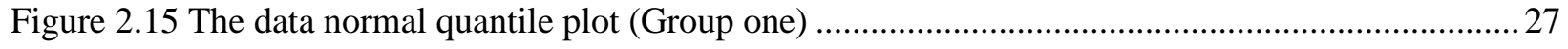

Figure 2.16 The data normal quantile plot (Group two) …................................................................2 27

Figure 2.17 The two-way interaction between type of filters and face velocities (Group two).................33

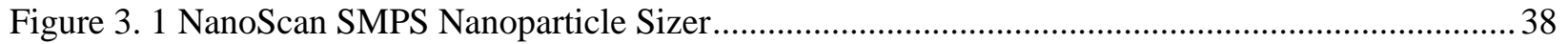

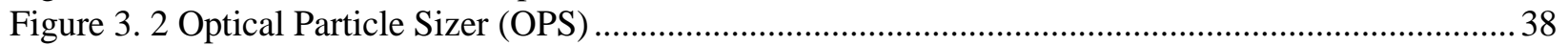

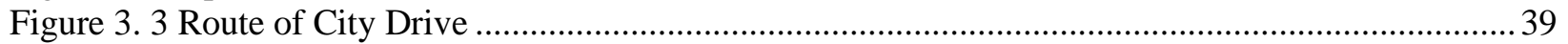

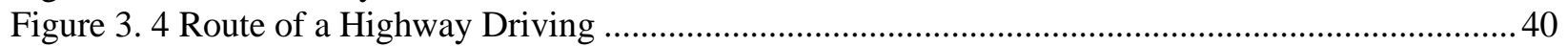

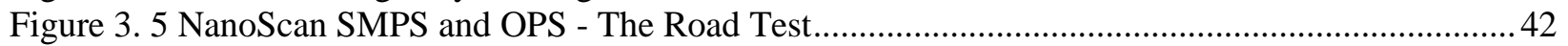

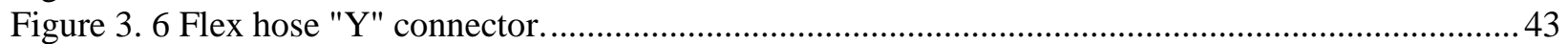

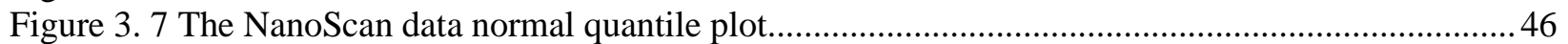

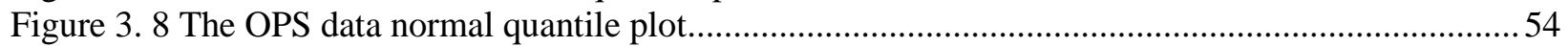

Figure 3. 9 Particle size distribution (City - Low Fan Level and Recirculation ON) ................................60

Figure 3. 10 Particle size distribution (Low Speed - High Fan Level and Recirculation Off)...................62

Figure 3. 11 Particle size distribution (High Speed - High Fan Level and Recirculation Off) .................. 64

Figure 3. 12 Filter 3 Challenge COVID-19 (City- Low Fan and Recirculation On) ................................67

Figure 3. 13 Filter 5 Challenge COVID-19 (City- Low Fan and Recirculation On) ...............................67

Figure 3. 14 Filter 3 Challenge COVID-19 (High Speed with High Fan Level and Recirculation Off) ....68

Figure 3. 15 Filter 5 Challenge COVID-19 (High Speed with High Fan Level and Recirculation Off) .... 69 


\section{Introduction}

\section{Background}

Vehicle cabin filters are essential in ensuring that a vehicle's air conditioning system provides clean air to its occupants. This is because the air coming from outside the vehicle is rapidly pulled into the air conditioning system under pressure and may carry with it dust particles, pollen, or other contaminants found in environmental air. These contaminants, depending on their concentration, may affect occupants in the vehicle due to their age and health condition. According to Sager (2012), cabin filters are effective in removing harmful aerosols that may penetrate the vehicle making occupants uncomfortable. The purpose of the cabin filter is to improve air quality inside the car to provide better comfort and help protect occupants from experiencing unwanted respiratory problems. The current study is to evaluate the performance of selected cabin filters against environmental factors that could influence their efficiency and effectiveness as well as their service life span.

Using cabin filters in air conditioning systems is common practice in modern vehicle manufacturing. Scientists and engineers are continually seeking new ways of improving the efficiency and effectiveness of cabin filters. Xu, Chen, and Xiong (2016) established that cabin filters provide varying filtration efficiencies depending on the settings of the vehicle's air conditioning system. They noted that most of the time, individual preferences influence the effectiveness of cabin filters.

Cabin air filters can eliminate various aerosols, but this depends on the age and type of air filter (Sager, 2012). Some manufacturers use high-efficiency cabin filters that they claim will provide higher efficiency and effectiveness than standard cabin filters. Lee and Zhu (2014) 
conducted a study in which they established that high-efficiency cabin filters have better collection efficiency for aerosols.

This study sought to provide an insight to the combined operational efficiency of five types of cabin filters from particles ranging from 10 to 10,000 nanometer in a normal operating condition, and to evaluate the performance of each condition when the five cabin filters were used.

\section{Objective}

This study was designed to evaluate differences in the aerosol filtration efficiency of five types of car air conditioning filters based on testing in the laboratory and during city and highway driving.

\section{Hypothesis}

\section{The first hypothesis:}

$H_{0}$ : The mean filtration efficiency of the car air conditioning filters in the laboratory at low concentration and face velocity for both groups $\leq$ the mean filtration efficiency of car air conditioning filters in the laboratory at higher concentration and face velocity for both groups.

$H_{a}$ : The mean filtration efficiency of the car air conditioning filters in the laboratory at low concentration and face velocity for both groups $>$ The mean filtration efficiency of the car air conditioning filters in the laboratory at higher concentration and face velocity for both groups.

\section{The second hypothesis:}

$H_{0}$ : The mean filtration efficiency of car air conditioning filters during city driving $\leq$ the mean filtration efficiency of car filters during highway driving. 
$H_{a}$ : The mean filtration efficiency of car air conditioning filters during city driving $>$ the mean filtration efficiency of car filters during highway driving.

\section{Specific Aims}

\section{$\operatorname{Aim} 1$}

(Study I): Evaluate the filtration efficiency of car air conditioning filters in the laboratory as a function of aerosol concentration and challenge face velocity. Challenge flow rate determines face velocities experienced by the filters.

\section{Aim 2}

(Study II): Evaluate the filtration efficiency of the car air conditioning filters during city and highway driving. Test conditions during city or highway driving included ventilation fan setting and car speed. 


\section{Introduction}

\section{Chapter 1}

One of the aims of installing ventilation filters in a car is to prevent vehicle occupants from potentially harmful aerosols emanating from the environment. There are basic mechanisms that determine how dust particles are captured on a given filter media. According to Dorman (2014), this relies on the principles of inertia, interception, and diffusion, which play a crucial role when understanding the basic principles behind the operation of fibrous filters. Dorman (2014) says that a typical filtration media will have fibers with smaller diameters than the distance between different fibers making up the system. Due to this small inter-fiber distance, the pores will clog as dust particles attempt to penetrate. This causes the air pressure to rise significantly preventing further penetration into the system (Dorman, 2014).

Determining on-road performance of cabin filters requires adequate understanding of the properties of aerosol particles present in the surrounding environment during transit. The performance of cabin filters in an on-road condition will depend on the concentration of particles, their chemical composition, and their size distribution (Colbeck \& Lazaridis, 2014). This requires determining the formation and growth rate of particles, which often varies and can go as low as $1 \mathrm{~nm}$ in size, which is the size that determines particle formation (Colbeck \& Lazaridis, 2014). Previous studies have established that particle size has a large influence on theoretical and experimental applications involving filters. According to Colbeck and Lazaridis (2014) there are limitations in studying macroscopic particles in reference to understanding functionality of filtration mechanisms.

Purchas and Sutherland (2013) remark that the fibers of cabin air filters are mostly made from a combination of polyacronitryl, polyethersulphone and polypropylene fibers to produce the thick sheet. This allows smooth flow of air, but sieves dust and other debris. The thickness of the 
filters range between $2.4 \mathrm{~mm}$ and $3.5 \mathrm{~mm}$ and the filters' flow resistances range between $8 \mathrm{~Pa}$ and $25 \mathrm{~Pa}$ at a velocity of $8 \mathrm{~cm} / \mathrm{s}$ depending on the material integrity (Purchas \& Sutherland, 2013). These characteristics are important in understanding the filtration efficiencies of different commercial cabin filters and the relative differences in filtration capacity among different filtration media.

The construction of a filter media relies upon the intended purpose regarding protecting indoors or inside vehicles from possible pollution. Sutherland and Chase (2011) remark that for filters intended to remove submicron sized particles, the preferred filter is made up of fibers having a diameter of less than a micrometer. To achieve its intended effectiveness, the penetrating gas velocity needs to be suitably restricted a few inches from the actual filter media in order to allow optimum diffusion to take place and thus filtration (Sutherland \& Chase, 2011). This means that when a vehicle is moving at a high speed in the forward direction and there is high inflow of air in the opposite direction, the design of the duct system should allow adequate reduction of the oncoming dust velocity.

The functionality of most cabin air filters primarily depends on the hardware components that went into the production process. He et al. (2016) examine the properties of cabin filters regarding the shape of loading curves, most penetrating particle size, and average filtration efficiency. The authors found that vehicle velocity plays a major role in determining the most penetrating particle size and the environment in which a vehicle is traveling at the time of measurement of the variables. The wind tunnel plays a role in determining how the shape of the loading curve turns out. The study found that the number of particles most often found during transit are ultrafine particles which would require the use of HEPA cabin filters. It was established that the relative humidity played a major role in determining the loading capacity of most cabin 
filters. It was established that the average particle size increased when the humidity was higher due to water condensation on the particles, which improved filter efficiency from impaction, interception and sedimentation. The authors found that the filtration efficiency decreased significantly when it came to particles that were classified as ultrafine, prompting better cabin filter designs to address the situation.

Cabin filter manufacturers are often faced with the challenging task of ensuring that the air filters that they are bringing into the market can adequately filter out ultrafine particles and other pollutants without compromising the ability of the same air filters to produce the much-needed cabin ventilation. Zhao et al. (2016) conducted a study in which they sought to find the surface area characteristics of cabin filters and how they influence the decision-making process. They studied the associated fiber properties of materials used in the production of cabin filters and their relative differences in terms of surface characteristics, pore measurement, and other attributes influencing cabin filter performance. Consideration was also given to the path in the fiber material allowing smooth penetration of air molecules while capturing particulate matter (Zhao et al., 2016). The study established that the pore structure of the materials used in cabin filter production played a major role in determining their efficiency against different particle sizes. The authors found that the type of membrane used in a filter element played a role in determining the surface pore structure.

The surface area of a cabin air filter also plays a major role in influencing the amount of cabin pollution that occurs. Qi et al. (2008) conducted a study in which they establish the extent to which the interaction between cabin filter and cabin ventilation settings change the characteristics of air quality, and thereby affect vehicle occupants. The study found that the combination of a vehicle cabin air filter and car ventilation system led to better outcomes in terms of cabin pollution. 
The research found a significant $43.9 \%$ improvement in cabin air filter performance when the invehicle ventilation system was adequately activated. Qui et al. (2008) further established that it was important for a motorist to set an amicable cabin ventilation setting that would achieve the most positive outcome in protecting vehicle occupants from unwanted pollution exposure. This helped greatly in dispersing unwanted particles, making the cabin interior suitable for accommodating passengers without resulting in potential harmful health effects. Thus, cabin filters proved to play a significant role in reducing pollution levels to car occupants.

In order to establish the filtration capacity of cabin filters, a single pass efficiency mechanism or cumulative efficiency mechanism can be adopted. The single pass efficiency approach focuses on testing the specified contaminant once as it passes the filter barrier (Hutten, 2007). The filter is subjected to weight analysis to determine filtration efficiency. The filtration efficiency equation is:

$$
e=100\left(\frac{\text { Cup }- \text { Cdown }}{\text { Cup }}\right)
$$

Where,

e: represents the filtration efficiency in \%

$\mathrm{C}$ up: represents the upstream quantity of contaminant

C down: represents the downstream quantity of the contaminant (Hutten, 2007).

Alternatively, a cumulative efficiency test can also be conducted in order to establish the efficiency of a cabin filter (Hutten, 2007). This requires making efficiency measurements at predetermined intervals during the active life of the cabin filter when the vehicle is actively being used on a road.

Environmental conditions vary according to season, for example, a winter season may have less humid air compared to the summer season. He et al. (2016) also examined the surface of the 
HEPA filters and found that microorganisms could grow there. It is not clear that microorganism growing on the surface of the filter would be able to penetrate the HEPA filter. These finding do indicate that the efficiency of cabin filters can depend on the environment in which they are used and on the promptness of vehicle owners servicing them whenever required.

Humidity plays an important role in determining the functionality and performance of a cabin filter. According to Sparks and Chase (2013), the presence of mist, rain, or fog causes moisture ingress in the intake air system where the vehicle cabin filter is normally found. The moisture in the air may dissolve salts and other substances, which may in turn crystallize, leading to generation of new particles downstream (Sparks \& Chase, 2013). High humidity in the air may also corrode metal parts present inside the air duct system leading to the cabin filter. The occurrence of rust may later shed and generate small amounts of dust downstream of the cabin filter (Sparks \& Chase, 2013). This shows how the presence of humidity is a crucial factor, especially considering varying intensities of weather in which vehicles operate.

Consequently, the finding that different ambient conditions influenced the filters loading characteristics indicated that there is a need to have defined service intervals for a typical cabin filter. He et al. (2016) examined the functional and efficiency attributes of high-efficiency particulate aerosol (HEPA) filters from selected manufacturers in order to establish the existence of structural factors that influence filtration capacity. To do this, it was necessary to create a laboratory setup where heavy, medium, and light use conditions could be mimicked to evaluate different manufacturer's HEPA filters. The laboratory used a powder particle generator and a mist dispenser to generate mixed aerosols that could be used to challenge the filters. From the study, it was evident that altering these conditions affected the efficiency of filtration. This means that 
manufacturers of HEPA filters need to conduct enough tests to establish suitable servicing intervals.

Given the increasing levels of pollution in the air, vehicles operating in densely populated urban areas subject their cabin filters to different concentrations of ultrafine particles. These ultrafine particles influence the period of operation and rely strongly on the speed of wind dispersal to penetrate the surface of given cabin filters. In this regard, a study using a laboratory experimental setup consisting of diesel generator, fan, air flow meter, different cabin filters, fan, differential mobility counter, and condensation particle counter, found that ultrafine particles sizes between 200 and 300 nanometers were best eliminated compared to those that fell beyond the identified parameters (Xu, B., Liu, S., \& Zhu, 2010). Interestingly, the study found that altering the density of ultrafine particles also affected the effectiveness of their elimination from the air.

In recent times, there has been a major shift and focus from environmental lobby groups, pushing for a reduction in pollution levels in cities. Ultrafine particles have been shown to readily pass from the lungs into the bloodstream, especially when in a confined setting such as a vehicle cabin, which could be solved by reducing the amount of particulate matter inside the vehicle cabin. Automobiles are among the highest polluters after heavy industry establishments. This means that automobile cabin filters should be at the forefront of protecting vehicle occupants from potentially harmful ultrafine particles that may come from the vehicle's engine system as well as the surrounding air.

Tartakovsky et al. (2013) examined the suitability of cabin air filters to reduce exposure to ultrafine particles taking into consideration possible variations such as the age of a vehicle, type of cabin filter used, car and bus setting, and cabin ventilation. This involved conducting an average 
of 185 trips at speeds of 30 kilometers per hour in order to establish the relative ultrafine particle size and concentration in each vehicle setting. The study found that selected high efficacy cabin filters were able to cause a significant $99 \%$ reduction in exposure to the number of ultrafine particles that penetrated different vehicle interior cabins. It was found that it only took about 10 minutes for these cabin filters to achieve optimum operation in terms of protecting the vehicle occupants from possible ultrafine particle exposure. Additionally, the study also found that bus occupants were exposed to higher amounts of ultrafine particles as compared to car occupants due to differences in the air ventilation settings available in either setup.

Road testing to establish cabin filter efficiency will require careful experimental evaluation of the air sampling system in order to establish occurrence of particle losses due to both diffusion and non-isokinetic sampling methods (Zhou et al, 2011). It will be important to establish the ambient and cabin particle concentration to compare efficiency levels in terms of filtration. During the actual testing process, ensuring uniformity demands that the vehicle windows be closed and properly sealed to decrease the occurrence of particle and air exchange, which may affect the ambient and in-cabin measurements (Zhou et al, 2011). Given that most cabin filters are located in the passenger compartment, the passenger compartment must be adequately cleaned including the air duct system to decrease the occurrence of particle losses and gains in the course of the experiment.

While air characteristics play a major role in influencing air quality parameters that affect the functionality of cabin filters, vehicle and driving patterns also play crucial roles in determining the in-cabin concentration of dust and organic and inorganic pollutants. According to Hudda et al. (2011), the fine particulate infiltration rate relies on the velocity at which air particles are flowing into a system capable of quantifying air entering and leaving the system. According to Hudda et 
al. (2011), vehicle speed plays a role in determining the air dispersion rates through the cabin filters. This means that the relative speed at which a vehicle is driven influences the outcome of particulate matter infiltration, leading to certain health ailments arising from such exposure. 


\section{Chapter 2}

\section{Study I - Lab-based Experimental Study on the Performance of Five different Cabin Filters}

\subsection{Applications}

Construction equipment comes in many different shapes and sizes, and the large amount of dust and other emissions they sometimes generate can cause significant health problems to workers. Applications involving construction equipment could be above or below ground level. Some examples of this type of equipment are discussed as follows.

\section{Caterpillar Mini Hydraulic Excavator}

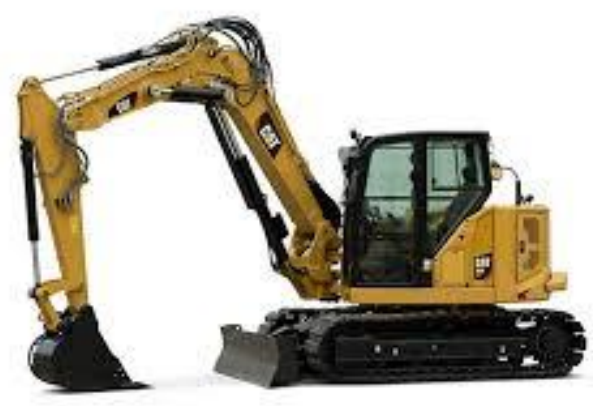

Figure 2.1 Caterpillar Mini Hydraulic Excavator

The operation of the Caterpillar Mini Hydraulic Excavator (Figure 2.1) generates airborne dust and respirable crystalline silica dust. The silica is produced during fracturing or abrading material that contains silica. It is important to note that numerous dust suppressants are used in combination during such operations, including cabin filters. Airborne dust and particles containing silica may measure between 0.01 and 100 micrometers (Tatiya, 2013). Inhalation of particles containing silica may cause upper respiratory problems, complicate existing asthma condition, lead to silicosis a restrictive lung, disease, and in worse case scenarios, cancer. 
There are specific design measures that should be incorporated in the design of the cabin where an operator would normally be located during operation of the mini hydraulic excavator. There must be a pre-filter barrier that keeps away coarse dust particles that are larger than 100 micrometers in order to increase the length of the filter operational efficiency (Tatiya, 2013).

\section{Doosan Drilling Rig}

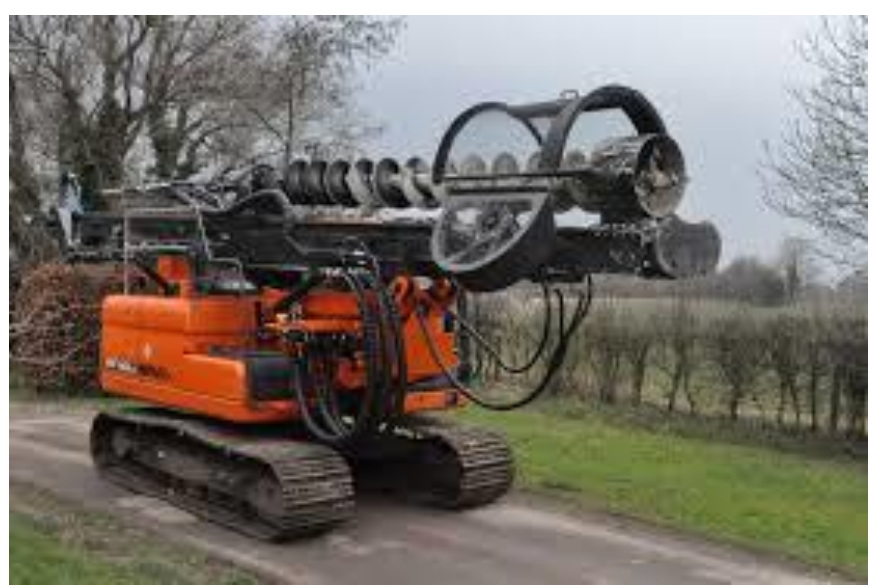

Figure 2.2 Doosan Drilling Rig

The Doosan Drilling Rig (Figure 2.2) is used to perform small scale, and large-scale commercial drilling operations. The cabin air filter should protect the operator from exposure to dust and silica particles during actual drilling (Mottrol International Inc., 2020). In addition, the cabin air filters must filter air going through the heating, ventilation, and air conditioning (HVAC) system, since the particles of dust and silica range between 0.1 and 100 micrometers (Tatiya, 2013).

Furthermore, the cabin within which the operator is positioned should have an adequate isolation system capable of maintaining cabin pressure to $10 \mathrm{~Pa}$ to increase effectiveness of reducing dust and silica ingress (Tatiya, 2013). Otherwise, the operators may have to have additional respirators to protect them adequately from dangerous silica dust. Dust and silica particles can significantly harm the drilling rig operator, especially where the operator is not 
working from a secluded compartment protecting them from outside debris. To further increase efficiency of the system, proper sealing of joints is done and provision of window grooves with tight sealing.

\section{Sandvik Underground Drill}

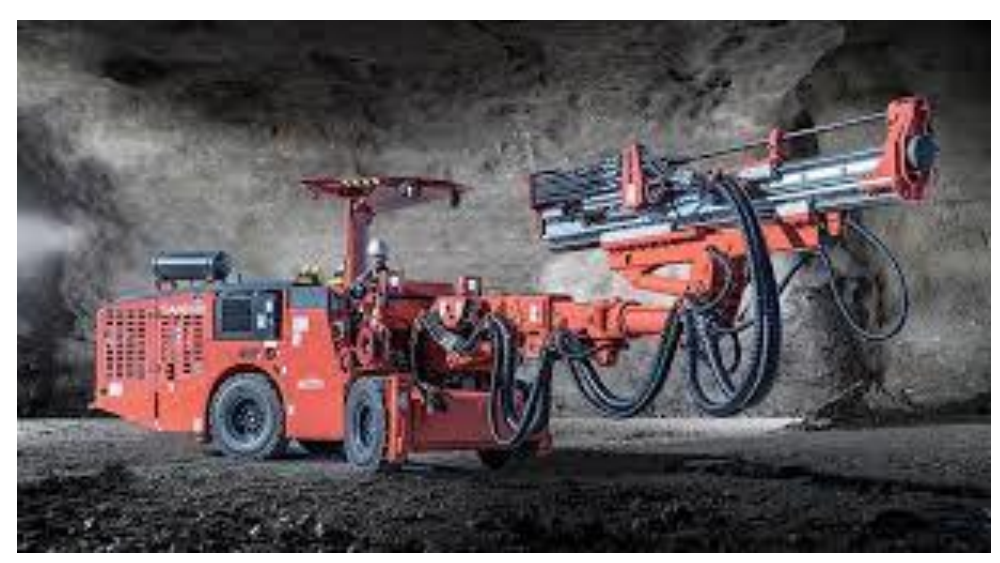

Figure 2.3 Sandvik Underground Drilling

The Sandvik Underground Drilling Machine (Figure 2.3) is commonly used in many underground drilling operations. Due to the complex nature of underground operations, the machine must have a sophisticated filtration mechanism that abides with the EU6/7 standard (Vitali \& De Mattia, 2020). The cabin filter should provide protection to the operator in the isolated cabin, especially in the underground drilling operations (Freudenberg Filtration Technologies, 2020). The cabin air filters must filter air going through the air conditioning system, since the particles of dust and silica are larger than 0.3 micrometer (Cecala et al, 2016).

\subsection{Equipment and Variables}

Five different types of Automotive Cabin Air Filters (ACAF) were tested in this study. These air filters included the Purolator ONE Cabin Air Filter (Figure 2.4), the Fram Fresh Breeze Cabin Air Filter (Figure 2.5), the Beck/Arnley Paper Cabin Air Filter (Figure 2.6), the 
Purolator Premium with Febreze Freshness (Figure 2.7), and the Bosch HEPA Premium Cabin Air Filter (Figure 2.8). These filters are designed and manufactured for under-hood conditions to prevent aerosol contaminants from entering the car's passenger compartment. These filters are designed with a width of $11 \mathrm{inch}$, a length of $11 \mathrm{inch}$, and a thickness of $0.72 \mathrm{inch}$.

The five cabin filters were separated into two groups based on the average of the filter surface area for each group. Each group had three different face velocities which were achieved with a ventilation setting level of low, medium, and high. The first group of filters were the Purolator ONE Cabin Air Filter (Filter 1), the Fram Fresh Breeze Cabin Air Filter (Filter 2), and the Purolator Premium with Febreze Freshness (Filter 4), which had surface areas of 152, 159.6, and $148.6 \mathrm{~cm}^{2}$, respectively, and an average surface area of $153.4 \mathrm{~cm}^{2}$. The second group of filters were the Beck/Arnley Paper Cabin Air Filter (Filter 3) with a surface area of $246.2 \mathrm{~cm}^{2}$ and the Bosch HEPA Premium Cabin Air Filter (Filter 5) with a surface area of $268.3 \mathrm{~cm}^{2}$, and these filters had an average surface area of $257.3 \mathrm{~cm}^{2}$.

Cabin filters are manufactured following specific designs intended to maximize their filtration ability under severely polluted environments. The location of a cabin filter will determine its shape, but most have a square to rectangular form. While cellulose was the major material for the base layer for many years, synthetic fibers have become popular because of their higher efficiency and durability (Hutten, 2007). Some of the synthetic fibers commonly used in the market include polyacronitryl, polyethersulphone and polypropylene fibers. 


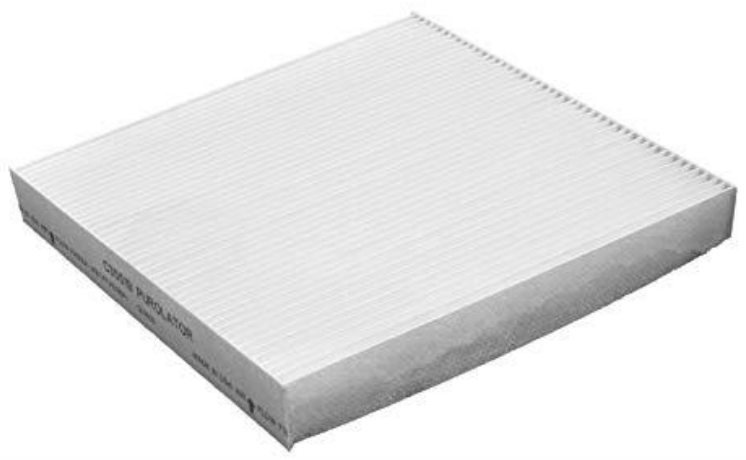

Figure 2.4 Purolator ONE Cabin Air Filter (Filter 1)

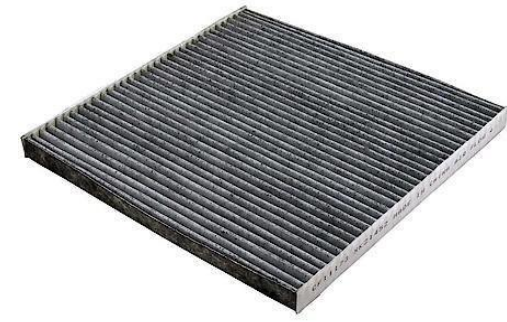

Figure 2.5 Fram Fresh Breeze Cabin Air Filter (Filter 2)

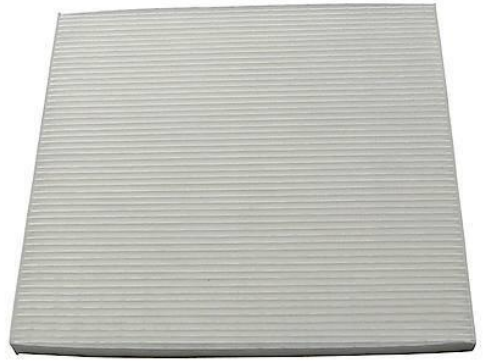

Figure 2.6 Beck/Arnley Paper Cabin Air Filter (Filter 3) 
Figure 2.7 Purolator Premium with Febreze Freshness (Filter 4)

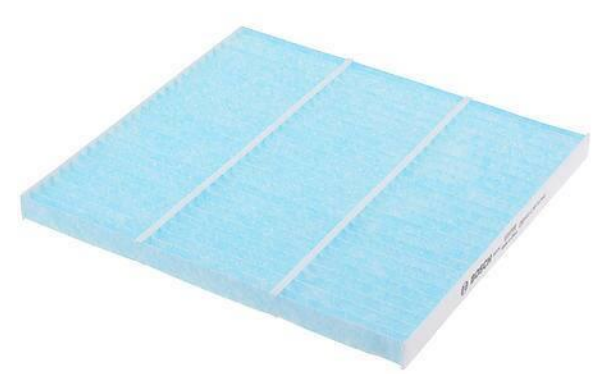

Figure 2.8 Bosch HEPA Premium Cabin Air Filter (Filter 5)

A rectangular sample were cut from each filter to fit the dimensions of the filter holder. In this study, the filter holder $\left(A_{h}\right)$, (Figure 2.9) we developed, has a rectangular shape, $A_{h}=8.9 \times 3.8$ $\mathrm{cm}$, and with a depth of $27.94 \mathrm{~cm}$. 


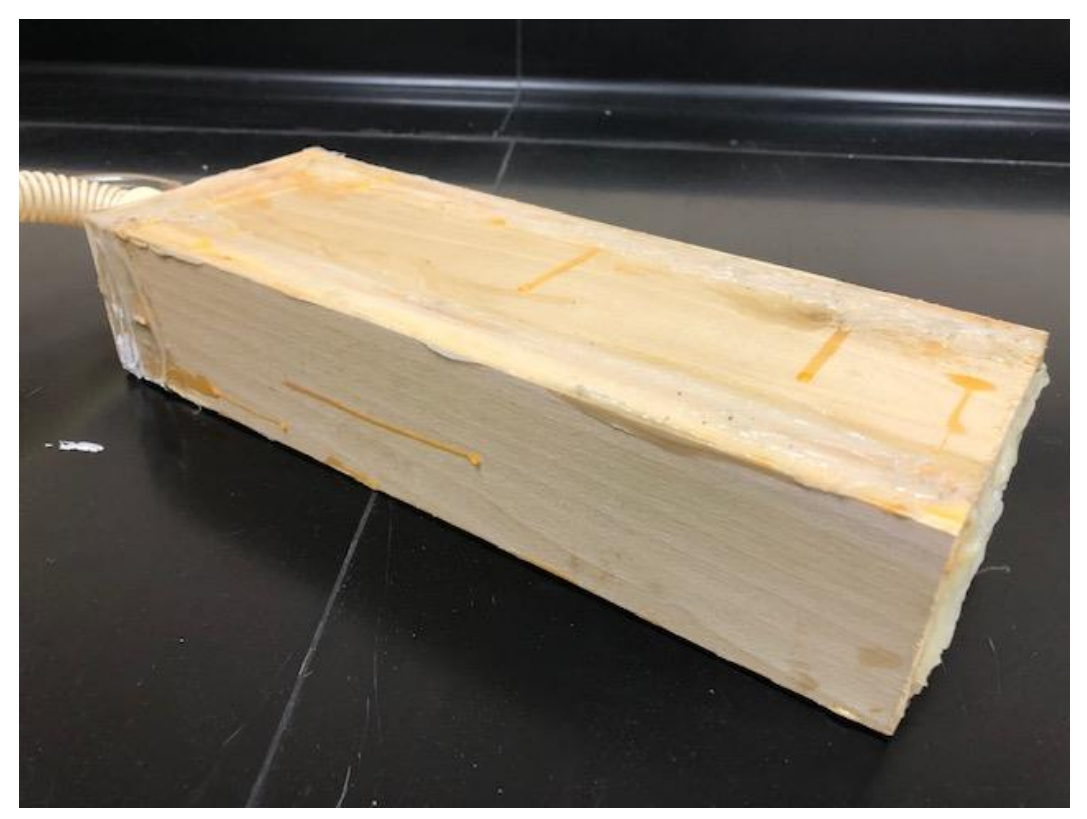

Figure 2.9 The Filter Holder $\left(A_{h}\right)$

The dimensions were chosen because of the available lab equipment and air supply. Changing the dimensions of the sample and holder to make it larger would require an extremely large rate flow, $\left(\mathrm{L} \mathrm{min}^{-1}\right)$, that would be difficult to handle.

Tests for the first group of filters were conducted at face velocities $\left(\mathrm{V}_{\mathrm{f} \text { one }}\right)$ of $4.3,8.8$, and $13.3 \mathrm{~cm} \mathrm{~s}^{-1}$ and tests for the second group at face velocities ( $\mathrm{V}_{\mathrm{f} \text { second }}$ ) of $2.6,5.3$, and $7.9 \mathrm{~cm} \mathrm{~s}^{-1}$. These face velocities were achieved with a ventilation setting level of 2 (low), 4 (medium), and 7 (high), respectively, with the test vehicle (a 2010 Nissan Maxima). Equation (1) shows the relation between flow rate, area of the sample, and face velocity.

$$
\text { Flow rate }=\text { Filter Surface Area } * \text { Face Velocity }
$$

The flow rate, which is in this study was a constant flow, was created by a vacuum pump (Model VP, 2200, HFS, Los Angles, California, USA). Tables 2.1 and 2.2 show the flow rates (40, 81, and $122 \mathrm{~L} \mathrm{~min}^{-1}$ ), which were required to achieve desired filter face velocities in each group. 
Flow rates were read measured with a Model 4148 Mass Flow Calibrator ( TSI Inc, Shoreview, MN, USA).

Table 2. 1 Flow rates required to achieve desired filter face velocities (Group one)

\begin{tabular}{ccc}
\hline $\begin{array}{c}\text { Average surface } \\
\text { Area }\left(\mathbf{c m}^{\mathbf{2}}\right)\end{array}$ & $\begin{array}{c}\text { Face Velocity } \\
\left(\boldsymbol{c m ~} \mathbf{s}^{-\mathbf{1}}\right)\end{array}$ & $\begin{array}{c}\text { Flow rate } \\
\left(\mathbf{L ~} \boldsymbol{~ m i n}^{\mathbf{- 1}}\right)\end{array}$ \\
\hline & 4.3 & 40 \\
$\mathbf{1 5 3 . 4} \mathbf{~ c m}^{\mathbf{2}}$ & 8.8 & 81 \\
\cline { 2 - 3 } & 13.3 & 122 \\
\hline
\end{tabular}

Table 2. 2 Flow rates required to achieve desired filter face velocities (Group two)

\begin{tabular}{|c|c|c|}
\hline Average surface & Face Velocity & Flow rate \\
\hline $\operatorname{Area}\left(\mathrm{cm}^{2}\right)$ & $\left(c m s^{-1}\right)$ & $\left(L \min ^{-1}\right)$ \\
\hline \multirow{3}{*}{$257.3 \mathrm{~cm}^{2}$} & 2.6 & 40 \\
\hline & 5.3 & 81 \\
\hline & 7.9 & 122 \\
\hline
\end{tabular}

A Chamber with a width of $1.02 \mathrm{~m}$, a length of $1.02 \mathrm{~m}$, and a height of $1.02 \mathrm{~m}$ was used for this experiment. $\mathrm{NaCl}$ aerosol were generated using a Model 8026 particle generator (TSI Inc, Shoreview, MN, USA). The experimental setup is shown in Figure 2.10. 

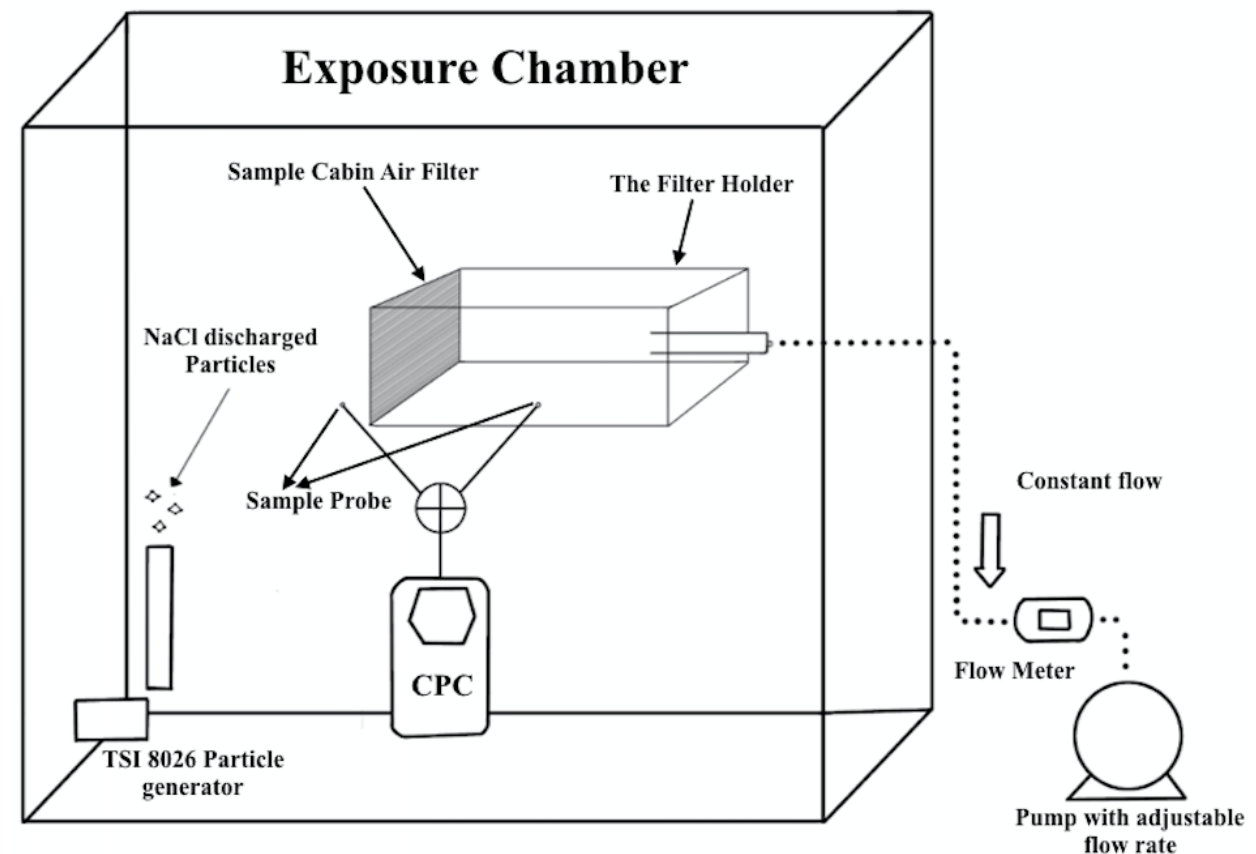

Figure 2.10 Experimental Setup (modified from He et al., 2013)

Particle concentrations were measured with a Model 3007 condensation particle counter (CPC) (TSI Inc, Shoreview, MN, USA). The CPC measured particle sizes ranging from 0.01 to $>1.0 \mu \mathrm{m}$, and at concentration ranges of 0 to 100,000 particle $\mathrm{cm}^{-1}$. In this study, three different concentrations were tested 40,000,60,000, and 80,000 particle $\mathrm{cm}^{-1}$. A particle concentration of 100,000 particle $\mathrm{cm}^{-1}$ could not be exceeded because of instrumentation limits.

\subsection{Data Collection}

A 0.25 -inch diameter tube was located on the top side of the filter holder. This tube measured the upstream particle concentration $\left(C_{u p}\right)$. Also, another 0.25 -inch diameter tube was located downstream of the filter to measure the downstream particle concentration $\left(C_{\text {down }}\right)$. The percent penetration $(\mathrm{P})$ was calculated as:

$$
P=\frac{C_{\text {down }}}{C_{u p}} \times 100 \%
$$

The percent efficiency $(\eta)$ was calculated by: 


$$
\eta=1-P=\left(1-\frac{C_{d o w n}}{C_{u p}}\right) \times 100 \%
$$

All data collected by the CPC was exported to spreadsheets by the Aerosol Instrument Manager (AIM), software provided by TSI Incorporated. Each measurement took one minute, and three replicates were taken for each condition. All conditions and replications were randomized to avoid any possible biases in the experiment. Table 2.3 and 2.4 show a summary of the experimental variables in the study for each group.

Table 2. 3 Experimental Variables for Group One

\begin{tabular}{ll}
\hline Variable & Levels \\
\hline Filter Type & $\begin{array}{l}3 \quad \text { (Purolator ONE, Fram Fresh Breeze, and } \\
\text { Purolator Premium with Febreze Freshness) }\end{array}$ \\
\hline $\begin{array}{l}\text { Challenge } \\
\text { Concentration }\end{array}$ & $3(40,000,60,000,80,000)$ particle $/ \mathrm{cm}^{3}$ \\
\hline Flow Type & $1($ Constant $)$. \\
\hline Face Velocity & $3(4.3,8.8,13.3) \mathrm{cm} / \mathrm{s}$ \\
\hline Replicates & 3 \\
\hline Total Runs & 81 \\
\hline
\end{tabular}


Table 2. 4 Experimental Variables for Group Two

\begin{tabular}{ll}
\hline Variable & Levels \\
\hline Filter Type & $\begin{array}{l}\text { 2 (Beck/Arnley Paper, and Bosch HEPA Premium } \\
\text { Cabin Air Filter) }\end{array}$ \\
\hline $\begin{array}{l}\text { Challenge } \\
\text { Concentration }\end{array}$ & $3(40,000,60,000,80,000)$ particle $/ \mathrm{cm}^{3}$ \\
\hline Flow Type & $1($ Constant). \\
\hline Face Velocity & $3(2.6,5.3,7.9) \mathrm{cm} / \mathrm{s}$ \\
\hline Replicates & 3 \\
\hline Total Runs & 54 \\
\hline
\end{tabular}

\subsection{Data analysis}

JMP Software, (JMP Statistical Discovery from SAS), was used to perform the statistical analysis. JMP has several methods of assessing whether data is normally distributed. In this research, the normality of the data was evaluated by two main tests: a graphical method such as Q-Q probability plots, and a statistical method, such as Kolmogorov-Smirnov test (K-S). Since the flow type was only constant flow, a three-way ANOVA was conducted to test the effects of filter type, challenge concentration, and face velocity in each group. The three-way ANOVA determined the average efficiency for each experimental condition. The three-way ANOVA was also used to determine if there were any interaction effects between filter type, face velocity, and challenge concentration for each group. A P-value of $<0.05$ was considered significant. 


\subsection{Results and Discussion}

Tables 2.5 and 2.6 show the mean efficiency of five different types of cabin air filters of two groups under different challenge concentrations and face velocities. As shown in Table 2.5, the overall efficiencies for filter type range from $51.7 \%$ to $79.1 \%$. The lowest mean value of the efficiency occurred when filter 1 was tested under the challenge concentration of 80,000 (particle/ $\left.\mathrm{cm}^{3}\right)$ and the face velocity of $13.3(\mathrm{~cm} / \mathrm{s})$, and filter 2 had the highest mean efficiency which was $79.1 \%$ when the challenge concentration was 40,000 particle/cm3, and the face velocity was 4.3 $(\mathrm{cm} / \mathrm{s})$. While Table 2.6 shows the mean efficiency of the second group (filter 3 and 5). The overall efficiencies range from $36.5 \%$ to $91.7 \%$. The highest mean efficiency occurred with filter 5 when the challenge concentration was 40,000 particle $/ \mathrm{cm}^{3}$, and the face velocity was $2.6(\mathrm{~cm} / \mathrm{s})$. The lowest efficiency occurred when filter 3 was tested under $80,000\left(\right.$ particle/ $\mathrm{cm}^{3}$ ) and the face velocity was $7.9(\mathrm{~cm} / \mathrm{s})$. Overall, the performance of filter 5 was the best in comparison to filter 3 in the second group.

Table 2. 5 Average efficiency $\%$ of the three cabin air filters (Group one)

\begin{tabular}{ccccc} 
& & \multicolumn{3}{c}{ Efficiency \%, (Mean) } \\
\cline { 3 - 5 } $\begin{array}{c}\text { Challenge } \\
\text { Concentration } \\
\left(\# / \mathrm{cm}^{3}\right)\end{array}$ & $\begin{array}{c}\text { Face Velocity } \\
(\mathbf{c m} / \mathbf{s})\end{array}$ & Filter $\mathbf{1}$ & Filter $\mathbf{2}$ & Filter 4 \\
\hline & $\mathbf{4 . 3}$ & 73.1 & 79.1 & 75.3 \\
$\mathbf{4 0 , 0 0 0}$ & $\mathbf{8 . 8}$ & 63.1 & 73.7 & 72.8 \\
& $\mathbf{1 3 . 3}$ & 59.5 & 64.6 & 71.4 \\
\hline & $\mathbf{4 . 3}$ & 71.5 & 73.9 & 72.3 \\
$\mathbf{6 0 , 0 0 0}$ & $\mathbf{8 . 8}$ & 61.7 & 68.9 & 69.1 \\
& $\mathbf{1 3 . 3}$ & 58.7 & 67.5 & 66.7 \\
\hline \multirow{2}{*}{$\mathbf{8 0 , 0 0 0}$} & $\mathbf{4 . 3}$ & 66.4 & 71.3 & 72.1 \\
& $\mathbf{8 . 8}$ & 55.1 & 63.4 & 67.6 \\
& $\mathbf{1 3 . 3}$ & 51.7 & 61.9 & 65.1 \\
\hline
\end{tabular}


Table 2. 6 Average efficiency \% of the two cabin air filters (Group Two)

\begin{tabular}{cccc} 
& & \multicolumn{2}{c}{ Efficiency \%, (Mean) } \\
\cline { 3 - 4 } $\begin{array}{c}\text { Challenge } \\
\text { Concentration } \\
\left(\# / \mathrm{cm}^{3}\right)\end{array}$ & $\begin{array}{c}\text { Face Velocity } \\
(\mathbf{c m} / \mathbf{s})\end{array}$ & Filter 3 & Filter 5 \\
\hline \multirow{4}{*}{$\mathbf{4 0 , 0 0 0}$} & $\mathbf{2 . 6}$ & 61.3 & 91.7 \\
& $\mathbf{5 . 3}$ & 48.7 & 90.3 \\
& $\mathbf{7 . 9}$ & 41.6 & 88.5 \\
\hline $\mathbf{6 0 , 0 0 0}$ & $\mathbf{2 . 6}$ & 59.2 & 91.1 \\
& $\mathbf{5 . 3}$ & 46.1 & 90.2 \\
& $\mathbf{7 . 9}$ & 39.3 & 88.1 \\
\hline $\mathbf{8 0 , 0 0 0}$ & $\mathbf{2 . 6}$ & 57.6 & 90.9 \\
& $\mathbf{5 . 3}$ & 44.1 & 88.8 \\
& $\mathbf{7 . 9}$ & 36.5 & 83.6 \\
\hline
\end{tabular}

As shown in Figures 2.11 and 2.12, at a challenge concentration of 40,000 (particle/cm3) for each group, the efficiency of all the filters decreased when the face velocity increased. For example, the mean efficiency for filter 2 was $79.1 \%$ at $4.3(\mathrm{~cm} / \mathrm{s})$, but decreased to $73.7 \%$ and $64.6 \%$ respectively when the face velocities increased from 8.8 and $13.3 \mathrm{~cm} / \mathrm{s}$. Also, the mean efficiency for filter 3 was $61.3 \%$ at $2.6(\mathrm{~cm} / \mathrm{s})$, but decreased to $48.7 \%$ when the face velocities increased to $5.3 \mathrm{~cm} / \mathrm{s}$. In a study by Yang, et al., (2007) they found that when the face velocity increased from $0.1 \mathrm{~m} / \mathrm{s}$ to $1 \mathrm{~m} / \mathrm{s}$, the penetration increased from $17 \%$ to $55 \%$. Results of this study were consistent with the Yang et al. study.

From Figures 2.13 and 2.14 it can be seen that the mean efficiency of all filters decreased when the particle challenge concentrations increased. For instance, the mean efficiency of filter 2 was $79.1 \%$ at 40,000 particle/ $\mathrm{cm}^{3}$ and $4.3 \mathrm{~cm} / \mathrm{s}$, but the mean efficiency fell slightly to $71.3 \%$ when the particle challenge concentrations increased to 80,000 particle $/ \mathrm{cm}^{3}$. In addition, the mean 
efficiency of filter 3 at face velocity of $2.6(\mathrm{~cm} / \mathrm{s})$ fell slightly from $61.3 \%$ to $57.6 \%$ when the particle challenge concentrations increased from 40,000 and 80,000 particle $/ \mathrm{cm}^{3}$

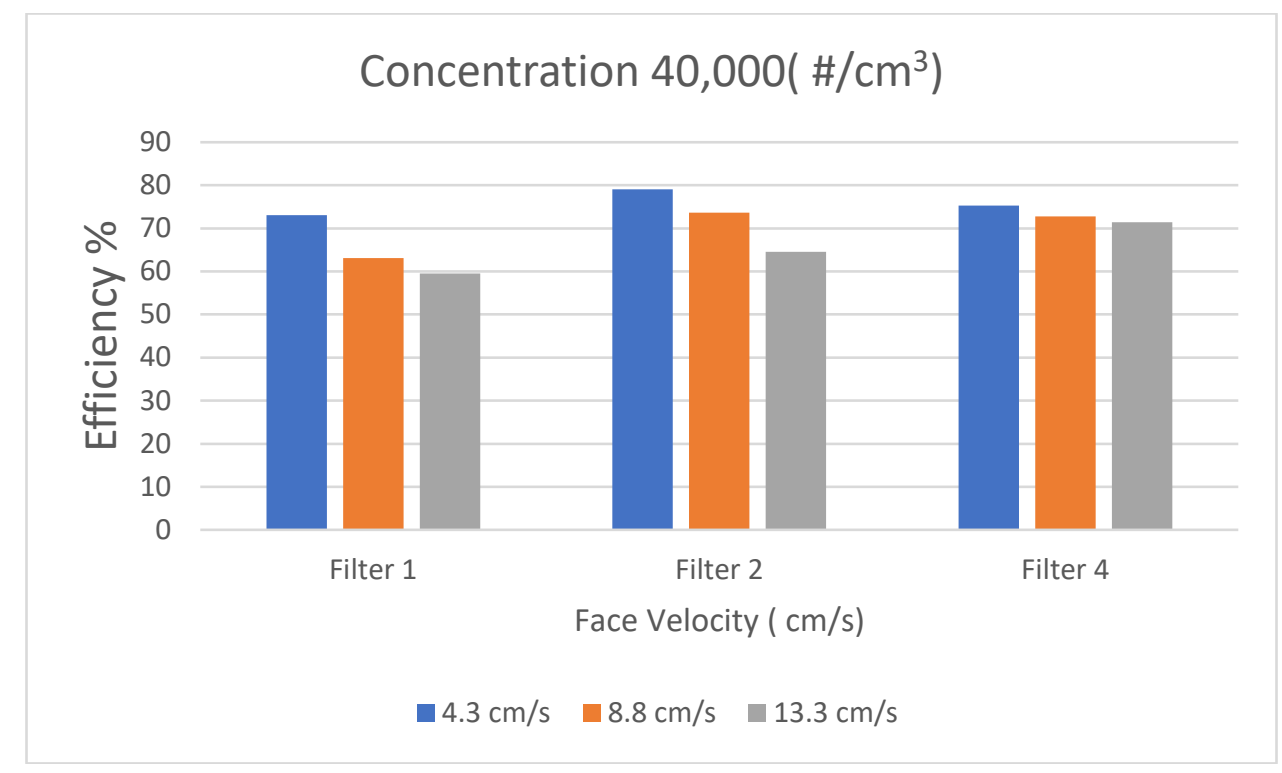

Figure 2.11 Filter efficiency at a challenge concentration of 40,000 particles $/ \mathrm{cm}^{3}$ versus face velocities (Group one)

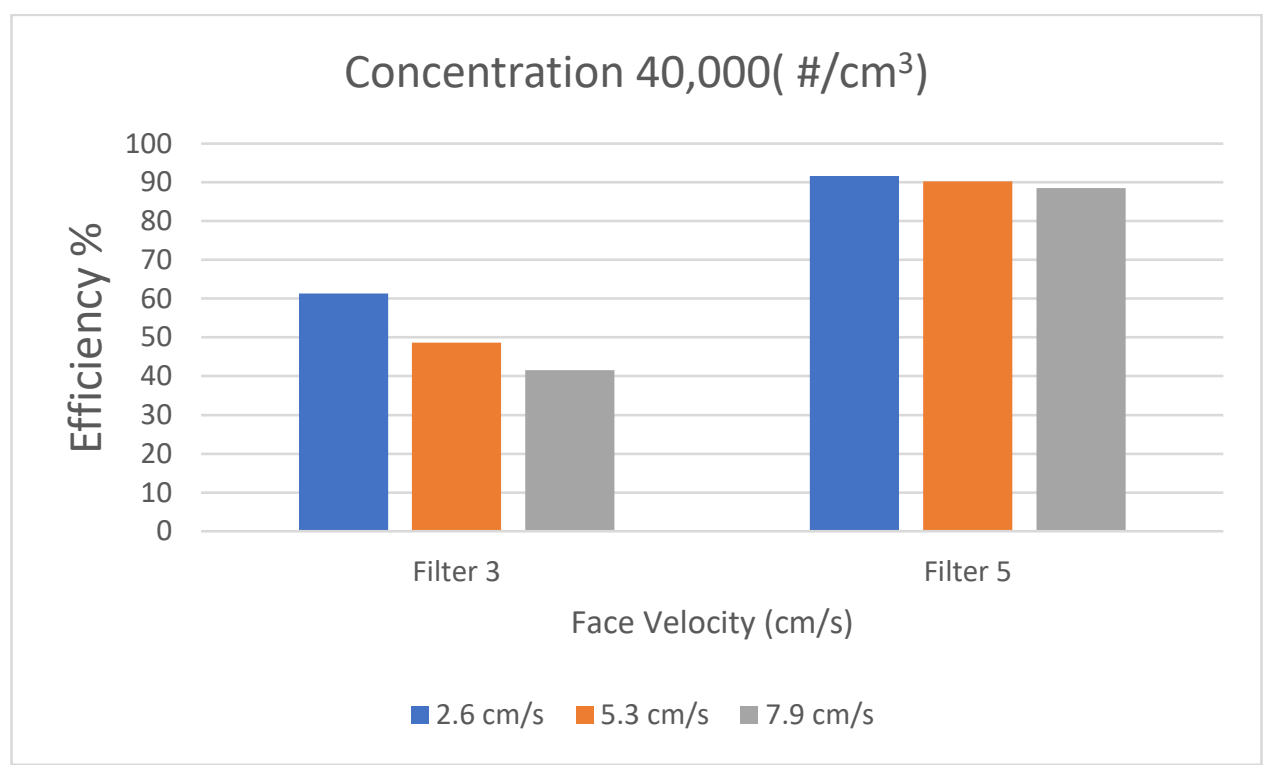

Figure 2.12 Filter efficiency at a challenge concentration of 40,000 particles $/ \mathrm{cm}^{3}$ versus face velocities (Group two) 


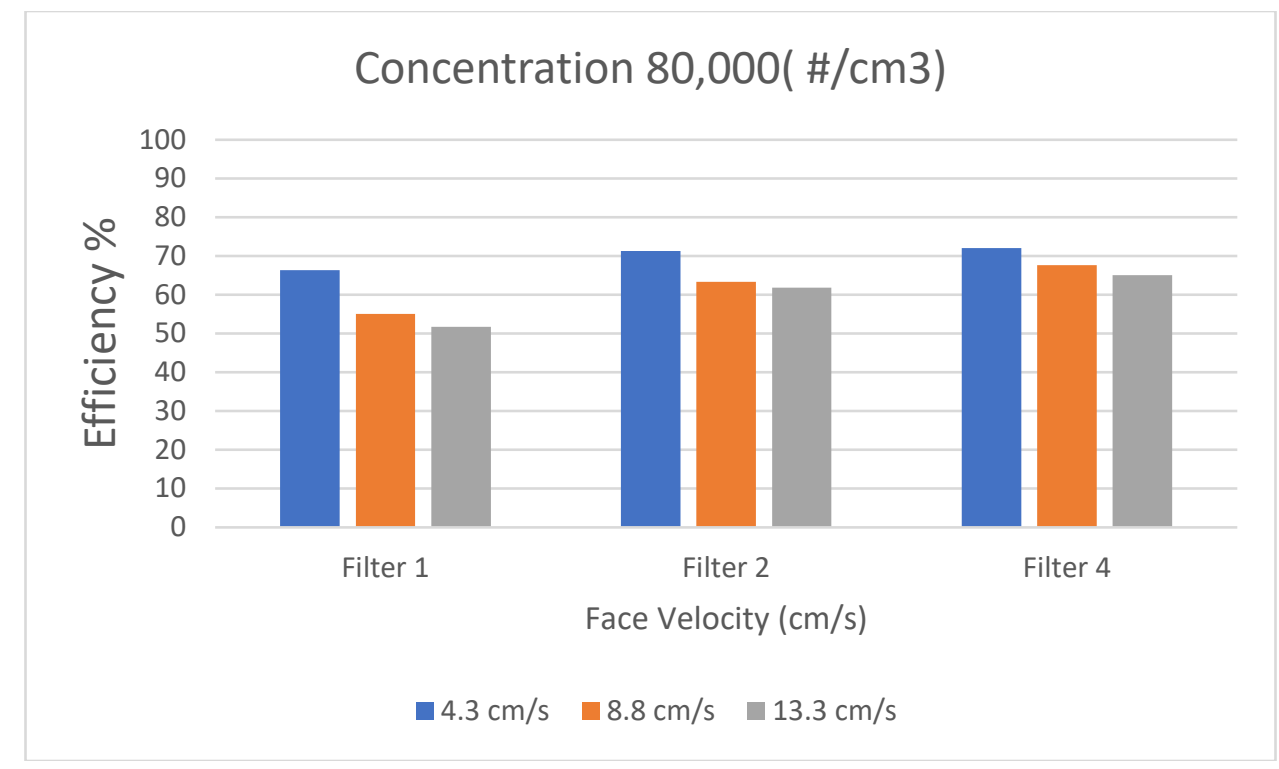

Figure 2.13 Filter efficiency at a challenge concentration of 80,000 particles $/ \mathrm{cm}^{3}$ versus face velocities (Group one)

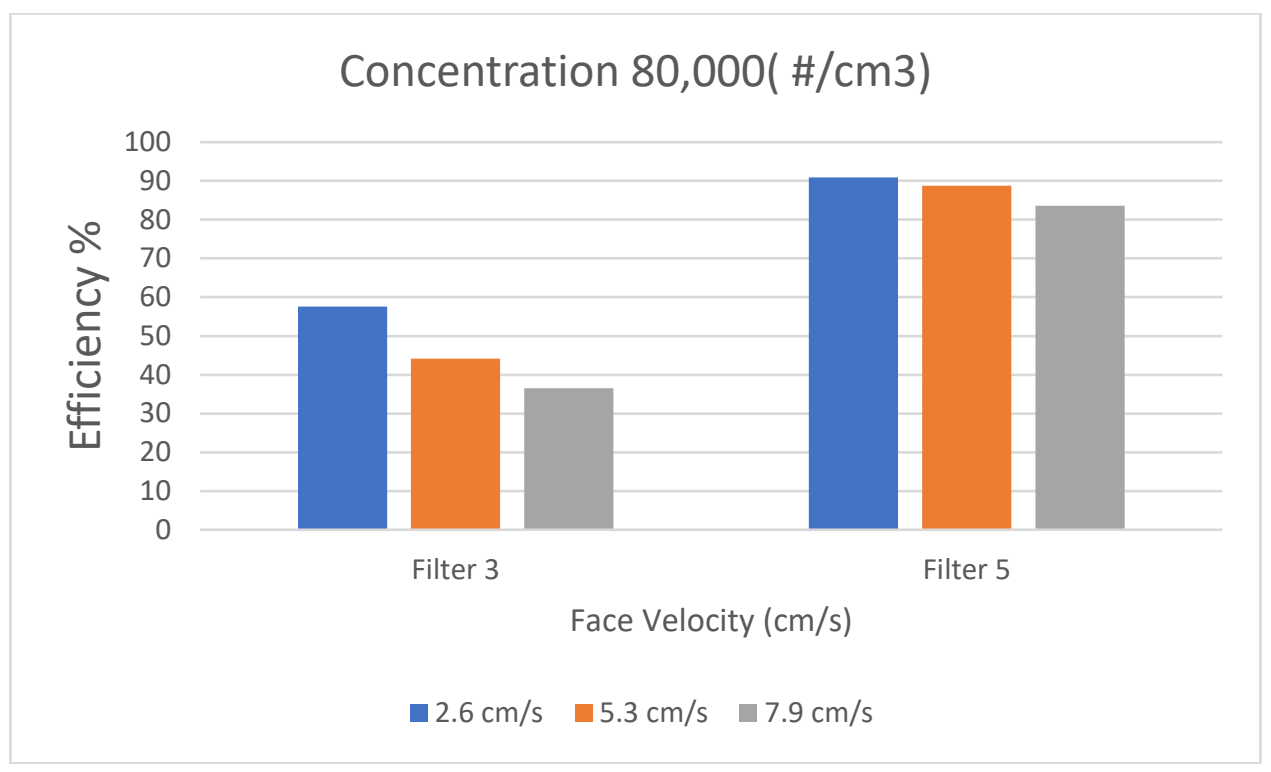

Figure 2.14 Filter efficiency at a challenge concentration of 80,000 particles $/ \mathrm{cm}^{3}$ versus face velocities (Group two) 
In this study, the normality of the data was checked with the JMP Software for groups one and two. As shown in Figures 2.15 and 2.16, the mean efficiencies were well modeled as a normal distribution and all data were located between the confidence bounds.

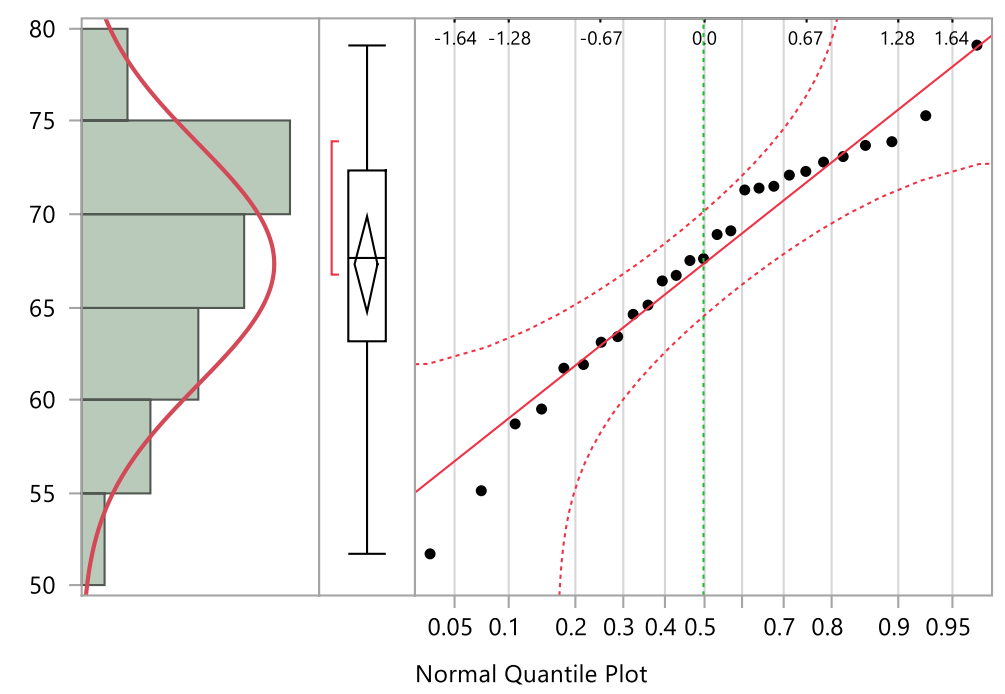

Figure 2.14 The data normal quantile plot (Group one)

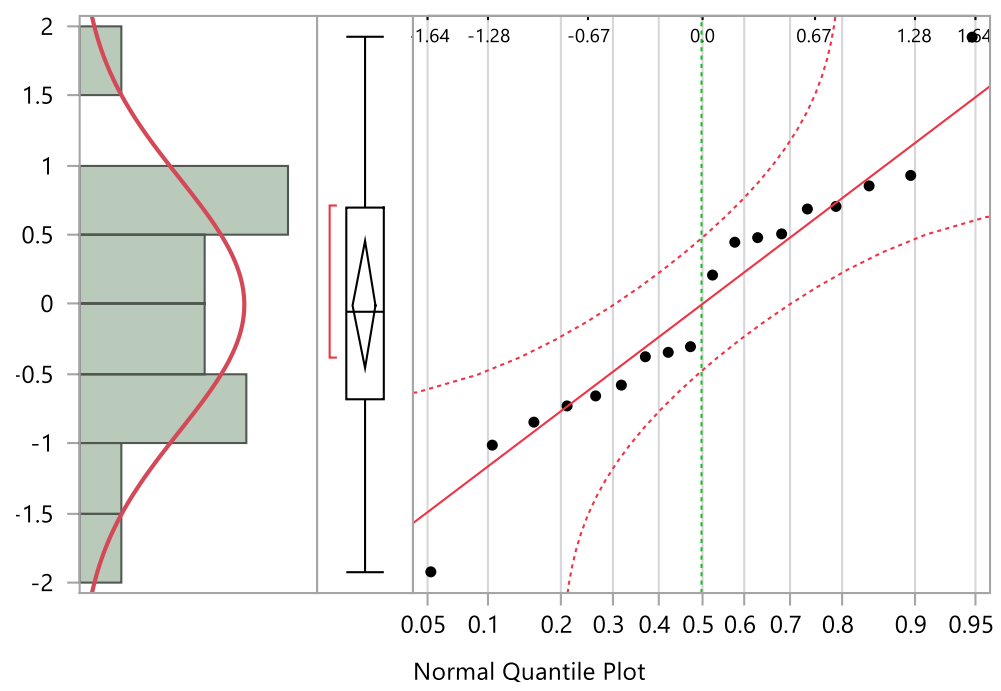

Figure 2.15 The data normal quantile plot (Group two)

A three-way ANOVA test had three independent variables and one dependent variable for each group of filters. In this study, the three independent variables were: type of filter (3 levels for 
group one and 2 levels for group two), challenge concentration (3 levels for both groups), and face velocity ( 3 levels for group one and a distinct set of 3 levels for group two), and the dependent variable was efficiency. A three-way ANOVA was analyzed in JMP software (see tables 2.7 and 2.8) and the analysis showed that the type of filters, challenge concentrations, and face velocities significantly affected the mean efficiency $(\mathrm{p}<0.05)$ for both groups, a similar conclusion has been drawn by Kim, et al., (2016). That study found that a flow rate of $75 \mathrm{~L} / \mathrm{min}$ had a significant effect on the filter collection efficiency. Also, Tables 2.7 and 2.8 show the way in which two-way interaction variables were analyzed for each group. The interaction between type of filters and face velocities had a significant effect on efficiency $(\mathrm{p}<0.05)$ for both groups. That meant the interaction with type of filters always had a significant effect on efficiency. However, in groups one and two, the interaction between type of filters and challenge concentrations and the interaction between the challenge concentrations and face velocities did not show a significant effect on the mean efficiency. 
Table 2. 7 Three-way ANOVA results for filter efficiency as a function of air filter type, face velocity, and particle challenge concentration (Group one)

\begin{tabular}{|l|c|c|c|c|}
\hline Source & DF & $\begin{array}{c}\text { Sum of } \\
\text { Squares }\end{array}$ & F Ratio & Prob > F \\
\hline Type of Filters & 2 & 341.64 & 68.44 & $<.0001^{*}$ \\
\hline Concentration (\#/cm3) & 2 & 190.21 & 38.10 & $<.0001^{*}$ \\
\hline Face Velocity (cm/s) & 2 & 447.38 & 89.63 & $<.0001^{*}$ \\
\hline Type of Filters*Concentration (\#/cm3) & 4 & 20.68 & 2.07 & 0.1767 \\
\hline Type of Filters*Face Velocity (cm/s) & 4 & 60.32 & 6.04 & $0.0153^{*}$ \\
\hline Concentration $(\# / c m 3) *$ Face Velocity $(\mathrm{cm} / \mathrm{s})$ & 4 & 9.51 & 0.95 & 0.4818 \\
\hline
\end{tabular}

Table 2. 8 Three-way ANOVA results for filter efficiency as a function of air filter type, face velocity, and particle challenge concentration (Group two)

\begin{tabular}{|l|c|c|c|c|}
\hline Source & DF & $\begin{array}{c}\text { Sum of } \\
\text { Squares }\end{array}$ & F Ratio & Prob > F \\
\hline Type of Filters & 1 & 7556.30 & 16587.00 & $<.0001^{*}$ \\
\hline Concentration $(\# / \mathrm{cm} 3)$ & 2 & 35.90 & 39.40 & $0.0023^{*}$ \\
\hline Face Velocity $(\mathrm{cm} / \mathrm{s})$ & 2 & 463.49 & 508.71 & $<.0001^{*}$ \\
\hline Type of Filters*Concentration $(\# / \mathrm{cm} 3)$ & 2 & 4.0744 & 4.47 & 0.0955 \\
\hline Type of Filters*Face Velocity $(\mathrm{cm} / \mathrm{s})$ & 2 & 199.59 & 219.06 & $<.0001^{*}$ \\
\hline Concentration $(\# / \mathrm{cm} 3) *$ Face Velocity $(\mathrm{cm} / \mathrm{s})$ & 4 & 5.33 & 2.92 & 0.1614 \\
\hline
\end{tabular}

After finding that the three independent variables had a significant effect on filter efficiency, the pairwise comparisons in Tables 2.9 and 2.10 show which means differ from one another for each group. Multiple pairwise comparisons show the difference between the mean efficiency of the different factor levels. Table 2.9 shows the pairwise multiple comparisons for the main factors, filter type, particle challenge concentration level, and face velocities for group one. From Table 2.9, the mean efficiency of Purolator Premium (filter 4) and Farm Fresh Breeze (filter 
2) filters was $70.3 \%$ and $69.4 \%$, respectively. The filter efficiencies of these two filters were not significantly different, however they were significantly higher than the Purolator ONE filter (filter 1) which had the mean efficiency of $62.3 \%$. Table 2.10 shows the pairwise multiple comparisons for the main factors for group two. The Bosch HEPA Premium filter (filter 5) efficiency of 89.2\% was significantly higher than the Beck/Arnley Paper filter (filter 3) which had the main efficiency of $48.3 \%$.

Tables 2.9 and 2.10 also show pairwise multiple comparisons for particle challenge concentrations $\left(40,000,60,000\right.$, and 80,000 particles $\left./ \mathrm{cm}^{3}\right)$. As shown in Table 2.9, the highest mean filter efficiency, $70.3 \%$, was found with a challenge concentration level of 40,000 particles $/ \mathrm{cm}^{3}$. The filter efficiencies measured for each particle challenge concentration level were significantly different. The filter efficiency at 60,000 particles $/ \mathrm{cm}^{3}$ was $67.8 \%$ and the filter efficiency at 80,000 particles $/ \mathrm{cm}^{3}$ was the lowest at $63.8 \%$. In addition, Table 2.7 shows the highest mean filter efficiency, $70.4 \%$, was found with a challenge concentration level of 40,000 particles $/ \mathrm{cm}^{3}$, while the lowest value $66.9 \%$ occurred at 80,000 particles $/ \mathrm{cm}^{3}$. Table 2.10 shows the filter efficiencies measured for the particle challenge concentration level of 40,000 particles $/ \mathrm{cm}^{3}$ and 60,000 particles $/ \mathrm{cm}^{3}$ were not significantly different, however they were significantly higher than the particle challenge concentration level of 80,000 particles $/ \mathrm{cm}^{3}$.

The results of the face velocity analysis for group one (filters 1,2 and 4) shown in Table 2.9 reveal that the highest mean efficiency, $72.8 \%$ was found with a $4.3 \mathrm{~cm} / \mathrm{s}$ face velocity. This filter efficiency was significantly higher than the filter efficiency observed with face velocities of 8.8 and $13.3 \mathrm{~cm} / \mathrm{s}$. The filter efficiencies for each face velocity condition was significantly different. The filter efficiency for the $8.8 \mathrm{~cm} / \mathrm{s}$ face velocity was $66.2 \%$ and for the $13.3 \mathrm{~cm} / \mathrm{s}$ face velocity it was $63.0 \%$. Also, Table 2.10 shows the results of the face velocity analysis for group 
two (filters 3, and 5), the highest mean efficiency, $75.3 \%$ was found with a $2.6 \mathrm{~cm} / \mathrm{s}$ face velocity.

Overall, from table 2.10, the filter efficiencies for each face velocity condition was significantly different.

Table 2. 9 Pairwise multiple comparisons: mean efficiency\% among type of filters, face velocities and challenge concentrations (Group one)

\begin{tabular}{|c|c|c|c|c|}
\hline Variable & $\begin{array}{c}\text { Mean } \\
\text { Efficiency\% }\end{array}$ & Levels & & Grouping 1 \\
\hline \multirow{3}{*}{ Filter Type } & 70.3 & Purolator Premium (Filter 4) & A & \multirow[b]{3}{*}{$\mathrm{B}$} \\
\hline & 69.4 & Fram Fresh Breeze (Filter 2) & A & \\
\hline & 62.3 & Purolator ONE(Filter 1) & & \\
\hline \multirow{3}{*}{$\begin{array}{l}\text { Challenge } \\
\text { concentration } \\
\left(\# / \mathrm{cm}^{3}\right) \\
\end{array}$} & 70.3 & 40,000 & $\mathrm{~A}$ & \multirow{3}{*}{$\mathrm{B}$} \\
\hline & 67.8 & 60,000 & & \\
\hline & 63.8 & 80,000 & & \\
\hline \multirow{3}{*}{$\begin{array}{l}\text { Face velocity } \\
(\mathrm{cm} / \mathrm{s})\end{array}$} & 72.8 & 4.3 & A & \multirow{3}{*}{$\mathrm{B}$} \\
\hline & 66.2 & 8.8 & & \\
\hline & 63.0 & 13.3 & & \\
\hline
\end{tabular}

Table 2. 10 Pairwise multiple comparisons: mean efficiency\% among type of filters, face velocities and challenge concentrations (Group two)

\begin{tabular}{lccccc}
\hline Variable & $\begin{array}{c}\text { Mean } \\
\text { Efficiency\% }\end{array}$ & Levels & \multicolumn{2}{c}{ Grouping $^{1}$} \\
\hline Filter Type & 89.2 & Bosch HEPA Premium (Filter 5) & A & & \\
& 48.3 & Beck/Arnley Paper (Filter 3) & & B \\
\hline Challenge & 70.4 & 40,000 & $\mathrm{~A}$ & \\
concentration & 69.0 & 60,000 & $\mathrm{~A}$ & & \\
$\left(\# / \mathrm{cm}^{3}\right)$ & 66.9 & 80,000 & & $\mathrm{~B}$ & \\
\hline Face velocity & 75.3 & 2.6 & $\mathrm{~A}$ & & \\
$(\mathrm{~cm} / \mathrm{s})$ & 68.0 & 5.3 & & $\mathrm{~B}$ & \\
& 62.9 & 7.9 & & $\mathrm{C}$ \\
\hline
\end{tabular}

${ }^{1}$ Means with different letters are significantly different

The pairwise two-way interaction comparisons presented in Table 2.11 show the interaction between types of filter and face velocity for group one (filters 1, 2, and 4). The range of mean efficiency for all interactions was between $74.8 \%$, for the interaction between filter 4 and $4.3 \mathrm{~cm} / \mathrm{s}$, and $56.6 \%$ for the interaction between filter 1 and $13.3 \mathrm{~cm} / \mathrm{s}$. In addition, Table 2.11 
shows the group levels and which of these interactions had a significant difference. For example, the interactions between filter 4 and the face velocity levels of $(4.3$ and $8.8 \mathrm{~cm} / \mathrm{s})$ found no differences. On the other hand, the efficiency of filter 4 at $4.3 \mathrm{~cm} / \mathrm{s}$ and filter 4 at $13.3 \mathrm{~cm} / \mathrm{s}$ were significantly different. In more detail, the efficiency of filter 1 at $4.3 \mathrm{~cm} / \mathrm{s}$ was significantly different from the efficiency of filter 1 at $8.8 \mathrm{~cm} / \mathrm{s}$ and filter 1 at $13.3 \mathrm{~cm} / \mathrm{s}$. However, the efficiency of filter 1 at $8.8 \mathrm{~cm} / \mathrm{s}$ and filter 1 at $13.3 \mathrm{~cm} / \mathrm{s}$ were not significantly different.

Table 2. 11 Mean efficiency\% among two way interaction between type of filters and challenge face velocities (Group one)

\begin{tabular}{ccccccccc}
\hline Interaction & $\begin{array}{c}\text { Mean } \\
\text { Efficiency } \%\end{array}$ & & \multicolumn{3}{c}{ Grouping $^{1}$} & \\
\hline $\mathrm{F} 4 * 4.3$ & 74.8 & $\mathrm{~A}$ & & & & & \\
$\mathrm{~F} 2 * 4.3$ & 73.2 & $\mathrm{~A}$ & $\mathrm{~B}$ & & & & \\
$\mathrm{~F} 1 * 4.3$ & 70.3 & $\mathrm{~A}$ & $\mathrm{~B}$ & $\mathrm{C}$ & & & \\
$\mathrm{F} 4 * 8.8$ & 69.8 & $\mathrm{~A}$ & $\mathrm{~B}$ & $\mathrm{C}$ & $\mathrm{D}$ & & \\
$\mathrm{F} 2 * 8.8$ & 68.7 & & $\mathrm{~B}$ & $\mathrm{C}$ & $\mathrm{D}$ & & \\
$\mathrm{F} 4 * 13.3$ & 67.7 & & & $\mathrm{C}$ & $\mathrm{D}$ & & \\
$\mathrm{F} 2 * 13.3$ & 64.6 & & & & $\mathrm{D}$ & $\mathrm{E}$ & \\
$\mathrm{F} 1 * 8.8$ & 60.0 & & & & & $\mathrm{E}$ & $\mathrm{F}$ \\
$\mathrm{F} 1 * 13.3$ & 56.6 & & & & & & $\mathrm{~F}$ \\
\hline${ }^{1}$ Means with different letters are significantly different & & & & & &
\end{tabular}

As shown in Table 2.12, the range of mean efficiency for the interaction of filter type and face velocity for group two (filter 3 and 5) ranged between $91.2 \%$ for the interaction between filter 5 and $2.6 \mathrm{~cm} / \mathrm{s}$, and $39.1 \%$ for the interaction between filter 3 and $7.9 \mathrm{~cm} / \mathrm{s}$. As shown in figure 2.17 , the efficiency of filter 5 at $2.6 \mathrm{~cm} / \mathrm{s}$ had no difference with the efficiency of filter 5 at 5.3 $\mathrm{cm} / \mathrm{s}$. However, the efficiency of filter 5 at $2.6 \mathrm{~cm} / \mathrm{s}$ and filter 5 at $7.9 \mathrm{~cm} / \mathrm{s}$ were significantly different. In addition, the filter efficiencies of filter 3 measured for each face velocity level were significantly different. Overall, filter efficiency, for any type filter, decreased when the face 
velocity increased. For instance, the mean efficiencies of (filter $3 * 2.6$ ), (filter $3 * 5.3$ ), and (filter $3 * 7.9$ ) were $59.4 \%, 46.3 \%$, and $39.1 \%$, respectively.

Table 2. 12 Mean efficiency\% among two-way interaction between type of filters and face velocities (Group two)

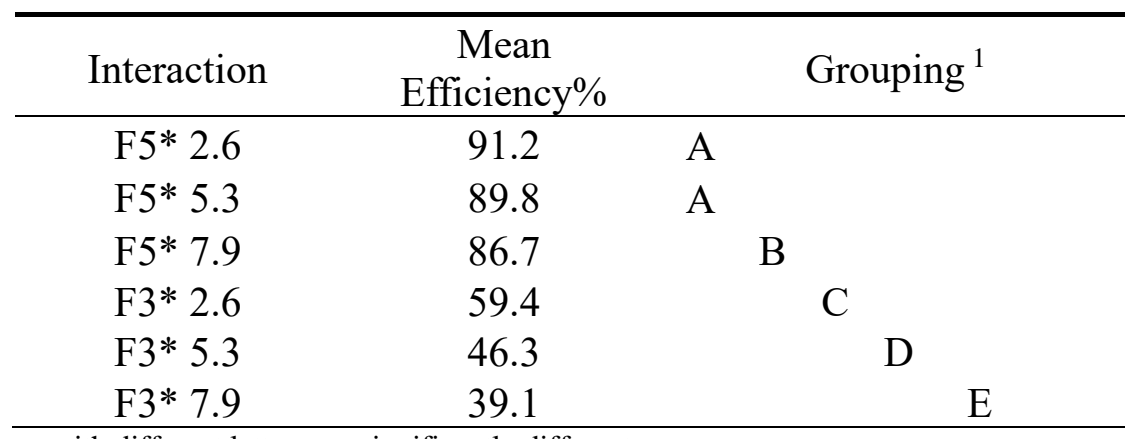

${ }^{1}$ Means with different letters are significantly different

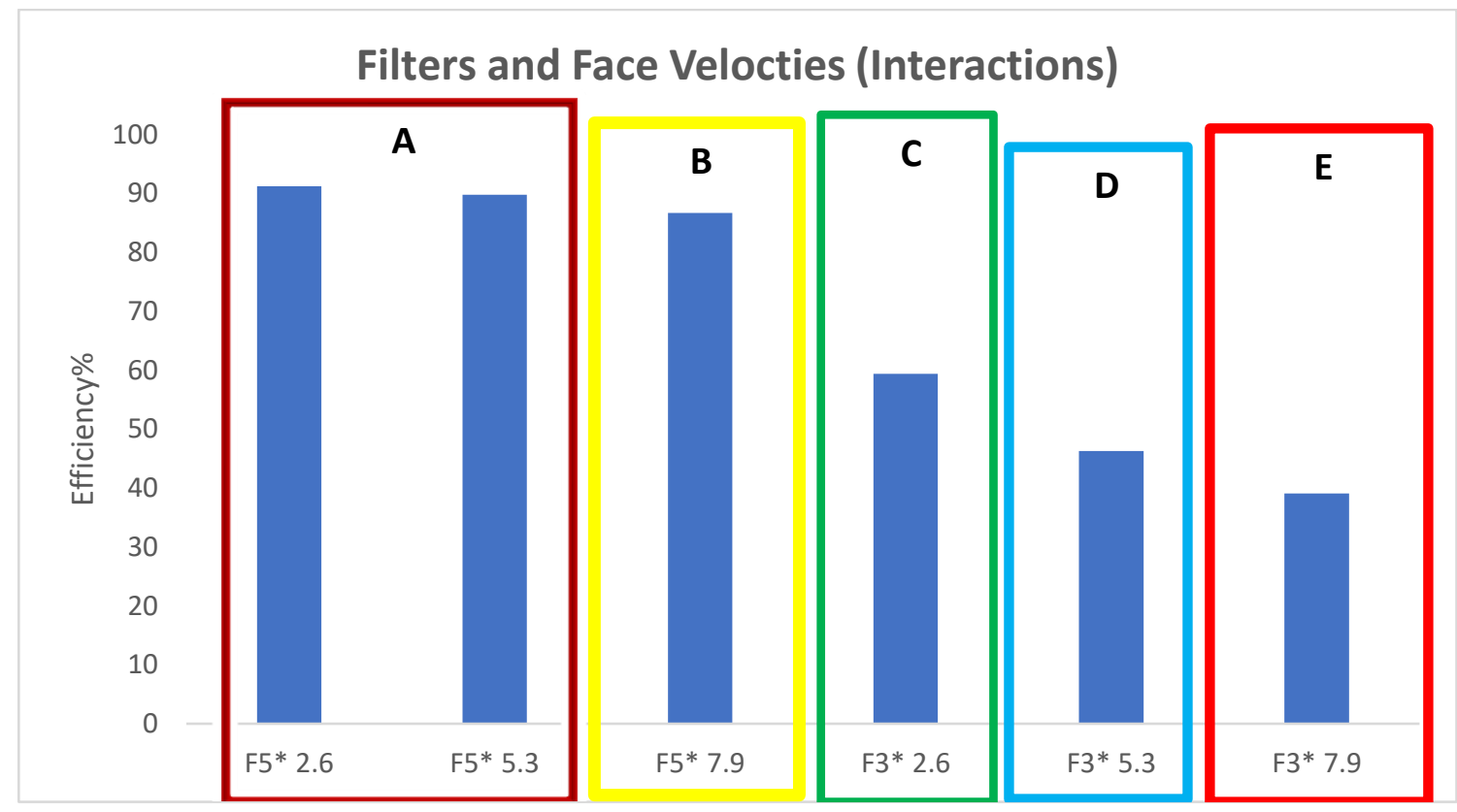

Figure 2.16 The two-way interaction between type of filters and face velocities (Group two)

In the construction equipment applications, the significant influence of the dust loading on the filtration efficiency and pressure drop is important. Also, media characteristics may change with dust loading. According to (Hinds, 2007), loading modified filter performance to provide 
greater resistance and higher efficiency. Also, the accumulation of solid particles in the media increases the pressure drop, filtration efficiency, and the resistance to airflow. In addition, the enclosed cab of construction equipment protects the operator from exposure to dust and silica particles during actual drilling. According to (Cecala, 2016), the cab filtration system needs to be well-sealed to extract the benefits of using high-efficiency dust filters. Also, the cab of construction equipment should have appropriate maintenance, because of the constant movement and vibration, which could cause a leakage that could affect the filtration system.

\subsection{Conclusion}

In this study, the five cabin air filters in two groups were tested under three different levels of challenge concentrations and face velocities. The main factors had a significant effect on the mean efficiency of cabin filters. In addition, the mean efficiencies of all filters were the highest at 40,000 particles $/ \mathrm{cm}^{3}$, ranging from $59.5 \%$ to $79.1 \%$ for group one (filters 1, 2, and 4), and ranging from $41.6 \%$ to $91.7 \%$ for group two (filters 3 and 5). On the other hand, at 80,000 particles $/ \mathrm{cm}^{3}$, the efficiencies were the lowest ranging from $51.7 \%$ to $72.1 \%$ for group one and ranging from $36.5 \%$ to $90.9 \%$ for group two. In this study also, the mean efficiency for all types of filters of group one was the highest at $4.3 \mathrm{~cm} / \mathrm{s}$ in comparison to efficiencies measured at higher face velocities. While the highest mean efficiency of the second group was at $2.6 \mathrm{~cm} / \mathrm{s}$. Further, the mean efficiencies for both groups always decreased when the face velocity and challenge concentration increased.

From the results of group one, the Purolator Premium filter, filter 4, had the highest mean efficiency and the Purolator ONE filter, filter 1, had the lowest value. In the second group, the Bosch HEPA Premium filter, filter 5, had higher mean efficiency than the Beck/Arnley Paper Filter, filter 3. The purpose of the cabin filters is to isolate passengers from the dust or other 
harmful aerosols and to also protect construction workers from occupational exposures, for example, dust containing silica which may measure between 0.01 and 100 micrometers. Thus, the Purolator ONE Filter, filter 1, and the Beck/Arnley Paper Filter, filter 3, should not recommended for use with construction machinery work since their efficiencies were less than 55\% and 50\%, respectively, when tested with high challenge concentrations; Otherwise, the operators may have to have additional respirators to protect them adequately from dangerous silica dust. Overall, this study can assist manufacturers in improving the performance of cabin air filters to protect the construction workers in heavy construction work.

\subsection{Limitation}

The major limitation of this study was that the average surface area samples of the filters were $153.4 \mathrm{~cm}^{2}$ for group one (filters 1,2, and 4) and $257.3 \mathrm{~cm}^{2}$ for group two (filters 3 and 5), which represented only $5 \%$ from the actual total area of each filter. Future studies need to utilize a larger sample area for the laboratory study in order to accurately measure the efficiencies of the cabin air filters. 


\section{Chapter 3}

\section{Study II - On-Road Experimental Study on the Performance of Five Different Cabin Filters}

\subsection{Applications}

The Coronavirus 2019, popularly referred to as COVID-19 is a severely infectious illness that primarily affects the human upper respiratory system resulting in severe acute respiratory syndrome. The first case of the illness was Wuhan Province of China, from which it spread quickly resulting in a global pandemic (World Health Organization, 2020). Consequently, there have been many concerns regarding the safety of people who have not yet contracted the virus. One of the measures applied is the use of face masks, and cabin air filters which basically make use of filtration mechanisms to trap the virus before reaching the upper respiratory tract.

A major application area that requires more focused research is the use of cabin filters in vehicles including personal cars, taxis, existing on different platforms such as Uber, and buses. It may also include some industrial vehicles. This application puts into focus the effectiveness and efficiency of present car cabin filters and their effectiveness in filtering out infectious particles in the air such as viruses, especially COVID-19. Most viruses vary in diameter from 20 to 500 nanometers. The primary spread mechanism of COVID-19 is through droplet infection, of which the droplet particles measure between $5 \mu \mathrm{m}$ and $10 \mu \mathrm{m}$. These size particles have a diameter of approximately 60 to 140 nanometers. This means that the different filtration solutions targeted at protecting humans from contracting COVID-19 through droplet infection must target capturing the specified droplet particle size to attain maximum effectiveness.

There are interesting observations made in ongoing studies and discussions about the filtration effectiveness of certain types of face masks used for the COVID-19. This prompts a 
similar analysis on the effectiveness of vehicle cabin filters in relation to the virus. Considering the identified means through which the virus spreads and the sensitization given on social distancing, there is need to find cabin air filters capable of addressing the emerging challenges. Nevertheless, the question needs to ask, are the current generation of cabin air filters used in personal vehicles and taxis capable of filtering the virus?

\subsection{Equipment and Variables}

New, unused filters of the five brands tested in the laboratory were tested in the "on-road" study. The on-road study provided actual performance data on the efficiency for each filter when used in the car's (a 2010 Nissan Maxima) ventilation system. The filters were installed in the ventilation system of the vehicle before starting the road test to make sure that testing data were comparable.

Particle concentrations were measured by the NanoScan SMPS Nanoparticle Sizer and the Optical Particle Sizer (OPS). The NanoScan SMPS Nanoparticle Sizer (SMPS, Model 3910, TSI Inc, Shoreview, MN, USA), measures midpoint particles size ranges from 11.5 to $365.2 \mathrm{~nm}$ in 13 size channels. The sample time is one minute (Figure 3.1). The Optical Particle Sizer (OPS, Model 3330, TSI Inc, Shoreview, MN, USA), uses light scatting to size particles from 0.3 to $10 \mu \mathrm{m}$ in 16 user-adjustable size channels (Figure 3.2). Particulate matter such as $P M_{2.5}$ and $P M_{10}$ were measured inside the vehicle because using both devices particle concentrations from $10 \mathrm{~nm}$ to 10 $\mu \mathrm{m}$ could be measured. 


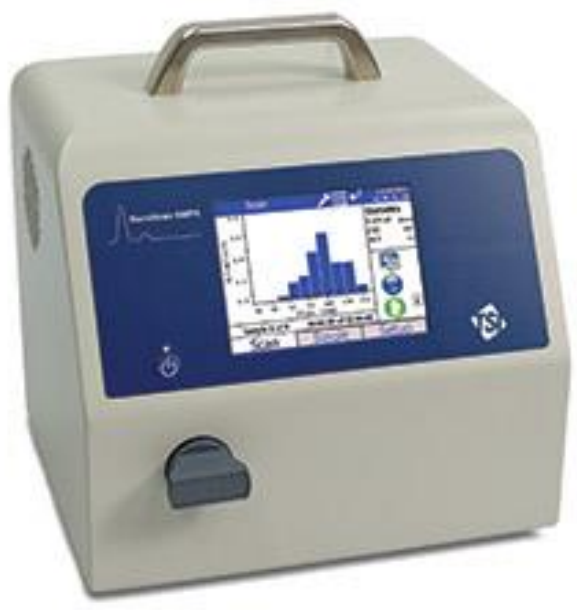

Figure 3. 1 NanoScan SMPS Nanoparticle Sizer

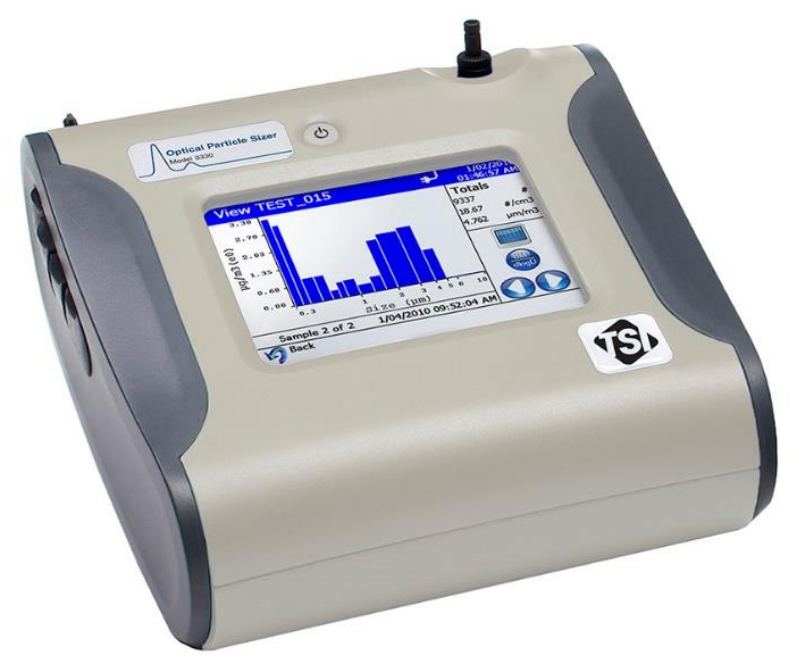

Figure 3. 2 Optical Particle Sizer (OPS)

The five cabin air filters were tested under two different types of driving conditions: driving in the city and driving on the highway. The city driving tests were done in Morgantown, WV, from University Ave to High Street (Figure 3.3). This route was chosen because it is located at the center of the city and many West Virginia University students use it daily. This route has stop signs, bus stations, and stores that could make it a high traffic volume area. The speed limit on this route is 25 miles per hour. 


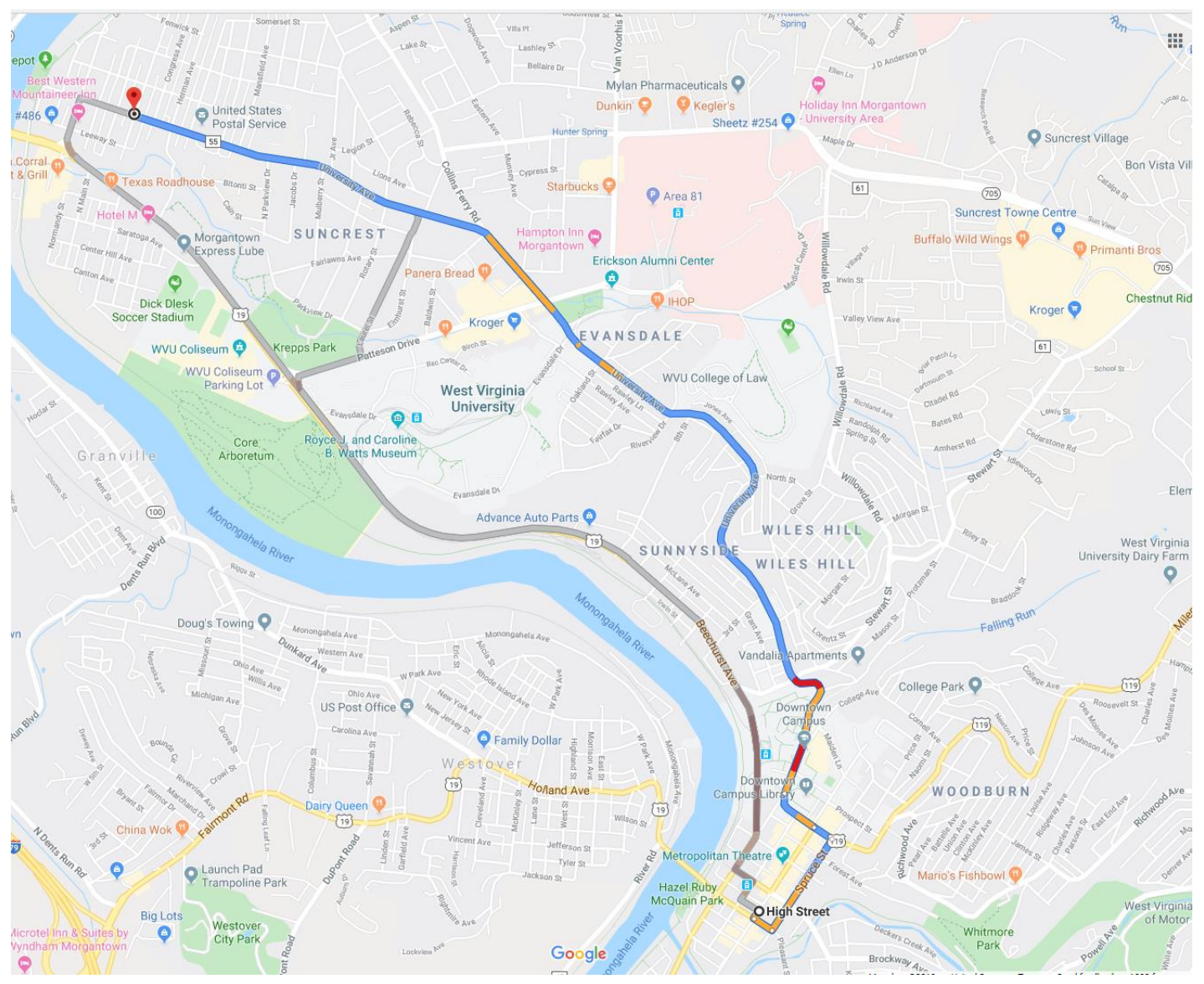

Figure 3. 3 Route of City Drive

The on-road driving tests were on I-79 North located near Morgantown, WV. I-79 North was selected for the on-road driving because of low traffic volume and because it is located close to Morgantown, WV (Figure 3.4). 


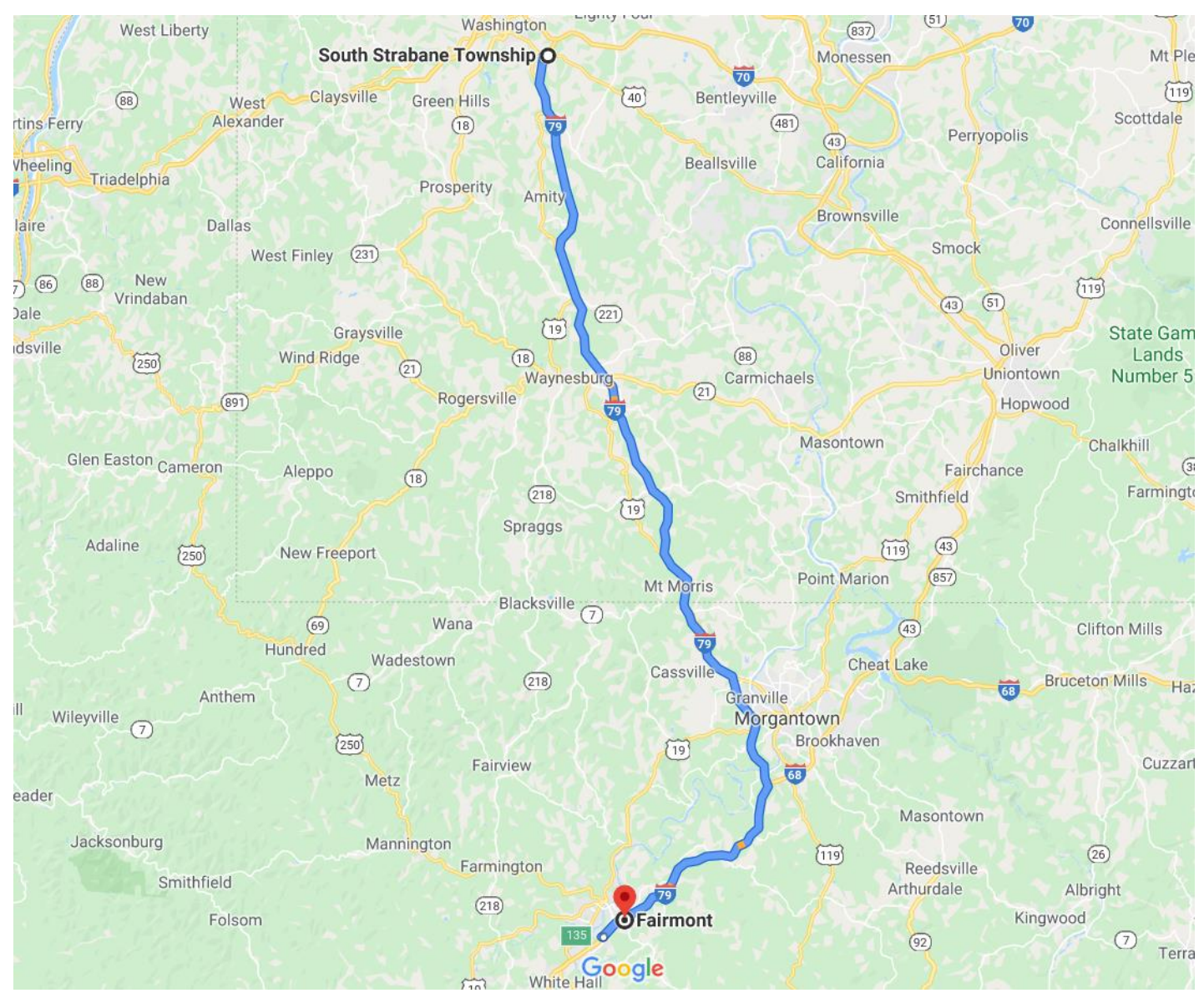

Figure 3. 4 Route of a Highway Driving

Each filter was tested with a total of 21 conditions in each route. Particle concentrations were measured during the city drive based on: i) type of filters; ii) recirculation off and on; and iii) fan speed: low, medium, and high. Table 3.1 shows a summary of the city drive variables. 
Table 3. 1 Summary of City Drive Variables

\begin{tabular}{ll}
\hline Variable & Levels \\
\hline Filter Type & 5 (Purolator ONE, Fram Fresh Breeze, Beck/Arnley Paper \\
& Cabin Air Filter, Purolator Premium with Febreze \\
& Freshness, and Bosch HEPA Premium Cabin Air Filter) \\
\hline Recirculation Mode & 2 (Recirculation off and Recirculation on). \\
\hline Fan Speed & 4 (off, low, medium, and high)
\end{tabular}

The variables considered during the on-road testing were completely randomized. The three fan speeds were achieved with a fan setting of 2 (low), 4 (medium), and 7 (high), respectively,). Table 3.2 shows the summary of highway variables.

Table 3. 2 Highway Variables

\begin{tabular}{ll}
\hline Variable & Levels \\
\hline Filter Type & 5 (Purolator ONE, Fram Fresh Breeze, Beck/Arnley Paper \\
& Cabin Air Filter, Purolator Premium with Febreze \\
& Freshness, and Bosch HEPA Premium Cabin Air Filter) \\
& 2 (50 and 70) mile per hour \\
\hline Car Speed & 2 (Recirculation off and Recirculation on). \\
\hline Recirculation Mode & 4 (off, low, medium, and high)
\end{tabular}

\subsection{Experimental Setup}

New cabin air filters were installed in the vehicle before each on-road test. A NanoScan SMPS Nanoparticle Sizer and an Optical Particle Sizer (OPS) were used to measure particle concentrations inside the test vehicle for particles having diameters ranging from $10 \mathrm{~nm}$ to $10 \mu \mathrm{m}$. 
The NanoScan SMPS and the OPS are battery powered and can record data without an external power supply. Both devices were kept in the front passenger seat and were securely installed to make sure they were stable for data recording during each driving test or recording (Figure 3.5).

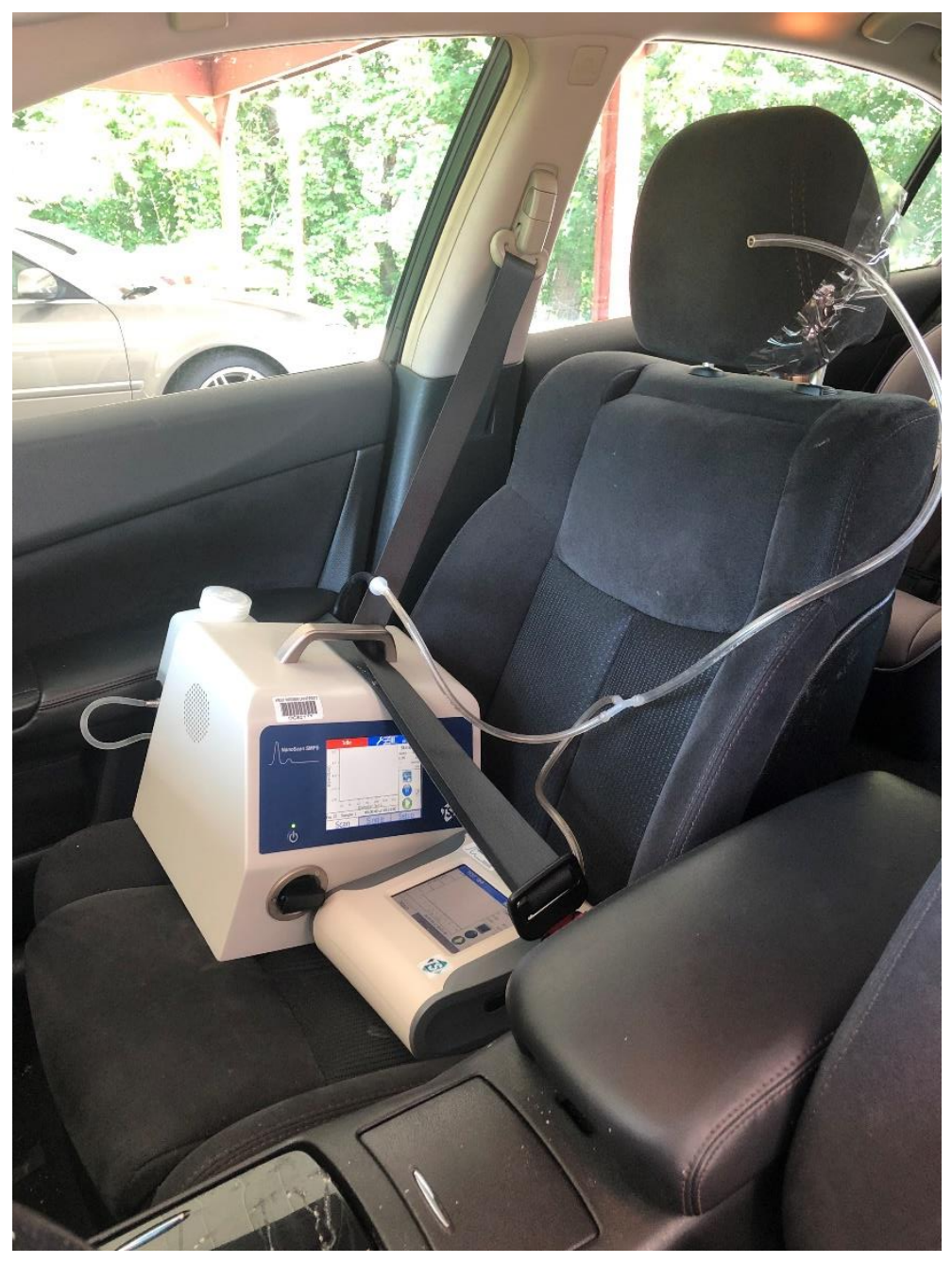

Figure 3. 5 NanoScan SMPS and OPS - The Road Test

The sampling location for both devices was located at a position close to the breathing area of a passenger when setting in the passenger's seat (Figure 3.6). The sample was collected with a 0.25 in diameter Tygon tube. The sample tubing was then split using a flex hose "Y" connector so that the same sample was going to each device. 


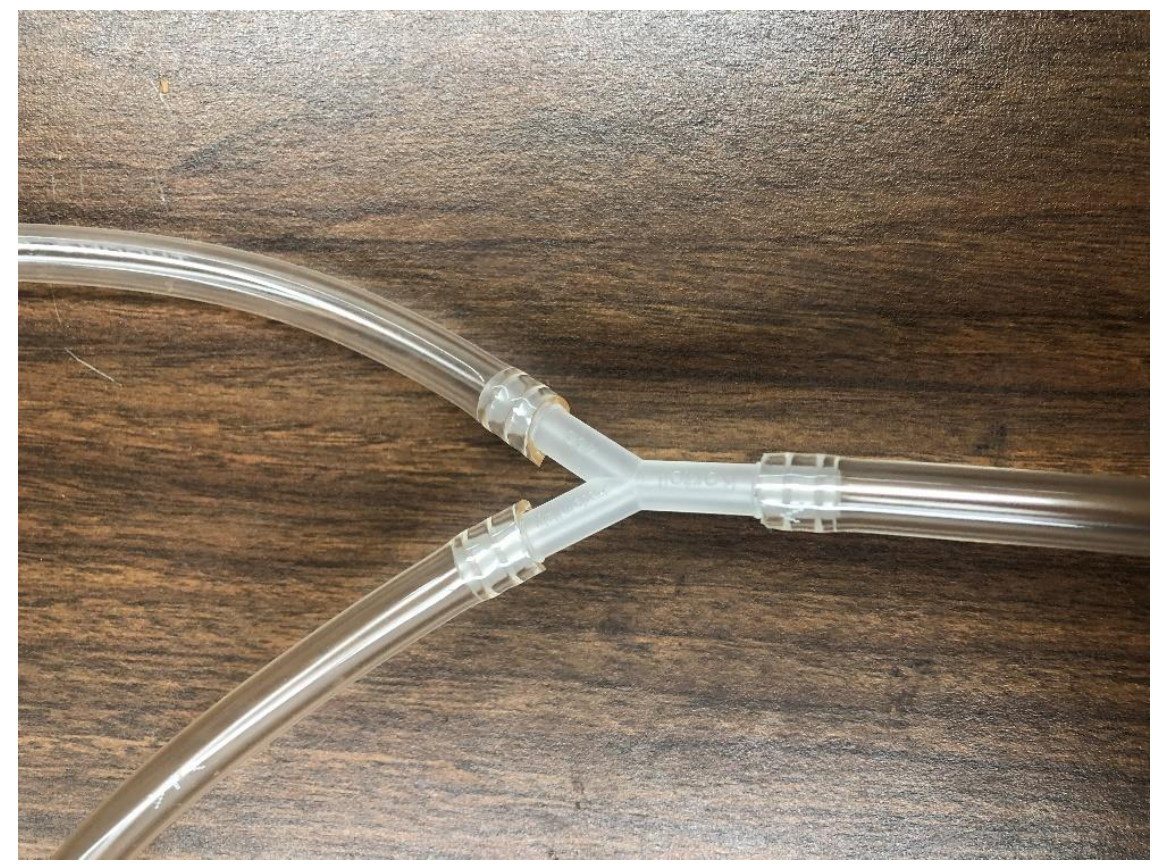

Figure 3. 6 Flex hose "Y" connector.

Depending on the settings of the NanoScan SMPS and OPS instruments, the devices took a sample every 60 seconds. The total time for each condition was 10 minutes. The total time to evaluate all 21 conditions for each filter was 210 minutes. All test conditions were randomized.

\subsection{Data analysis}

JMP Software was used to perform statistical analysis (JMP Statistical Discovery from SAS). JMP was used to assess whether the data were normally distributed. Two main tests were conducted for the assessment of normality: a graphical method such as Q-Q probability plots; and a statistical method, such as Kolmogorov-Smirnov (K-S) test, based on the P-value. A three-way ANOVA with Tukey's range tests were conducted to test for interactions effects of fan speed (low, medium, and high) on particle penetration while driving in a city and highway (low and high speed), while the recirculation was off or on. A P-value of $<0.05$ was considered significant. 


\subsection{Results and Discussion}

\subsubsection{NanoScan Results for Midpoint Particle Size Range from $11.5 \mathrm{~nm}$ to $273.8 \mathrm{~nm}$}

Table 3.3 shows the mean efficiency determined with the NanoScan particle sizer for the midpoint particle size range from $11.5 \mathrm{~nm}$ to $273.8 \mathrm{~nm}$, for each different type of cabin air filter under the variables considered in the study. The three driving conditions were city driving and highway driving at $50 \mathrm{mph}$ and at $70 \mathrm{mph}$. In addition, there were seven different fan speeds (recirculation modes) for each driving condition. As shown in Table 3.3, the overall efficiency range of the five type of filters were from $44.8 \%$ to $96.6 \%$. Furthermore, the lowest observed mean efficiency, $44.8 \%$, was filter 1 tested under highway driving at 70 with a fan speed of high with the recirculation turned off. While driving in the city, the highest mean value was observed with filter 5 , with a fan speed of high and the recirculation turned on.

Overall, the fan speeds with recirculation turned off always showed much lower mean efficiency in comparison to the others which had recirculation on. This was consistent with research of Jung, et al., (2017), on cabin particles, where they used 100\% recirculated air and 100\% fresh air. They found that by using $100 \%$ recirculated air the cabin particle concentrations dropped to 950 particles $/ \mathrm{cm}^{3}$, while particle concentrations exceeded more than 2000 particles $/ \mathrm{cm}^{3}$ with $100 \%$ fresh air. The reason behind that was with recirculated air the airflow was in a closed loop which made the air pass the cabin air filter repeatedly so the chance of capturing the particles increased. 
Table 3. 3 Mean Efficiency \% for the particle size range from 11.5 to $273.8 \mathrm{~nm}$

Efficiency \%, (Mean)

\begin{tabular}{|c|c|c|c|c|c|c|}
\hline $\begin{array}{c}\text { Driving } \\
\text { Conditions }\end{array}$ & $\begin{array}{r}\text { Fan Speeds } \\
\left(\text { Rec Mode }^{1}\right)\end{array}$ & Filter 1 & Filter 2 & Filter 3 & Filter 4 & Filter 5 \\
\hline \multirow{7}{*}{ City Driving } & Off Fan & $79.2 \%$ & $84.3 \%$ & $81.5 \%$ & $78.3 \%$ & $86.4 \%$ \\
\hline & Low Fan (Rec on) & $81.4 \%$ & $89.5 \%$ & $82.4 \%$ & $81.8 \%$ & $88.6 \%$ \\
\hline & Med Fan (Rec on) & $82.8 \%$ & $90.2 \%$ & $83.8 \%$ & $80.3 \%$ & $94.2 \%$ \\
\hline & High Fan (Rec on) & $84.9 \%$ & $93.8 \%$ & $85.2 \%$ & $81.2 \%$ & $96.6 \%$ \\
\hline & Low Fan (Rec off) & $80.4 \%$ & $87.2 \%$ & $76.8 \%$ & $74.5 \%$ & $83.8 \%$ \\
\hline & Med Fan (Rec off) & $78.6 \%$ & $86.5 \%$ & $74.3 \%$ & $72.2 \%$ & $80.4 \%$ \\
\hline & High Fan (Rec off) & $74.3 \%$ & $77.7 \%$ & $72.6 \%$ & $69.7 \%$ & $80.8 \%$ \\
\hline \multirow{7}{*}{$\begin{array}{l}\text { Highway (Low } \\
\text { Speed) }\end{array}$} & Off Fan & $69.5 \%$ & $72.9 \%$ & $55.4 \%$ & $72.7 \%$ & $81.9 \%$ \\
\hline & Low Fan (Rec on) & $73.5 \%$ & $74.2 \%$ & $60.2 \%$ & $77.9 \%$ & $84.9 \%$ \\
\hline & Med Fan (Rec on) & $73.7 \%$ & $80.9 \%$ & $63.5 \%$ & $78.8 \%$ & $85.3 \%$ \\
\hline & High Fan (Rec on) & $75.7 \%$ & $85.8 \%$ & $64.9 \%$ & $80.8 \%$ & $88.8 \%$ \\
\hline & Low Fan (Rec off) & $71.9 \%$ & $64.4 \%$ & $57.3 \%$ & $76.0 \%$ & $81.4 \%$ \\
\hline & Med Fan (Rec off) & $68.4 \%$ & $60.0 \%$ & $55.2 \%$ & $71.5 \%$ & $76.2 \%$ \\
\hline & High Fan (Rec off) & $64.1 \%$ & $51.7 \%$ & $51.2 \%$ & $67.6 \%$ & $79.2 \%$ \\
\hline \multirow{7}{*}{$\begin{array}{l}\text { Highway (High } \\
\text { Speed) }\end{array}$} & Off Fan & $50.6 \%$ & $63.8 \%$ & $60.8 \%$ & $74.7 \%$ & $78.2 \%$ \\
\hline & Low Fan (Rec on) & $54.4 \%$ & $65.4 \%$ & $58.3 \%$ & $76.4 \%$ & $80.2 \%$ \\
\hline & Med Fan (Rec on) & $53.1 \%$ & $71.5 \%$ & $62.0 \%$ & $77.7 \%$ & $83.8 \%$ \\
\hline & High Fan (Rec on) & $54.8 \%$ & $79.2 \%$ & $63.8 \%$ & $80.8 \%$ & $86.0 \%$ \\
\hline & Low Fan (Rec off) & $52.3 \%$ & $59.0 \%$ & $51.6 \%$ & $70.2 \%$ & $78.8 \%$ \\
\hline & Med Fan (Rec off) & $50.7 \%$ & $56.9 \%$ & $48.7 \%$ & $70.9 \%$ & $75.4 \%$ \\
\hline & High Fan (Rec off) & $44.8 \%$ & $47.3 \%$ & $46.4 \%$ & $64.4 \%$ & $72.2 \%$ \\
\hline
\end{tabular}

${ }^{1}$ Rec Means recirculation air mode

After the data was collected with the NanoScan device for the midpoint particle sizes range

from $11.5 \mathrm{~nm}$ to $273.8 \mathrm{~nm}$, a normality test was checked by JMP Software. The data were found not to be normally distributed. A Johnson transformation was applied to the data. The transformed data was found to be normally distribution. Figure 3.7 shows the transformed NanoScan mean efficiency data plot. 


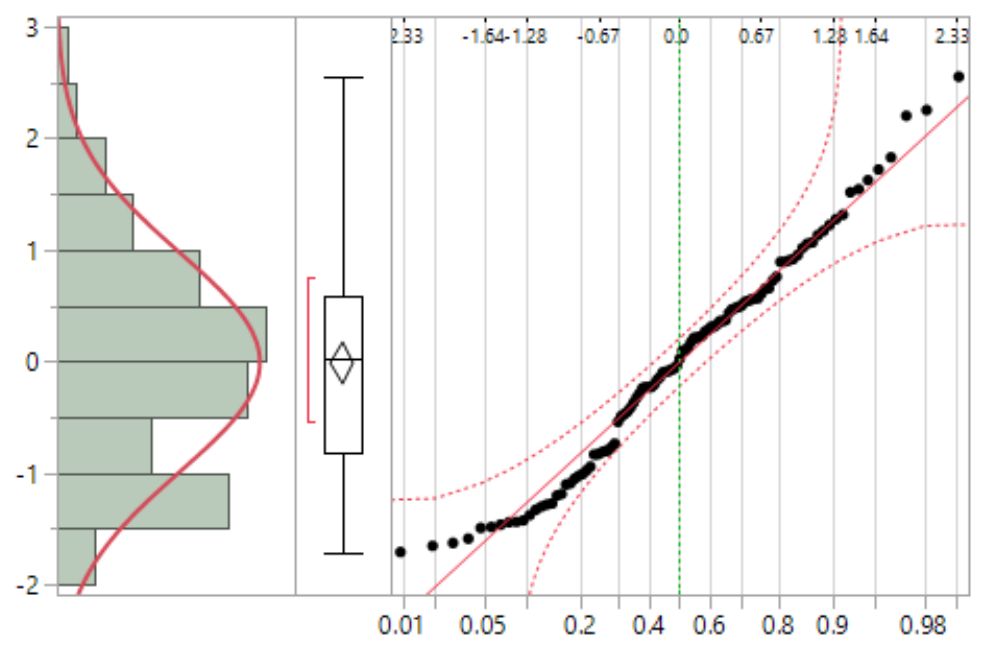

Figure 3. 7 The NanoScan data normal quantile plot

Table 3.4 shows the three-way ANOVA test for the mean efficiency of the three independent variables: fan speeds (recirculation mode); driving condition; and filter type. The three-way ANOVA was analyzed using JMP Software. As shown in Table 3.4, the fan speeds (recirculation modes), driving conditions, and filter types significantly affected the mean efficiency $(\mathrm{P}<0.05)$. In addition, the interaction between fan speeds (recirculation mode) and filter type, along with the interaction between driving condition and filter type $(\mathrm{P}<0.05)$, had a significant effect on the mean efficiency. However, the interaction between driving condition and fan speeds (recirculation mode) did not have a significant effect on the mean efficiency $(\mathrm{P}>0.05)$. 
Table 3. 4 Three-way ANOVA results for the Efficiency of particle size range from 11.5 to 273.8 $\mathrm{nm}$ as a function of type of cabin air filter, fan speeds (recirculation mode), and driving conditions

\begin{tabular}{|l|c|c|c|c|}
\hline Source & DF & $\begin{array}{c}\text { Sum of } \\
\text { Squares }\end{array}$ & F Ratio & Prob > F \\
\hline Fan Speeds (Rec Mode ${ }^{1}$ ) & 6 & 17.4 & 63.3 & $<.0001^{*}$ \\
\hline Driving Conditions & 2 & 31.7 & 346.3 & $<.0001^{*}$ \\
\hline Filters & 4 & 29.6 & 161.5 & $<.0001^{*}$ \\
\hline Fan Speeds (Rec Mode)*Driving Conditions & 12 & 0.6 & 1.1 & 0.3154 \\
\hline Fan Speeds (Rec Mode)*Filters & 24 & 4.0 & 3.7 & $<.0001^{*}$ \\
\hline Driving Conditions*Filters & 8 & 13.8 & 37.6 & $<.0001^{*}$ \\
\hline
\end{tabular}

${ }^{1}$ Rec Means recirculation air mode

A pairwise multiple comparison was applied to the data set in order to obtain a complete description of the independent variables that had a significant effect on the mean efficiency. The pairwise comparison for filter types in Table 3.5 found that the Bosch HEPA Premium filter had a mean efficiency of $83.6 \%$ which was significantly higher than the mean efficiencies of the four other filters. The mean efficiency of the Purolator Premium and Fram Fresh Breeze filters, 75.2\% and $73.8 \%$, respectively, were not significantly different, but these filters were significantly different from filters 1 and 3. The lowest performance of all the filters was filter 1, the Beck/Arnley Paper filter, with a mean efficiency of $64.5 \%$ which was significantly $(\mathrm{P}<0.05)$ lower than the other four filters.

The pairwise comparison of the seven fan speeds (recirculation modes) are shown in table 3.5 showed that the high and medium fan level with recirculation on had a mean filter efficiency of $80.4 \%$ and $77.4 \%$, respectively. They were significantly different. The mean filter efficiency measured when the fan was turned off or on low was not significantly different. This was due to the fact that when the recirculation was activated, the AC with low fan had a low air flow speed. When this low air flow, in comparison to other recirculation modes, went through the filters it lowered the chance of capturing the particles. However, in the fan speeds with recirculation off 
modes, low, medium, and high fan levels had different group levels, which meant that they had a significant difference, with mean efficiencies of $71.4 \%, 68.7 \%$, and $65.2 \%$, respectively. These findings were consistent with research of Qi et al., (2008). They measured in-cabin particles with two different fan speeds and the fresh air mode was on. They found that when the recirculation was off, the filtration efficiency was $22.9 \%$ and $17 \%$ at medium and high fan speeds, respectively. Table 3.5 also shows that the three driving conditions, city driving, low speed driving on a highway, and high speed on a highway resulted in significant differences in mean filter efficiency. In addition, the lowest mean efficiency of $65.2 \%$ was at high highway speed. These findings agreed with research of Hudda et al. (2011). They studied two different driving speeds and found that mean filter efficiency always decreased (particle number concentrations increased) with high vehicle speed.

Table 3. 5 Pairwise multiple comparisons: Mean efficiency\% for particle size from 11.5 to 273.8 $\mathrm{nm}$ among type of filters, recirculation mode, and driving conditions

\begin{tabular}{|c|c|c|c|}
\hline Variable & $\begin{array}{c}\text { Mean } \\
\text { Efficiency\% }\end{array}$ & Levels & Grouping ${ }^{1}$ \\
\hline \multirow{5}{*}{ Filter Type } & 83.6 & Bosch HEPA Premium (Filter 5) & A \\
\hline & 75.2 & Purolator Premium (Filter 4) & B \\
\hline & 73.8 & Fram Fresh Breeze (Filter 2) & B \\
\hline & 67.6 & Purolator ONE (Filter 1) & $\mathrm{C}$ \\
\hline & 64.5 & Beck/Arnley Paper (Filter 3) & $\mathrm{D}$ \\
\hline \multirow{7}{*}{$\begin{array}{l}\text { Fan Speeds } \\
\left(\operatorname{Rec}^{2}{ }^{2}\right)\end{array}$} & 80.4 & High Fan (Rec on) & A \\
\hline & 77.4 & Med Fan (Rec on) & B \\
\hline & 74.7 & Low Fan (Rec on) & $\mathrm{C}$ \\
\hline & 72.7 & Off Fan & $\mathrm{C}$ \\
\hline & 71.4 & Low Fan (Rec off) & D \\
\hline & 68.7 & Med Fan (Rec off) & $\mathrm{E}$ \\
\hline & 65.2 & High Fan (Rec off) & $\mathrm{F}$ \\
\hline Driving & 82.0 & City & A \\
\hline \multirow[t]{2}{*}{ Conditions } & 71.6 & Low Speed & B \\
\hline & 65.2 & High Speed & $\mathrm{C}$ \\
\hline
\end{tabular}


Table 3.6 presents the pairwise two-way interactions comparisons between type of filters and fan speeds (recirculation mode). The mean efficiency of all interactions ranged from $91.2 \%$ for the interaction between filter 5 and high fan speed with recirculation on to $58.1 \%$ for the interaction between filter 3 and high fan speed with recirculation off. This result was expected, since filter 5 always had the highest mean filter efficiency as compared to the other filters. In addition, Table 3.6 shows that the interaction between high fan level with (recirculation on) and filter 5 and 2 had no difference. Also, the interaction between medium fan level with (recirculation on) and filter 5 had no difference.

Table 3.6 shows that the mean efficiencies of the interaction between filter type and recirculation mode with activated recirculation always measured higher than the efficiencies with the recirculation off. Also, the mean efficiencies decreased with increase in fan speed while the recirculation was activated. However, the opposite happened with increased fan speed when the recirculation was turned off. For example, when the recirculation was activated, the efficiency of the interaction between filter 2 and high fan speed was $87.2 \%$ then it decreased to $78.9 \%$ at low fan speed. On the other hand, when the recirculation was off, the mean efficiency of the interaction between filter 2 and high fan speed was $61.2 \%$ then it increased to $71.7 \%$ with a low fan speed. 
Table 3. 6 Mean efficiency\% among two-way interaction between type of filters and fan speeds (recirculation mode)

\begin{tabular}{|c|c|c|c|c|c|c|c|c|c|c|c|c|c|}
\hline Interaction & Mean & & & & & & cou & ping & & & & & \\
\hline High Fan (Rec on),F5 & $91.2 \%$ & A & & & & & & & & & & & \\
\hline Med Fan (Rec on),F5 & $87.4 \%$ & A & B & & & & & & & & & & \\
\hline High Fan (Rec on),F2 & $87.2 \%$ & $\mathrm{~A}$ & $\mathrm{~B}$ & & & & & & & & & & \\
\hline Low Fan (Rec on),F5 & $84.2 \%$ & & $\mathrm{~B}$ & $\mathrm{C}$ & & & & & & & & & \\
\hline Med Fan (Rec on),F2 & $82.2 \%$ & & $\mathrm{~B}$ & $\mathrm{C}$ & $\mathrm{D}$ & & & & & & & & \\
\hline Off Fan,F5 & $82.3 \%$ & & $\mathrm{~B}$ & $\mathrm{C}$ & $\mathrm{D}$ & & & & & & & & \\
\hline High Fan (Rec on),F4 & $82.2 \%$ & & B & $\mathrm{C}$ & $\mathrm{D}$ & & & & & & & & \\
\hline Med Fan (Rec on),F4 & $80.6 \%$ & & & $\mathrm{C}$ & $\mathrm{D}$ & $\mathrm{E}$ & & & & & & & \\
\hline Low Fan (Rec on),F2 & $78.9 \%$ & & & $\mathrm{C}$ & $\mathrm{D}$ & $\mathrm{E}$ & $\mathrm{F}$ & & & & & & \\
\hline Low Fan (Rec on),F4 & $78.7 \%$ & & & $\mathrm{C}$ & $\mathrm{D}$ & $\mathrm{E}$ & $\mathrm{F}$ & & & & & & \\
\hline Off Fan,F4 & $78.6 \%$ & & & $\mathrm{C}$ & $\mathrm{D}$ & $\mathrm{E}$ & $\mathrm{F}$ & G & & & & & \\
\hline Off Fan,F2 & $77.6 \%$ & & & $\mathrm{C}$ & $\mathrm{D}$ & $\mathrm{E}$ & $\mathrm{F}$ & G & & & & & \\
\hline High Fan (Rec on),F1 & $76.4 \%$ & & & & $\mathrm{D}$ & $\mathrm{E}$ & $\mathrm{F}$ & G & $\mathrm{H}$ & & & & \\
\hline Low Fan (Rec off),F5 & $75.2 \%$ & & & & & $\mathrm{E}$ & $\mathrm{F}$ & G & $\mathrm{H}$ & I & & & \\
\hline Med Fan (Rec off),F5 & $73.7 \%$ & & & & & $\mathrm{E}$ & $\mathrm{F}$ & $\mathrm{G}$ & $\mathrm{H}$ & I & & & \\
\hline Low Fan (Rec off),F4 & $73.5 \%$ & & & & & $\mathrm{E}$ & $\mathrm{F}$ & $\mathrm{G}$ & $\mathrm{H}$ & I & & & \\
\hline High Fan (Rec on),F3 & $71.8 \%$ & & & & & $\mathrm{E}$ & $\mathrm{F}$ & $\mathrm{G}$ & $\mathrm{H}$ & I & & & \\
\hline Low Fan (Rec off),F2 & $71.7 \%$ & & & & & $\mathrm{E}$ & $\mathrm{F}$ & G & $\mathrm{H}$ & I & $\mathrm{J}$ & & \\
\hline High Fan (Rec off),F5 & $71.3 \%$ & & & & & $\mathrm{E}$ & $\mathrm{F}$ & $\mathrm{G}$ & $\mathrm{H}$ & I & $\mathrm{J}$ & & \\
\hline Med Fan (Rec on),F3 & $70.2 \%$ & & & & & & $\mathrm{~F}$ & $\mathrm{G}$ & $\mathrm{H}$ & I & $\mathrm{J}$ & K & \\
\hline Low Fan (Rec on),F3 & $69.9 \%$ & & & & & & $\mathrm{~F}$ & G & $\mathrm{H}$ & I & $\mathrm{J}$ & K & $\mathrm{L}$ \\
\hline Med Fan (Rec off),F4 & $69.7 \%$ & & & & & & $\mathrm{~F}$ & $\mathrm{G}$ & $\mathrm{H}$ & I & $\mathrm{J}$ & K & $\mathrm{L}$ \\
\hline Med Fan (Rec on),F1 & $68.8 \%$ & & & & & & $\mathrm{~F}$ & $\mathrm{G}$ & $\mathrm{H}$ & I & $\mathrm{J}$ & K & $\mathrm{L}$ \\
\hline Med Fan (Rec off),F2 & $68.2 \%$ & & & & & & $\mathrm{~F}$ & G & $\mathrm{H}$ & I & $\mathrm{J}$ & K & $\mathrm{L}$ \\
\hline Off Fan,F3 & $67.8 \%$ & & & & & & & $\mathrm{G}$ & $\mathrm{H}$ & I & $\mathrm{J}$ & K & $\mathrm{L}$ \\
\hline Low Fan (Rec on),F1 & $67.0 \%$ & & & & & & & & $\mathrm{H}$ & I & $\mathrm{J}$ & K & $\mathrm{L}$ \\
\hline High Fan (Rec off),F4 & $68.9 \%$ & & & & & & & & & I & $\mathrm{J}$ & K & $\mathrm{L}$ \\
\hline Low Fan (Rec off),F3 & $66.4 \%$ & & & & & & & & & I & $\mathrm{J}$ & K & $\mathrm{L}$ \\
\hline Med Fan (Rec off),F3 & $65.9 \%$ & & & & & & & & & I & $\mathrm{J}$ & K & $\mathrm{L}$ \\
\hline Off Fan,F1 & $65.9 \%$ & & & & & & & & & I & $\mathrm{J}$ & K & $\mathrm{L}$ \\
\hline High Fan (Rec off),F2 & $61.2 \%$ & & & & & & & & & & $\mathrm{~J}$ & K & $\mathrm{L}$ \\
\hline Low Fan (Rec off),F1 & $61.1 \%$ & & & & & & & & & & & K & $\mathrm{L}$ \\
\hline High Fan (Rec off),F1 & $59.4 \%$ & & & & & & & & & & & $\mathrm{~K}$ & $\mathrm{~L}$ \\
\hline Med Fan (Rec off),F1 & $58.9 \%$ & & & & & & & & & & & & $\mathrm{~L}$ \\
\hline High Fan (Rec off),F3 & $58.1 \%$ & & & & & & & & & & & & $\mathrm{~L}$ \\
\hline
\end{tabular}


The pairwise two-way interaction comparisons presented in Table 3.7 showed the interaction between type of filters and driving conditions. The mean efficiency of all interactions measured with the midpoint particle sizes $(11.5-273.8 \mathrm{~nm})$ ranged from $88.0 \%$ for the interaction between filter 5 and city driving to $51.5 \%$ for the interactions between filter 3 and high-speed driving on a highway. Table 3.7 shows which of these interactions had a significant difference. For example, the interactions between filter 5 and city driving was not significantly difference from the interaction between filter 2 and city driving. Also, the interaction between filter 2 and city driving was not significantly different from the interaction between filter 4 and city driving. Overall, the interactions between city driving and filters had overall higher performance than other interactions between the filters.

Table 3. 7 Mean efficiency\% among two-way interaction between type of filters and driving conditions

\begin{tabular}{|c|c|c|c|c|c|c|c|c|c|c|c|}
\hline Interaction & Mean Efficiency \% & & & & & ou & jin & & & & \\
\hline City,F5 & $88.0 \%$ & $\mathrm{~A}$ & & & & & & & & & \\
\hline City,F2 & $86.0 \%$ & A & $\mathrm{B}$ & & & & & & & & \\
\hline City,F4 & $83.5 \%$ & & $\mathrm{~B}$ & $\mathrm{C}$ & & & & & & & \\
\hline City,F1 & $81.2 \%$ & & & $\mathrm{C}$ & $\mathrm{D}$ & & & & & & \\
\hline City,F3 & $80.2 \%$ & & & $\mathrm{C}$ & $\mathrm{D}$ & $\mathrm{E}$ & & & & & \\
\hline low speed,F5 & $79.5 \%$ & & & & $\mathrm{D}$ & $\mathrm{E}$ & $\mathrm{F}$ & & & & \\
\hline high speed,F5 & $76.2 \%$ & & & & & $\mathrm{E}$ & $\mathrm{F}$ & $\mathrm{G}$ & & & \\
\hline low speed,F4 & $75.7 \%$ & & & & & & $\mathrm{~F}$ & $\mathrm{G}$ & $\mathrm{H}$ & & \\
\hline high speed,F4 & $73.6 \%$ & & & & & & & $\mathrm{G}$ & $\mathrm{H}$ & & \\
\hline low speed,F2 & $71.0 \%$ & & & & & & & $\mathrm{G}$ & $\mathrm{H}$ & & \\
\hline low speed,F3 & $70.0 \%$ & & & & & & & & $\mathrm{H}$ & & \\
\hline high speed,F2 & $63.3 \%$ & & & & & & & & & & \\
\hline low speed,F1 & $57.7 \%$ & & & & & & & & & & $\mathrm{~J}$ \\
\hline high speed,F1 & $56.4 \%$ & & & & & & & & & & $\mathrm{~J}$ \\
\hline high speed,F3 & $51.5 \%$ & & & & & & & & & & $\mathrm{~J}$ \\
\hline
\end{tabular}




\subsubsection{OPS Results for Midpoint Particle Size Range from $335 \mathrm{~nm}$ to 8,962.1 nm}

Table 3.8 shows the OPS mean efficiency for the five different types of filters under different driving conditions and fan conditions. During this study, the OPS device has measured the midpoint particle sizes between 335 and 8,962.1 nanometers. The overall efficiency range of the five different types of filters was between $40.6 \%$ and $95.7 \%$. This is lower than the mean efficiency range of the filters obtained from the NanoScan, which measured midpoint particle sizes from 11.5-273.8 nanometers.

The mean efficiency of $95.7 \%$ was the highest value observed. It occurred with filter 4 while driving in the city using a high fan setting with recirculation on. The lowest value, $40.6 \%$ occurred while driving at high speed on the highway with filter 1 with a high fan level and recirculation off. Overall, as shown in Table 3.8, filter 5 showed the best performance compared to others with a mean filter efficiency of $89.8 \%$. On the other hand, the performance of filter 3 was the lowest at $64.5 \%$.

Overall trends observed with the midpoint particles ranging from 335 to $8,962.1 \mathrm{~nm}$ were the same as those observed with the particles ranging from 11.5 to $273.8 \mathrm{~nm}$. The mean efficiencies detected for the driving condition of low speed for all types of filters was higher than the values for the high-speed driving condition. This observation was consistent with research of Jung, et al., (2017). Also, this study demonstrated that the mean efficiency of the filters while driving in the city was higher than driving on the highway both at low and high speed. The reason for this observation was that the vehicle speed in the city was very slow, because city driving included stop signs and traffic lights, On the other hand, the driving speed on the highway was higher compared to the city, which made the mean filtration efficiency lower due to the speed of the car. 
In addition, the mean efficiencies of all types of filters observed with the particles range $(11.5-273.8 \mathrm{~nm})$ and $(335-8962.1 \mathrm{~nm})$ under different face velocities were affected by the driving conditions. For example, for the midpoint particles size ranging from 335 to $8,962.1 \mathrm{~nm}$, the mean efficiency of filter 2 with a low fan level and recirculation on for city driving, low speed driving, and high speed driving were respectively $90.6 \%, 88.4 \%$, and $85.7 \%$. Overall, the mean efficiency observed during city driving at a certain face velocity was always higher than the mean efficiency of low and high speed driving.

Table 3. 8 Mean Efficiency \% for the particle size range from 335 to $8,962.1 \mathrm{~nm}$

\begin{tabular}{|c|c|c|c|c|c|c|}
\hline \multirow[b]{2}{*}{$\begin{array}{c}\text { Driving } \\
\text { Conditions }\end{array}$} & \multirow[b]{2}{*}{$\begin{array}{l}\text { Fan Speeds } \\
\left(\text { Rec Mode }^{1}\right)\end{array}$} & \multicolumn{5}{|c|}{ Efficiency \%, (Mean) } \\
\hline & & Filter 1 & Filter 2 & Filter 3 & Filter 4 & Filter 5 \\
\hline \multirow{7}{*}{ City Driving } & Off Fan & $81.4 \%$ & $87.5 \%$ & $81.6 \%$ & $87.8 \%$ & $91.6 \%$ \\
\hline & Low Fan (Rec on) & $82.6 \%$ & $90.6 \%$ & $82.4 \%$ & $90.7 \%$ & $93.6 \%$ \\
\hline & Med Fan (Rec on) & $83.7 \%$ & $91.5 \%$ & $83.8 \%$ & $94.6 \%$ & $93.8 \%$ \\
\hline & High Fan (Rec on) & $86.1 \%$ & $94.2 \%$ & $85.2 \%$ & $95.7 \%$ & $95.2 \%$ \\
\hline & Low Fan (Rec off) & $84.3 \%$ & $93.2 \%$ & $76.6 \%$ & $88.6 \%$ & $92.6 \%$ \\
\hline & Med Fan (Rec off) & $80.6 \%$ & $90.4 \%$ & $74.4 \%$ & $87.0 \%$ & $90.6 \%$ \\
\hline & High Fan (Rec off) & $79.7 \%$ & $88.5 \%$ & $72.8 \%$ & $86.1 \%$ & $90.2 \%$ \\
\hline \multirow{7}{*}{$\begin{array}{c}\text { Highway (Low } \\
\text { Speed) }\end{array}$} & Off Fan & $71.5 \%$ & $86.2 \%$ & $55.5 \%$ & $85.8 \%$ & $87.6 \%$ \\
\hline & Low Fan (Rec on) & $73.7 \%$ & $88.4 \%$ & $61.2 \%$ & $90.3 \%$ & $91.9 \%$ \\
\hline & Med Fan (Rec on) & $74.9 \%$ & $92.8 \%$ & $62.4 \%$ & $93.6 \%$ & $91.6 \%$ \\
\hline & High Fan (Rec on) & $75.2 \%$ & $93.8 \%$ & $64.9 \%$ & $94.4 \%$ & $93.5 \%$ \\
\hline & Low Fan (Rec off) & $68.5 \%$ & $79.4 \%$ & $59.2 \%$ & $86.9 \%$ & $89.8 \%$ \\
\hline & Med Fan (Rec off) & $64.3 \%$ & $78.6 \%$ & $55.2 \%$ & $86.2 \%$ & $88.9 \%$ \\
\hline & High Fan (Rec off) & $61.4 \%$ & $75.8 \%$ & $51.2 \%$ & $85.3 \%$ & $85.2 \%$ \\
\hline \multirow{7}{*}{$\begin{array}{c}\text { Highway (High } \\
\text { Speed) }\end{array}$} & Off Fan & $52.8 \%$ & $83.3 \%$ & $60.7 \%$ & $88.6 \%$ & $87.5 \%$ \\
\hline & Low Fan (Rec on) & $54.4 \%$ & $85.7 \%$ & $58.4 \%$ & $87.5 \%$ & $88.3 \%$ \\
\hline & Med Fan (Rec on) & $54.9 \%$ & $88.5 \%$ & $61.0 \%$ & $93.4 \%$ & $91.1 \%$ \\
\hline & High Fan (Rec on) & $55.8 \%$ & $92.3 \%$ & $63.8 \%$ & $93.6 \%$ & $92.4 \%$ \\
\hline & Low Fan (Rec off) & $48.4 \%$ & $78.2 \%$ & $51.7 \%$ & $85.3 \%$ & $86.6 \%$ \\
\hline & Med Fan (Rec off) & $44.8 \%$ & $76.7 \%$ & $48.4 \%$ & $80.5 \%$ & $84.6 \%$ \\
\hline & High Fan (Rec off) & $40.6 \%$ & $71.1 \%$ & $46.4 \%$ & $78.3 \%$ & $81.3 \%$ \\
\hline
\end{tabular}


As shown in figure 3.8, after transforming the data via Johnson transformation, the data of the mean efficiency for the midpoint particle sizes from 335 to $8,962.1 \mathrm{~nm}$ followed a normal distribution and the (P-value >0.05). The normality of the data was checked by JMP Software.

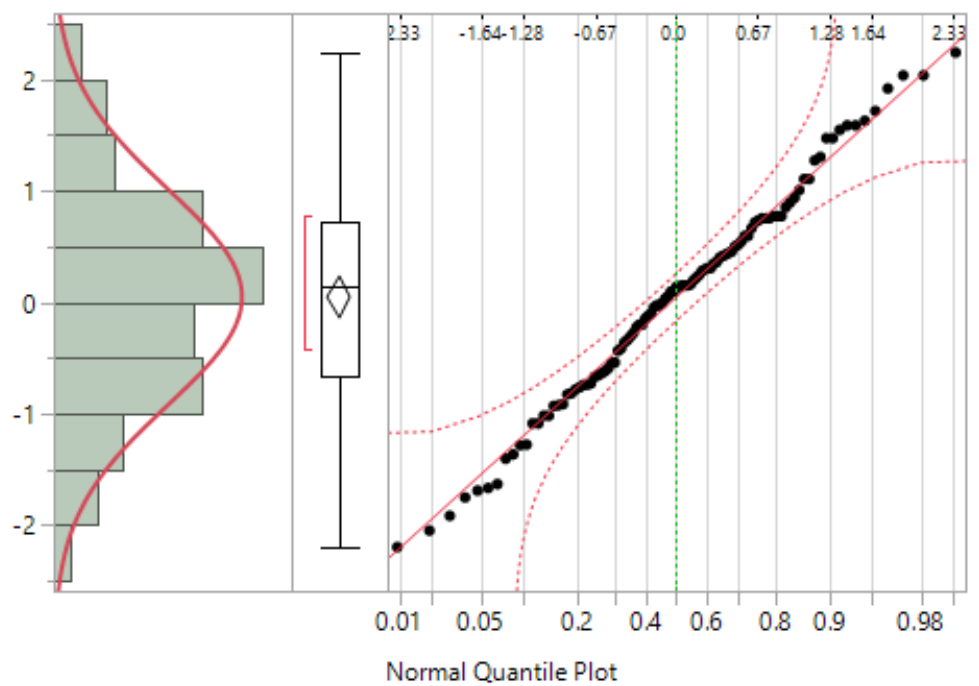

Figure 3. 8 The OPS data normal quantile plot

As shown in Table 3.9, the independent variables, which were fan speeds (recirculation mode) (seven levels), driving conditions (three levels), and filter type (five levels), had a significant effect on the mean efficiency $(\mathrm{P}<0.05)$. Also, the interaction between driving conditions and filter types showed a significant effect, $\mathrm{P}<0.05$. However, neither the interaction between fan speeds and driving conditions nor the interaction between fan speeds and filters type showed a significant effect.

As shown in Table 3.9, the interaction between fan speeds (recirculation mode) and filters for the particle size range from 335 to $8,962.1 \mathrm{~nm}$ did not show a significant effect $(\mathrm{P}=0.0941)$. In the other hand, the interaction between fans speeds (recirculation mode) and filters for the particle size range from 11.5 to $273.8 \mathrm{~nm}$ (Table 3.4) showed a significant effect $(\mathrm{P}<0.0001)$. One of the possible reasons could be that the particle size range which used in the NanoScan device 
was different from the OPS device. The OPS device is capable of scanning wider midpoint particle range (335 to $8,962.1 \mathrm{~nm}$ ) with 16 channels, while the NanoScan device has smaller midpoint particle size range (11.5 to $273.8 \mathrm{~nm})$.

Table 3. 9 Three-way ANOVA results for the Efficiency of midpoint particle size range (335$8,962.1 \mathrm{~nm}$ ) as a function of type of cabin air filter, fan speeds (recirculation mode), and driving conditions

\begin{tabular}{|l|c|c|c|c|}
\hline Source & DF & $\begin{array}{c}\text { Sum of } \\
\text { Squares }\end{array}$ & F Ratio & Prob > F \\
\hline Fan speeds (Rec Mode ${ }^{1}$ ) & 6 & 20.31 & 30.80 & $<.0001^{*}$ \\
\hline Driving Conditions & 2 & 13.45 & 61.22 & $<.0001^{*}$ \\
\hline Filters & 4 & 43.95 & 99.97 & $<.0001^{*}$ \\
\hline Fan speeds (Rec Mode) *Driving Conditions & 12 & 0.45 & 0.34 & 0.9768 \\
\hline Fan speeds (Rec Mode)*Filters & 24 & 4.11 & 1.56 & 0.0941 \\
\hline Driving Conditions*Filters & 8 & 9.79 & 11.14 & $<.0001^{*}$ \\
\hline
\end{tabular}

Table 3.10 presents the pairwise multiple comparisons of the mean efficiency for the midpoint particle sizes range from $335 \mathrm{~nm}$ to $8,962.1 \mathrm{~nm}$. The table shows further details of which variable levels differed from one another. The overall range of the mean efficiency for all types of filters was between $64.5 \%$ and $89.8 \%$ for the particles with sizes between 335 and $8,962.1$ nanometers. In addition, the Bosch HEPA Premium and Purolator Premium filters had the same group level, which means that their mean filter efficiencies are not significantly different from each other. Also, Purolator Premium and Fram Fresh Breeze filters with means of $87.4 \%$ and $85.7 \%$, respectively, did not show a significant difference since they were in the grouping connection. The Purolator ONE filter and Beck/Arnley Paper filters had different group levels, showing that they were significantly different.

In this study, the medium fan level with recirculation on did not show a difference with high fan level and low fan level with recirculation on. Also, low fan level with recirculation on had no difference with the fan being of on low with recirculation off. Additionally, high fan level 
with recirculation off had a difference with all levels except medium fan level with recirculation off. Overall, with recirculation on, the mean efficiency always increased when the speed of fan increased, on the other hand, the opposite happened in recirculation was off. The main reason for this observation was that in the fresh air mode the duct system allowed air to enter inside the cabin, which increased the number of particles in the car.

Table 3.10 also shows that all levels of driving conditions were significantly difference. The lowest mean efficiency was $73.2 \%$ at high speed on the highway, and the highest value was measured during city driving. These results were consistent with research of Hudda et al. (2011), in which three driving speeds were tested, and the results showed that the penetration of the cabin filters increased as driving speed increased.

Table 3. 10 Pairwise multiple comparisons: Mean efficiency\% for the particle size from 335 to $8,962.1 \mathrm{~nm}$ among type of filters, fan speeds (recirculation mode), and driving conditions

\begin{tabular}{|c|c|c|c|}
\hline Variable & $\begin{array}{c}\text { Mean } \\
\text { Efficiency\% }\end{array}$ & Levels & Grouping ${ }^{1}$ \\
\hline \multirow{5}{*}{ Filter Type } & 89.8 & Bosch HEPA Premium (Filter 5) & A \\
\hline & 87.4 & Purolator Premium (Filter 4) & A B \\
\hline & 85.7 & Fram Fresh Breeze (Filter 2) & B \\
\hline & 67.6 & Purolator ONE (Filter 1) & $\mathrm{C}$ \\
\hline & 64.5 & Beck/Arnley Paper (Filter 3) & $\mathrm{D}$ \\
\hline \multirow{7}{*}{$\begin{array}{l}\text { Fan Speeds } \\
\left(\text { Rec Mode }^{2}\right)\end{array}$} & 84.6 & High Fan (Rec on) & A \\
\hline & 83.7 & Med Fan (Rec on) & A B \\
\hline & 81.0 & Low Fan (Rec on) & B C \\
\hline & 79.3 & Off Fan & C D \\
\hline & 77.2 & Low Fan (Rec off) & C D \\
\hline & 75.1 & Med Fan (Rec off) & D E \\
\hline & 72.7 & High Fan (Rec off) & $\mathrm{E}$ \\
\hline Driving & 86.1 & City & $\mathrm{A}$ \\
\hline Conditions & 77.6 & Low Speed & $\mathrm{B}$ \\
\hline & 73.2 & High Speed & $\mathrm{C}$ \\
\hline
\end{tabular}


Table 3.11 presents the pairwise two-way interaction comparisons between type of filters and driving conditions for midpoint particle sizes between 335 and 8,962.1 nanometers. The mean filter efficiency of all interactions ranged from $92.4 \%$ for the interaction between filter 5 and city driving and $50.2 \%$ for the interactions between filter 3 and high speed highway driving. These trends were the same as those observed for particle sizes between 11.5 and 273.8 nanometers. In addition, Table 3.11 shows which of these interactions were significantly difference. For example, the interactions between filter 5 and city driving was not different from the interaction between filter 2 and city driving. Also, the interaction between filter 2 and city driving was not significantly different from the interaction between filter 4 and city driving. From the Table 3.11, the mean efficiency of all filters during driving in the city were higher than those observed with low and high speed driving interactions with the filters. For instance, the efficiency of the interaction between filter 3 and city driving was $79.5 \%$, which was much higher than the interaction between filter 3 and low and high speed which were $57.7 \%$ and $50.2 \%$, respectively. 
Table 3. 11 Mean efficiency\% among two way interaction between type of filters and driving conditions

\begin{tabular}{|c|c|c|c|c|c|c|c|c|c|}
\hline Interaction & Mean Efficiency & \multicolumn{8}{|c|}{ Grouping ${ }^{1}$} \\
\hline City,F5 & $92.4 \%$ & A & & & & & & & \\
\hline City,F2 & $90.7 \%$ & A & B & & & & & & \\
\hline City,F4 & $88.8 \%$ & & B & $\mathrm{C}$ & & & & & \\
\hline low speed,F5 & $88.6 \%$ & & B & $\mathrm{C}$ & & & & & \\
\hline high speed,F5 & $88.3 \%$ & & B & $\mathrm{C}$ & $\mathrm{D}$ & & & & \\
\hline low speed,F4 & $88.3 \%$ & & B & $\mathrm{C}$ & D & & & & \\
\hline high speed,F4 & $85.4 \%$ & & B & $\mathrm{C}$ & D & $\mathrm{E}$ & & & \\
\hline City,F1 & $83.3 \%$ & & & $\mathrm{C}$ & D & $\mathrm{E}$ & $\mathrm{F}$ & & \\
\hline low speed,F2 & $83.0 \%$ & & & $\mathrm{C}$ & D & $\mathrm{E}$ & $\mathrm{F}$ & & \\
\hline high speed,F2 & $82.6 \%$ & & & & D & $\mathrm{E}$ & $\mathrm{F}$ & & \\
\hline City,F3 & $79.5 \%$ & & & & & $\mathrm{E}$ & $\mathrm{F}$ & & \\
\hline low speed,F1 & $69.8 \%$ & & & & & & & G & \\
\hline low speed,F3 & $57.7 \%$ & & & & & & & G & \\
\hline high speed,F1 & $56.3 \%$ & & & & & & & G & \\
\hline high speed,F3 & $50.2 \%$ & & & & & & & & $\mathrm{H}$ \\
\hline
\end{tabular}

\subsubsection{Particle size distributions}

\section{City Driving - Low Fan Level with Recirculation ON}

In this study, the particle size distribution was measured by two devices. The first device, the NanoScan measured particle sizes in 12 channels with midpoints ranging between 11.5-273.8 $\mathrm{nm}$. The second device, the OPS, measured particles in 16 channels ranging between 335-8,962.1 nm. Figure 3.9 shows the efficiency for all types of filters under a condition of low fan level with recirculation on, as a function of particle size.

As shown in Figure 3.9, the majority of filters had lowest efficiency in the size range from 154 to $335 \mathrm{~nm}$. In more detail, for example, for filter 3 the lowest efficiency, $64 \%$ to $70 \%$, occurred between particle sizes of 154-335 nm. The filter efficiencies for these particle sizes were generally the lowest range of efficiency observed for all the filters. However, the highest range of efficiency 
in the same size range occurred in filter 4 , which had the efficiency range between $78 \%$ to $92 \%$, except in channel 205.4 in which the efficiency was below 50\%. These results were consistent with the research of William C. Hinds (1982), that the minimum efficiency of all filters usually occurred in the size range between 50 and $500 \mathrm{~nm}$. 
Figure 3. 9 Particle size distribution (City - Low Fan Level and Recirculation ON)
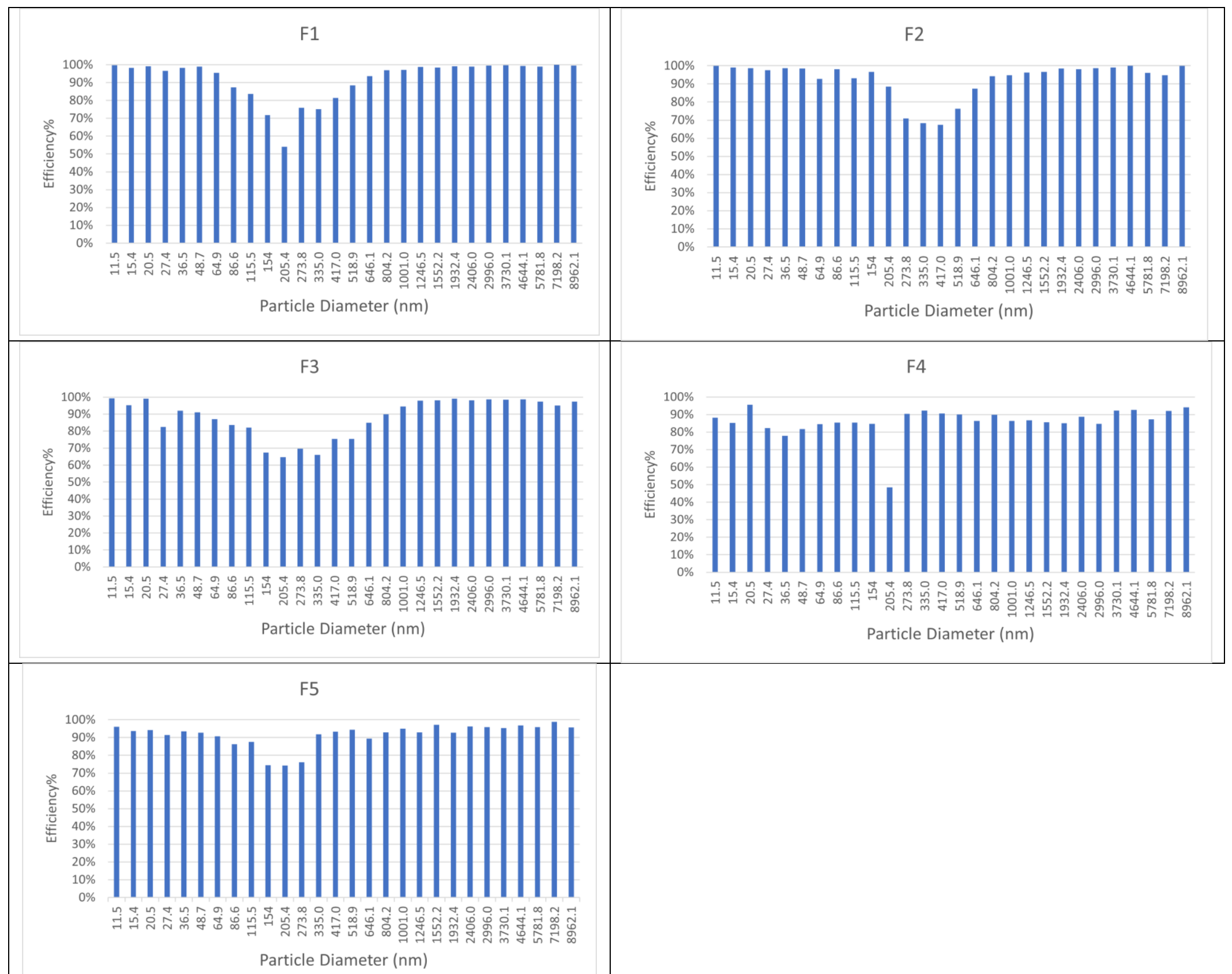


\section{Low Speed - High Fan Level with Recirculation Off}

Figure 3.10 shows that the efficiencies for highway driving with a speed of 50 miles per hour with a high fan level add recirculation off. Much lower filter efficiencies were observed as compared to driving in a city. In low speed driving with a high fan and recirculation off, the particle diameter range between $64.9-335 \mathrm{~nm}$ had the lowest efficiencies ranging between $42 \%$ to $74 \%$. This observation was found for all filters except filter 3. For filter 3, the particle diameter range between 64.9-417 $\mathrm{nm}$ registered as the lowest efficiency, measuring below 50\%, and it reached as low as $20 \%$ at the particle size of $273.8 \mathrm{~nm}$. 


\section{High Speed - High Fan Level with Recirculation Off}

In this study, the majority of filters, tested at a high driving speed (70 mile per hour) with a high fan level and recirculation off showed much lower efficiency compared to other conditions. The reason behind this was when the recirculation was off, the duct system of the air conditioner was open which allowed more aerosol particles to enter the car cabin, also as the speed of the car increased the chances of unwanted air to flow through the filters increased. As shown in Figure 3.11, the particle diameter range of filter 3, 64.9-335 nm, showed the lowest efficiency, measuring less than $47 \%$, reaching as low as $22 \%$ for the particle size range between $154-273.8 \mathrm{~nm}$. On the other hand, the efficiency of filter 4 was above $70 \%$, except in the particle diameter range between $115.5-335 \mathrm{~nm}$, in which the efficiency was below 61\%. Overall, the lowest efficiencies for most filters were observed to occur between $86.6-335 \mathrm{~nm}$. These results are consistent with the research of William C. Hinds (1982), that the minimum efficiency usually in the size range between 50 and $500 \mathrm{~nm}$. 
Figure 3. 11 Particle size distribution (High Speed - High Fan Level and Recirculation Off)

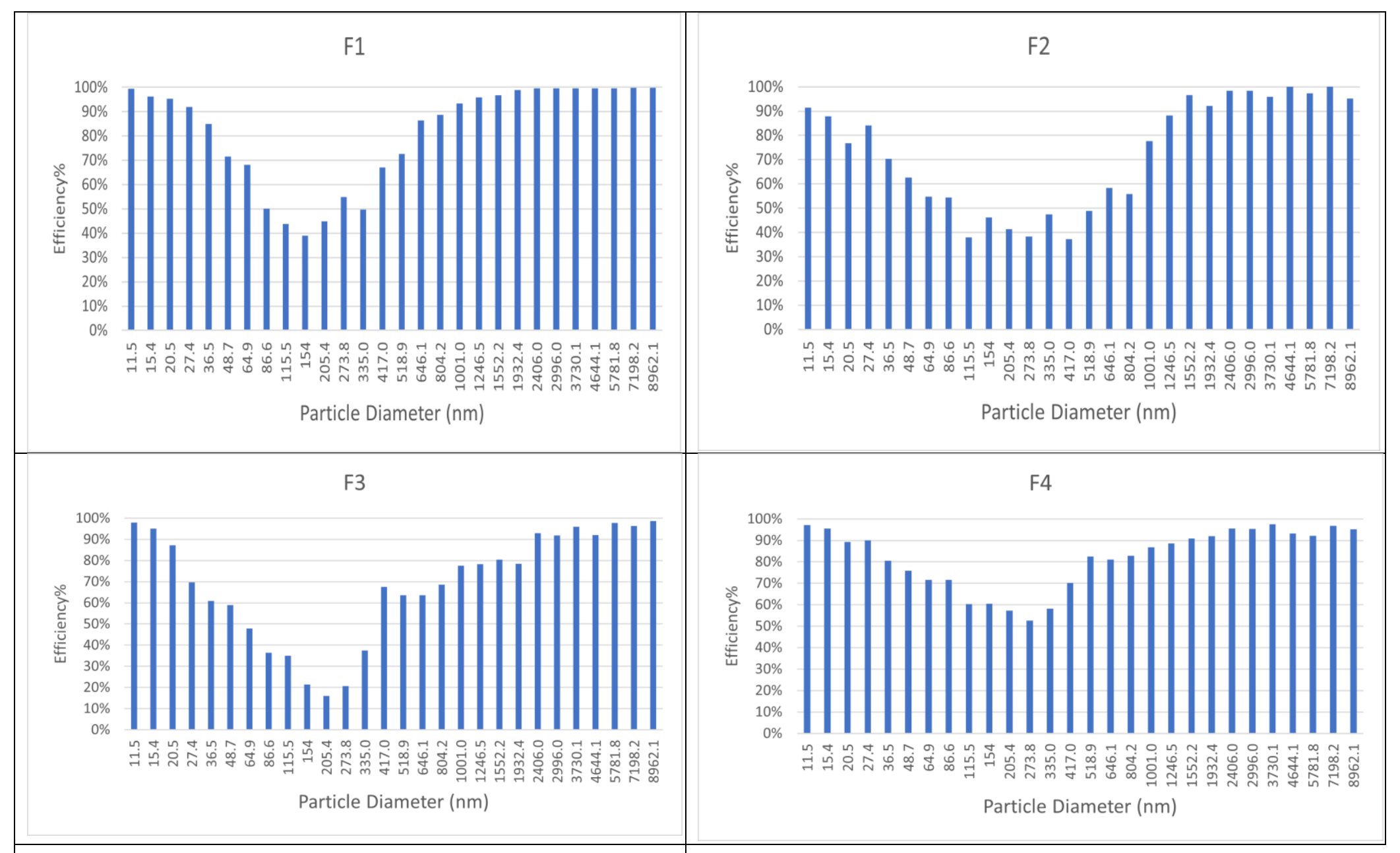

F5

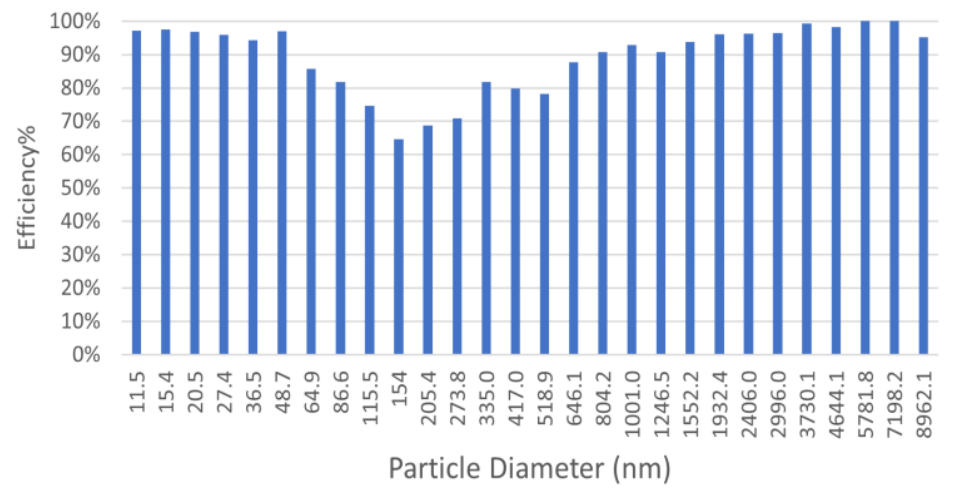




\section{- City Driving - Low Fan Level and Recirculation ON}

According to ANSI/ASHRAE Standard 52.2-2017, filters should maintain efficiency in the range of $30 \%$ to $70 \%$ for particles measuring in the 300 to $400 \mathrm{~nm}$ diameter size range, and more than $90 \%$ efficiency for particle in the 7,000 to $10,000 \mathrm{~nm}$ diameter size range. The results of all filters' efficiency at low fan level with recirculation on were consistent with this standard.

\section{- $\quad$ Low Speed - High Fan Level and Recirculation Off}

From the results of low speed highway driving with high fan level and recirculation off all filters were consistent with the Standard of ASHRAE 2017, except filter 3 which showed an efficiency that was lower than $30 \%$ in the range size between 300 and $400 \mathrm{~nm}$. However, it did have higher than $90 \%$ of efficiency for the range sizes greater than $7,000 \mathrm{~nm}$.

\section{- $\quad$ High Speed - High Fan Level and Recirculation Off}

For filter 3, the efficiency observed with high speed driving with high fan level and recirculation off was less than 30\%, for size range between 300 and $400 \mathrm{~nm}$. This efficiency was lower than the ASHRAE Standard. However, all the rest of the filters' efficiencies were higher than $30 \%$.

The three figures above demonstrate that small particles were captured by the filtering mechanisms of diffusion, while the large particles were captured by interception and impaction. Overall, it was obvious that the diffusion decreased when the particle diameter increased; likewise, the interception and impaction increased when the particle diameter increased. The lowest filter efficiency was always observed at the cross over from filtration by interception and impaction and filtration by diffusion. According to Mao (2016), the primary filtration mechanism for small particles is diffusion and the filter in that region is efficient. Mao added that the minimum filter efficiency occurs when the particles are large for diffusion and small for interception effect. Also, 
in the region of interception and impaction, the size of particles become larger and the filter usually is more efficient.

\subsubsection{Filters challenge Coronavirus}

According to the World Health Organization (WHO), 2020, the virus particle of COVID19 has a diameter ranging between 60 to $140 \mathrm{~nm}$, while the range in size of most viruses is between 20 to $500 \mathrm{~nm}$. Also, the WHO, 2020 mentioned that the most likely form of spread for the COVID19 is by droplets carried in the air which has a diameter ranging between 5 to 10 micrometers. Figures 3.12-3.15 show the performances of the filters if they were challenged by viruses' particles in these size ranges.

Figures 3.12 and 3.13 show the performance of filter 3 and filter 5 for city driving with low fan level and recirculation on. In the COVID-19 virus size range between $60-140 \mathrm{~nm}$, the efficiency of filter 3 ranged between $67 \%$ and $87 \%$. However, the efficiency range of filter 5 was between $74 \%$ and $90 \%$. In addition, the efficiency range of filter 3 was between $75 \%$ and $99 \%$ for size range typical to most viruses, which is 20 to $500 \mathrm{~nm}$. The efficiency of filter 5 under the same parameters was between $74 \%$ to $94 \%$. Both filters had efficiencies ranging between $95 \%$ and $99 \%$ for the droplet particle range. 


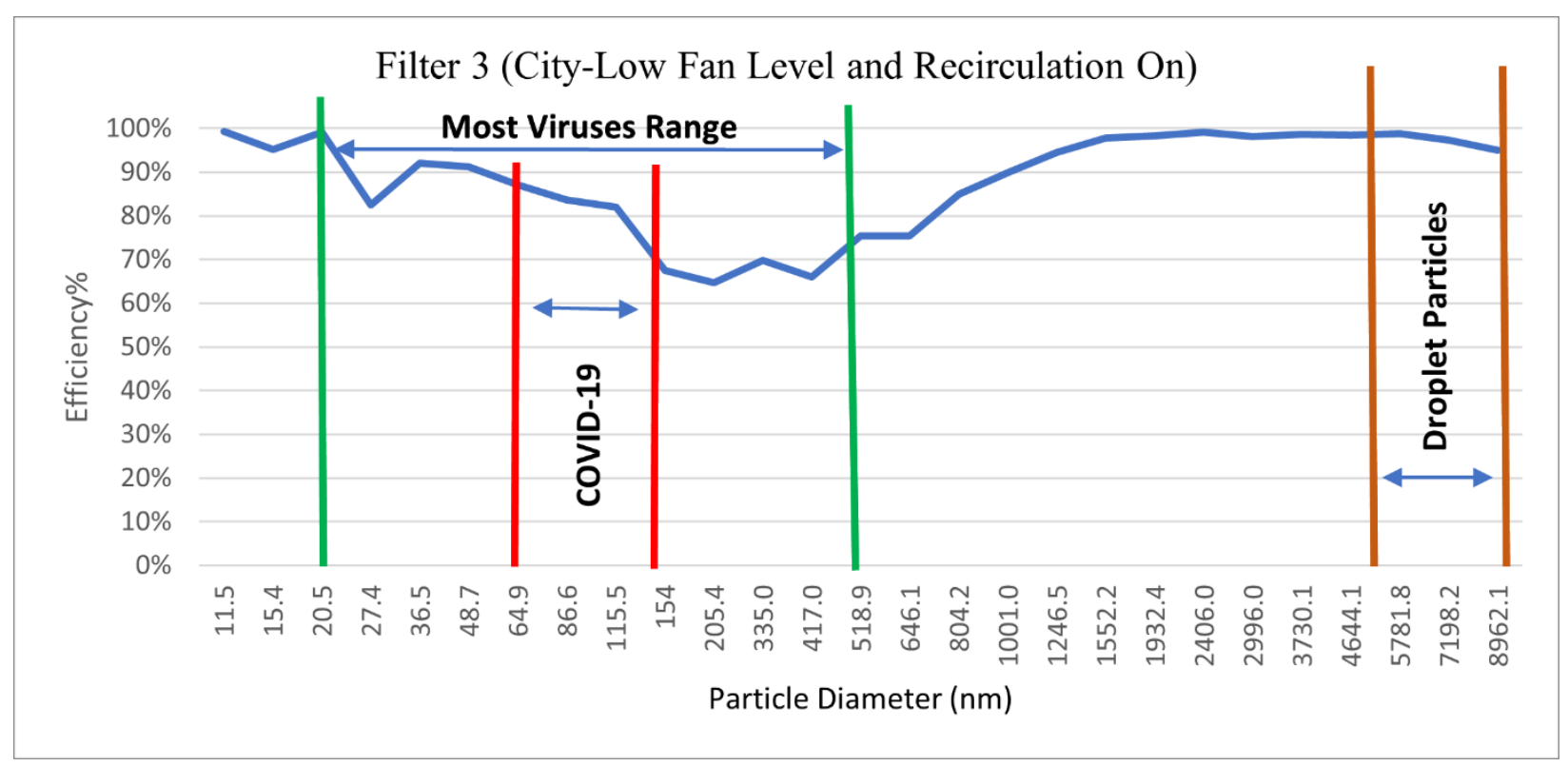

Figure 3. 12 Filter 3 Challenge COVID-19 (City- Low Fan and Recirculation On)

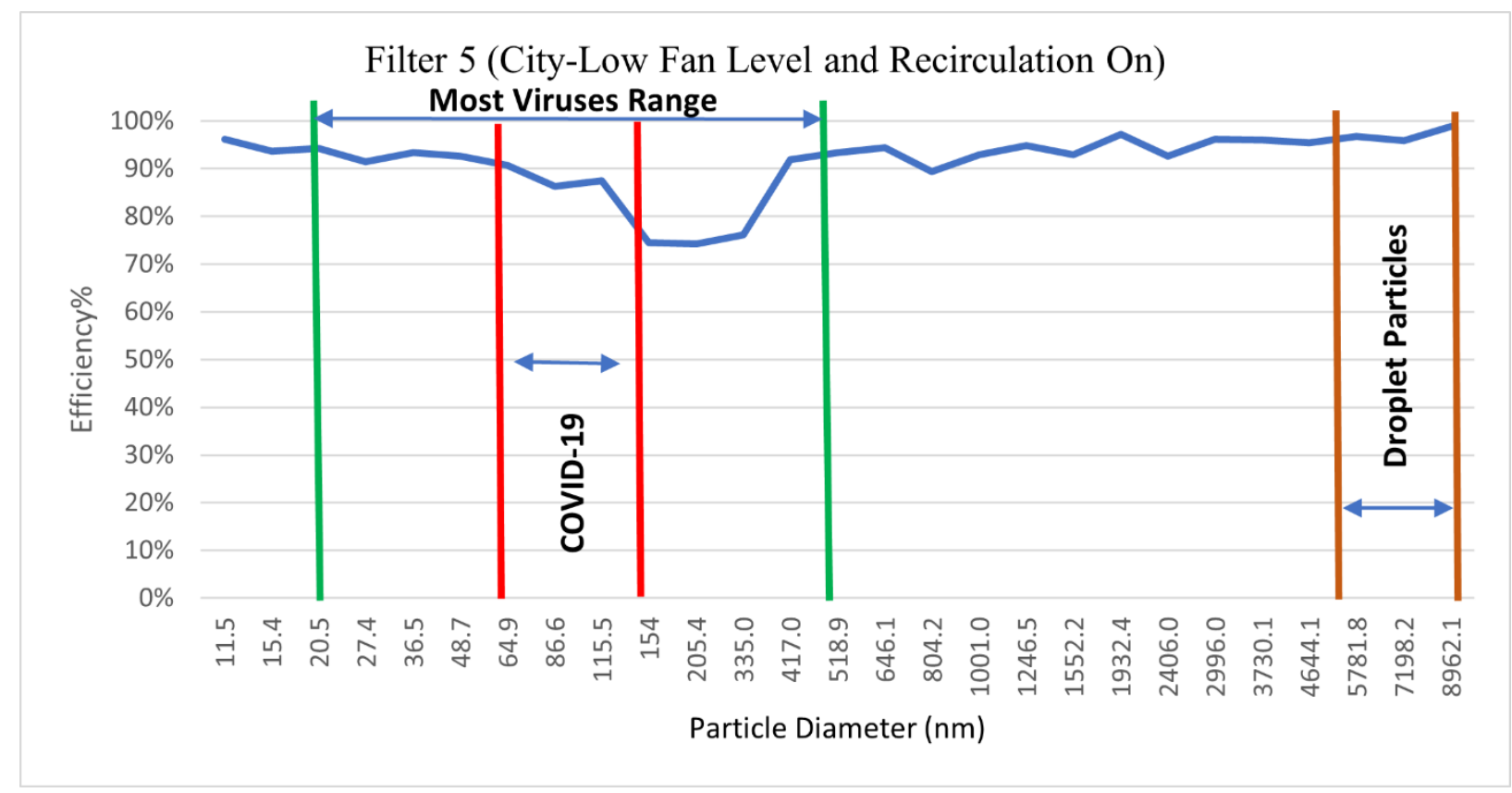

Figure 3. 13 Filter 5 Challenge COVID-19 (City- Low Fan and Recirculation On)

Figures 3.14 and 3.15 show the performance of filter 3 and filter 5 when driven on a highway at 70 miles per hour with high fan level and recirculation off. The efficiency of filter 3 
for the COVID-19 virus size range was between $21 \%$ and $48 \%$, which was much lower than the efficiency measured for city driving. Filter 5 had an efficiency between $52 \%$ and $80 \%$. The figures showed that the efficiency of filter 3 was between $16 \%$ and $87 \%$, while filter 5 had an efficiency of $52 \%$ and $86 \%$ for the particle size range that most viruses. For the range of the droplet particle sizes both filters had efficiencies between $93 \%$ and $97 \%$.

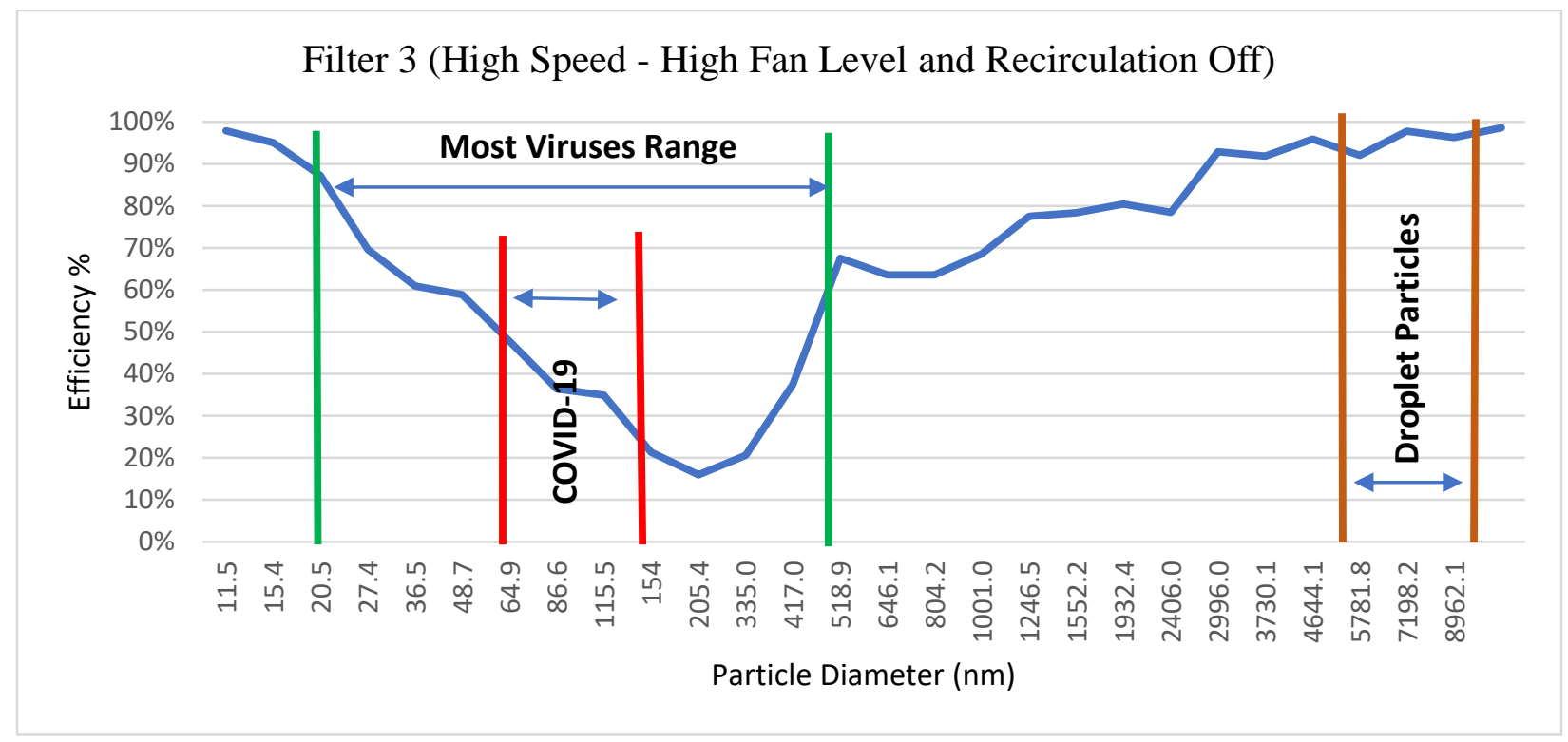

Figure 3. 14 Filter 3 Challenge COVID-19 (High Speed with High Fan Level and Recirculation Off) 


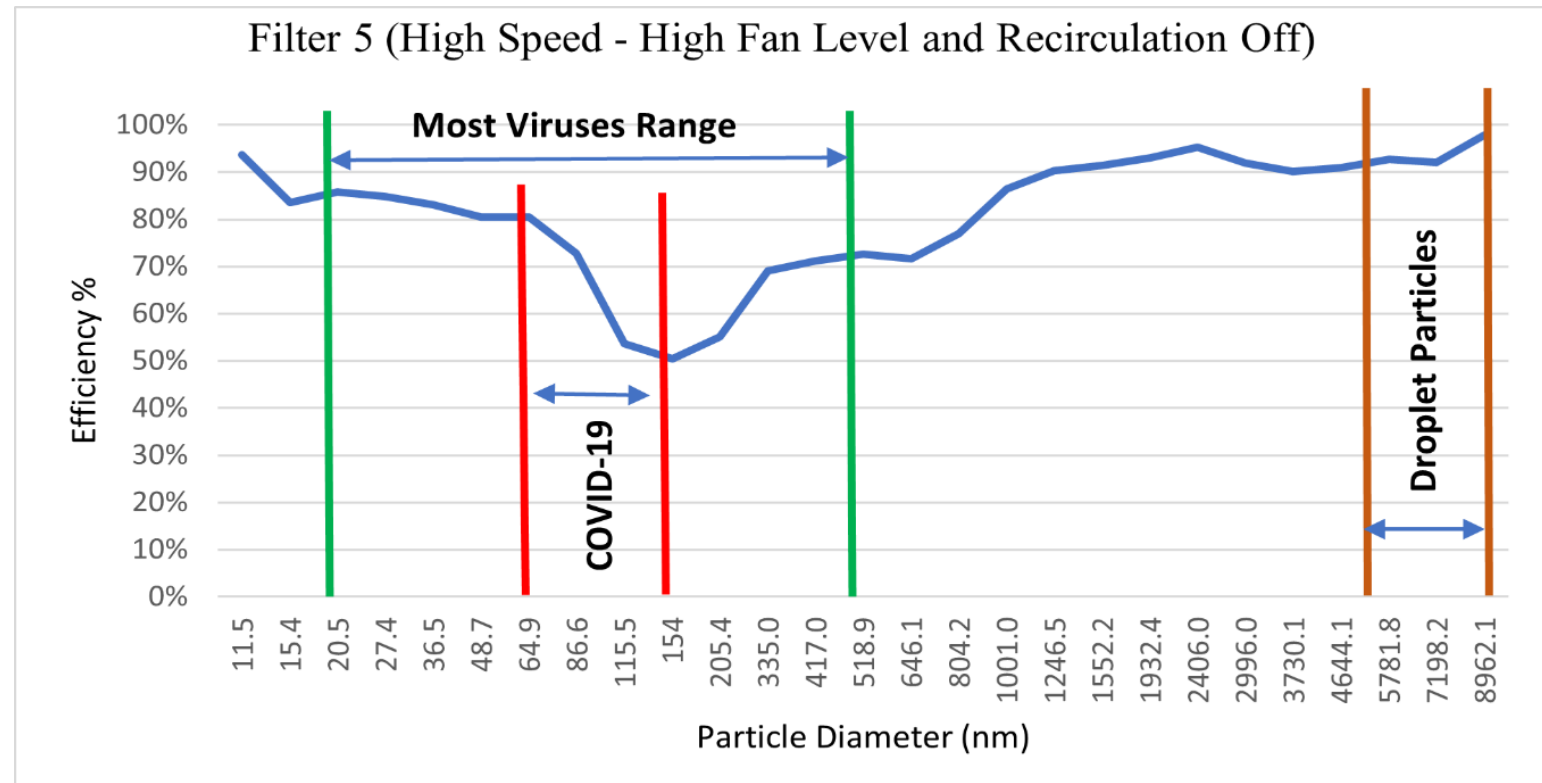

Figure 3. 15 Filter 5 Challenge COVID-19 (High Speed with High Fan Level and Recirculation Off)

\subsubsection{Filters challenge Humidity}

Filter 5 was tested under three driving conditions, two fan speeds (recirculation mode), and two levels of humidity. This section focuses on filter testing at two levels of humidity (51\%-62\%) and $(\geq 93 \%)$. The mean efficiency of filter 5 was tested at these humidity levels to see if it was different from prior results.

\section{Results for Midpoint Particles Ranging from 11.5 to 273.8 nanometers}

Table 3.12 shows the mean efficiency for midpoint particles ranging in size from 11.5 to 273.8 nanometers under different driving, fan, and humidity conditions. High humidity in this experiment, $\geq 93 \%$ resulted in lower mean efficiency as compared to a humidity the level of $51 \%$ $62 \%$. For example, at $51 \%-62 \%$ humidity the mean efficiency of city driving with high fan level and recirculation off was $80.8 \%$; on the other hand, the efficiency at $\geq 93 \%$ humidity was $73.7 \%$. 
Table 3. 12 Mean Filter Efficiency\% for Particles Ranging from 11.5 to 273.8 nanometers Under Different Humidity

\begin{tabular}{|l|c|c|c|}
\hline \multirow{2}{*}{ Driving Conditions } & Fan Speeds (Rec Mode $\left.{ }^{\mathbf{1}}\right)$ & Humidity\% & $\begin{array}{c}\mathbf{1 1 . 5} \text { to 273.8 } \\
\text { Nanometer Particle } \\
\text { Efficiency }\end{array}$ \\
\hline \multirow{2}{*}{ City } & High Fan Level (Rec on) & $(51 \%-62 \%)$ & $96.6 \%$ \\
\cline { 2 - 4 } & High Fan Level (Rec off) & $(51 \%-62 \%)$ & $80.8 \%$ \\
\hline \multirow{2}{*}{ Highway (Low Speed) } & High Fan Level (Rec on) & $(51 \%-62 \%)$ & $88.8 \%$ \\
\cline { 2 - 4 } & High Fan Level (Rec off) & $(51 \%-62 \%)$ & $79.2 \%$ \\
\hline \multirow{2}{*}{ Highway (High Speed) } & High Fan Level (Rec on) & $(51 \%-62 \%)$ & $86.0 \%$ \\
\cline { 2 - 4 } City & High Fan Level (Rec off) & $(51 \%-62 \%)$ & $72.2 \%$ \\
\hline \multirow{2}{*}{ Highway (Low Speed) } & High Fan Level (Rec on) & $(\geq 93 \%)$ & $88.8 \%$ \\
\cline { 2 - 4 } & High Fan Level (Rec off) & $(\geq 93 \%)$ & $73.7 \%$ \\
\cline { 2 - 4 } Highway (High Speed) & High Fan Level (Rec on) & $(\geq 93 \%)$ & $82.5 \%$ \\
\cline { 2 - 4 } & High Fan Level (Rec off) & $(\geq 93 \%)$ & $71.4 \%$ \\
\hline & High Fan Level (Rec off) & $(\geq 93 \%)$ & $81.5 \%$ \\
\hline
\end{tabular}

${ }^{1}$ Rec Means recirculation air mode

As shown in table 3.13, fan speeds (two levels), driving condition (three levels), and humidity (two levels), had a significant effect on the mean efficiency of filter 5 ( $\mathrm{P}<0.05)$. However, the interactions between driving conditions and humidity and the interaction between fan speed and humidity were not significant.

Table 3. 13 Three-way ANOVA results for the mean Efficiency for particles ranging from 11.5 to 273.8 nanometers as a function of type of cabin air filter, fan speeds (recirculation mode), and humidity

\begin{tabular}{|l|c|c|c|c|}
\hline Source & DF & Sum of Squares & F Ratio & Prob > F \\
\hline Fan Speeds (Rec Mode ${ }^{1}$ ) & 1 & 0.039 & 565.364 & $<.0001^{*}$ \\
\hline Driving Conditions & 2 & 0.002 & 16.905 & $0.0112^{*}$ \\
\hline Humidity\% & 1 & 0.020 & 283.471 & $<.0001^{*}$ \\
\hline Driving Conditions*Humidity\% & 2 & 0.0001 & 0.872 & 0.4848 \\
\hline Fan Speeds (Rec Mode)*Humidity\% & 1 & 0.0001 & 2.498 & 0.1891 \\
\hline
\end{tabular}

${ }^{1}$ Rec Means recirculation air mode

In Table 3.14, the pairwise multiple comparison was applied, in order to obtain a complete description of the two levels of humidity. The analysis showed that the mean filter efficiency of 
$83.9 \%$ at a humidity level of $51 \%-62 \%$ was significantly higher than the mean efficiency at a humidity level $\geq 93 \%$.

Table 3. 14 Pairwise multiple comparisons: Mean efficiency for particles ranging from 11.5 to 273.8 nanometers among two levels of humidity

\begin{tabular}{|l|c|c|}
\hline Level & Mean Efficiency\% & Grouping $^{1}$ \\
\hline $\mathbf{( 5 1 \% - 6 2 \% )}$ & 83.9 & A \\
\hline $\mathbf{( \geq 9 3 \% )}$ & 77.9 & B \\
\hline
\end{tabular}

${ }^{1}$ Means with different letters are significantly different

\section{Results for Midpoint Particles Ranging from 335 to 8,962.1 nanometers}

Table 3.15 shows the mean filter efficiency achieved with particles ranging from 335 to 8,962.1 nanometer under different driving, fan, and humidity conditions. The table shows that the mean filter efficiency of all conditions under high humidity levels were always much lower than the mean efficiency with 51\%-62\% humidity. For instance, the efficiency at high speed highway driving with a high fan level and 51\%-62\% humidity was $92.4 \%$, while the efficiency at humidity $\geq 93 \%$ was $85.9 \%$. The mean efficiency decreased by $6.5 \%$ with the increased humidity level.

Table 3. 15 Mean Efficiency for Particles Ranging from 335 to 8,962.1 nanometers Under Different Humidity Under Different Humidity

\begin{tabular}{|l|c|c|c|}
\hline \multirow{2}{*}{ Driving Conditions } & Fan Speeds (Rec Mode & Humidity\% & $\begin{array}{c}\text { 335 to 8,962.1 } \\
\text { Nanometer Particle } \\
\text { Efficiency }\end{array}$ \\
\hline \multirow{2}{*}{ City } & High Fan Level (Rec on) & $(51 \%-62 \%)$ & $95.2 \%$ \\
\cline { 2 - 4 } & High Fan Level (Rec off) & $(51 \%-62 \%)$ & $90.2 \%$ \\
\hline \multirow{2}{*}{ Highway (Low Speed) } & High Fan Level (Rec on) & $(51 \%-62 \%)$ & $93.5 \%$ \\
\cline { 2 - 4 } & High Fan Level (Rec off) & $(51 \%-62 \%)$ & $85.2 \%$ \\
\hline \multirow{2}{*}{ Highway (High Speed) } & High Fan Level (Rec on) & $(51 \%-62 \%)$ & $92.4 \%$ \\
\cline { 2 - 4 } & High Fan Level (Rec off) & $(51 \%-62 \%)$ & $81.3 \%$ \\
\hline \multirow{2}{*}{ City } & High Fan Level (Rec on) & $(\geq 93 \%)$ & $90.5 \%$ \\
\cline { 2 - 4 } & High Fan Level (Rec off) & $(\geq 93 \%)$ & $87.4 \%$ \\
\hline \multirow{2}{*}{ Highway (Low Speed) } & High Fan Level (Rec on) & $(\geq 93 \%)$ & $86.6 \%$ \\
\cline { 2 - 4 } & High Fan Level (Rec off) & $(\geq 93 \%)$ & $79.7 \%$ \\
\hline \multirow{2}{*}{ Highway (High Speed) } & High Fan Level (Rec on) & $(\geq 93 \%)$ & $85.9 \%$ \\
\cline { 2 - 4 } & High Fan Level (Rec off) & $(\geq 93 \%)$ & $76.1 \%$ \\
\hline
\end{tabular}

${ }^{1}$ Rec Means recirculation air mode 
The three-way ANOVA analysis, shown in Table 3.16, found significant effects for fan condition and humidity levels on the mean efficiency of filter $5(\mathrm{P}<0.05)$. Driving condition did not have a significant effect on mean filter efficiency $(\mathrm{P}>0.05)$. The interaction between driving conditions and humidity and the interaction between fan speeds and humidity were not significant.

Table 3. 16 Three-way ANOVA results for the Filter Efficiency of 335-8,962.1 Nanometer Particles as a function of type of cabin air filter, fan speeds, and humidity

\begin{tabular}{|l|c|c|c|c|}
\hline Source & DF & Sum of Squares & F Ratio & Prob > F \\
\hline Fan Speeds (Rec Mode ${ }^{1}$ ) & 1 & 0.009 & 15.784 & $0.0165^{*}$ \\
\hline Driving Conditions & 2 & 0.006 & 4.857 & 0.0851 \\
\hline Humidity\% & 1 & 0.029 & 47.937 & $0.0023^{*}$ \\
\hline Fan Speeds (Rec Mode)*Humidity\% & 1 & 0.0003 & 0.004 & 0.9478 \\
\hline Driving Conditions*Humidity\% & 2 & 0.0001 & 0.150 & 0.8647 \\
\hline \multicolumn{4}{|l}{${ }^{1}$ Rec Means recirculation air mode }
\end{tabular}

As shown in table 3.17, the pairwise multiple comparison of the two levels of humidity showed that humidity level had a significant difference. The mean efficiencies of low and high humidity levels were $89.5 \%$ and $84.7 \%$, respectively.

Table 3. 17 Pairwise multiple comparisons: Mean efficiency of 335-8,962.1 Nanometer Particles among two levels of humidity

\begin{tabular}{|l|c|c|}
\hline Level & Mean Efficiency\% & Grouping $^{\mathbf{1}}$ \\
\hline $\mathbf{( 5 1 \% - 6 2 \% )}$ & 89.5 & $\mathrm{~A}$ \\
\hline $\mathbf{( \geq 9 3 \% )}$ & 84.7 & $\mathrm{~B}$ \\
\hline
\end{tabular}

For midpoint particle size ranging from 11.5-273.8 nanometer and particle sizes ranging from 335-8,962.1 nanometer, changes in humidity level resulted in significant changes in mean filtration efficiency. The results showed that the mean filtration efficiency through the electret filter (HEPA) decreased with increasing humidity level. According to Yang (2007), The main reason behind that the water molecules could reduce the ions and electrons on the electret fibers, and that leads to a reduction of the fiber surface charge with high levels of humidity. Also, the 
high level of humidity tends to dissipate the charge carried by the aerosol particles, which removes the advantage of the electret filter (HEPA) to capture aerosols carrying a charge. These results are consistent with the research of Yang et al. (2007). They found that when the humidity was increased from $30 \%$ to $70 \%$, the efficiencies decreased from $83 \%$ to $73 \%$, respectively. In addition, moisture condensation on hydroscopic increases the particle sizes, and that leads to increased efficiency from mechanical capture mechanisms. On the other hand, the efficiency from electrostatic capture mechanisms decreases with a high humidity level (Montgomery et al, 2015).

\subsection{Conclusion}

In the road study, the measurement of midpoint particle concentrations in size ranges of 11.5-273.8 nanometers and 335-8,962.1 nanometers was completed by using the, NanoScan and OPS. The results of the mean efficiency data analysis found that the independent factors, of driving condition, fan speeds (recirculation mode), and type of filter, had significant influence on filter efficiency. Two-way interactions between these factors also produced significant differences in the mean efficiency, for example the interaction between fan speeds (recirculation mode) and type of filters. In addition, the mean efficiency of city driving under different fan speeds always resulted in higher filter efficiency in comparison to driving on a highway. The results of this study indicate that there is an inverse relationship between the speed of car and mean filter efficiency, that is the mean filter efficiency decreased when car speed increased. For example, for 11.5-273.8 nanometer particles the mean efficiency of filter 2 at a velocity of 50 miles per hour with low fan level and recirculation on was $64.4 \%$, while the mean efficiency dropped to $59.0 \%$ at a speed of 70 miles per hour. The mean filter efficiency was also affected by recirculation mode. The mean efficiency for all types of filters was higher with recirculation on. 
The particle size distribution analysis found that the majority of filters had the lowest efficiency at the particle diameter range between $64.9-374 \mathrm{~nm}$. These results were consistent with the research of Hinds (1982), which presented that the minimum efficiency occurred in the size range 50-500 $\mathrm{nm}$. In addition, the humidity level affected the mean efficiency. The two levels of humidity used with filter 5 showed that the mean efficiency decreased when the humidity level increased. Over the midpoint particle size range of 11.5 to $8,962.1 \mathrm{~nm}$, filter 5 had the best mean filter efficiency compared to the other filters. On other hand, filter 3 had the lowest mean filter efficiency performance over this particle size range.

COVID-19 is reported to have a size range between 60-140 $\mathrm{nm}$. Over this size range, filter 5 had efficiency above $75 \%$ during city driving, but the efficiency dropped to $60 \%$ at high speed driving. In contrast, the efficiency of filter 3 over this particle size range during in city driving was $67 \%$ and dropped to $21 \%$ with high speed driving. Based on this study's results, filter 5 and other filters manufactured like it are recommended as minimum filtration levels that should be used in school buses, taxis, Uber, and industrial vehicles to provide cabin occupants with filtered air.

\subsection{Limitation}

This study was conducted in Morgantown WV, which is considered a small city. This study could provide more useful details if it were repeated in large cities, which likely have heavier traffic than Morgantown. A heavy traffic in large cities could increase the particle concentration in the air. The sample time in the road study was only 10 minutes for each condition. Future studies need to adopt longer sampling times to examine the effects of loading on the efficiency of filters. 


\section{References}

ASHRAE, Standard 52.2 (2017). Method of Testing General Ventilation Air-Cleaning Devices for Removal Efficiency by Particle Size. American Society of Heating, Refrigerating and Air-Conditioning Engineers, Inc.

Caterpillar Inc. (2020). 327-6618. Retrieved from https://parts.cat.com/en/catcorp/327-6618

Cecala, B.A. et al. (2016). Comparison of MERV 16 and HEPA filters for cab filtration of underground mining equipment. Mining engineering 68(8), 50-58. Retrieved from https://www.ncbi.nlm.nih.gov/pmc/articles/PMC4982552/

Colbeck, I \& Lazaridis, M. (2014). Aerosol science: Technology and applications. Hoboken, NJ: John Wiley \& Sons.

Dorman, G.R. (2014). Dust control and air cleaning: International series of monographs in heating, ventilation, and refrigeration. Amsterdam: Elsevier.

Freudenberg Filtration Technologies. (2020). Cabin filters. Retrieved from https://freudenbergfilter.com.au/industrial-filtration/products/cabin-air-filters

Grady, M. et al. (2013). Vehicle Cabin Air Quality with Fractional Air Recirculation. SAE Technical Paper 2013-01-1494. Retrieved from https://doi.org/10.4271/2013-01-1494.

He, X. et al. (2016). Effects of relative humidity and particle type on the performance and service life of automobile cabin air filters. Aerosol science and Technology 50(4), 542-554. 4http://dx.doi.org/10.1080/02786826.2016.1167832.

Helfgott, C.D. (2020). Respiratory transmission of SARS-Cov-2: What do we really know? Retrieved from https://www.infectiousdiseaseadvisor.com/home/topics/covid19/respiratory-transmissionof-covid19-coronavirus/ 
Hinds, W. C. (1982). Aerosol Technology: Properties, behavior, and measurement of airborne particles ( $2^{\text {nd }}$ ed.). New York: John Wiley \& Sons, Inc.

Hinds, et al. (2007). The Effect of Dust Loading on Penetration and Resistance of Glass Fiber Filters. Aerosol Science and Technology, 27:2, 162-173.

Hudda, N. et al. (2011). Vehicle and driving characteristics that influence in-cabin particulate number concentrations. Environmental science technology 45(20,), 8691-8697.

Hutten, M.I. (2007). Handbook of nonwoven filter media. Amsterdam: Elsevier

Interstate-guide. (2012). The source for interstate news, and information. Retrieved from https://www.interstate-guide.com/i-079/

J. Johansson, et al. (1999). PERFORMANCE OF AUTOMOTIVE CABIN AIR FILTERS.AIVC. https://www.aivc.org/resource/performance-automotive-cabin-air-filters

Jung, et al. (2017). Simultaneously reducing CO2 and particulate exposures via fractional recirculation of vehicle cabin air. Atoms Environ 160, 77-88.

Kim, et al. (2016). Performance of Electret Filters for Use in a Heating, Ventilation and Air Conditioning System and an Automotive Cabin against Combustion and $\mathrm{NaCl}$ Particles. Aerosol and Air Quality Research 16: 1523-1531.

Lee, S. \& Zhu, Y. (2014). Application of a high efficiency cabin filter for simultaneous mitigation of ultrafine particle and carbon dioxide exposures inside passenger vehicles. Environment science technology, 18(48), 2328-2335.

Montgomery, et al. (2015). Impact of Relative Humidity on HVAC Filters Loaded with Hygroscopic and Non-Hygroscopic Particles. Aerosol Science and Technology, 49:5, $322-331$. 
Mottrol International Inc. (2020). Filters series. Retrieved from http://mottrolusa.com/24746050-cabin-air-filter-inside-fits-for-doosan-dh220-7-dh225-7-dh150-7-dh300-7-dh330-7/

N. Mao. (2016). Advances in Technical Nonwoven: Nonwoven Fabric filters. Woodhead Publishing Series in Textiles, pp 273-310.

Papachristou, J.C. (2020). Introduction to mechanics of particles and systems. META Publishing.

Purchas, D. \& Sutherland, K. (2002). Handbook of filter media. Amsterdam: Elsevier.

Qi, C. et al. (2008). Laboratory and on-road evaluations of cabin air filters using number and surface area concentration monitors. Environmental science technology 42(11), 41284132.

Sager, U. (2012). Automotive air quality: Adsorption performance of a cabin air filter during a life cycle. Filtration and separation, 49(4), 38-41.

Sandvik AB. (2020). Maintenance kits. Retrieved from https://my.sandvik/maintenance-kits/

Sparks, T. \& Chase, G. (2013). Filters and filtration handbook. Oxford: Butterworth-Heinemann.

Statistical Analysis Software for Mac and Windows. (n.d.). Retrieved from https://www.jmp.com/en_us/offers/statistical-analysis-software.

Sutherland, S.K. \& Chase, G. (2011). Filters and filtration handbook. Amsterdam: Elsevier.

Tatiya, R.R. (2013). Surface and underground excavations: Methods, techniques, and equipment. CRC Press.

Tartakovsky, L. et al. (2013). In-vehicle particle air pollution and its mitigation. Atmospheric environment 64(2013), 320-328.

Vitali, S. \& De Mattia, G. (2020). Underground productivity. Retrieved from http://www.onsitenews.it/_upload/rivista/46.pdf 
World Health Organization. (2020). Modes of transmission of virus causing COVID-19:

Implications for IPC precaution: Scientific brief. Retrieved from

https://www.who.int/news-room/commentaries/detail/modes-of-transmission-of-virus-causingcovid-19-implications-for-ipc-precaution-recommendations

Xinjian He, Michael Yermakov, Tiina Reponen, Roy T. McKay, Kelley James and Sergey A. Grinshpun. Manikin-Based Performance Evaluation of Elastomeric Respirators Against Combustion Particles. Journal of Occupational and Environmental Hygiene, 2013. 10: $203-212$.

Xu, B., Chen, X., \& Xiong, J. (2016). Air quality inside motor vehicles' cabins. A review. Indoor and built environment, 27(4), 452-465.

Xu, B., Liu, S., \& Zhu, Y. (2010). Effects of vehicle cabin filter efficiency on ultrafine particle concentration ratios measured in-cabin and on-roadway. Aerosol science and technology, 45(2), 234-243.

Yang, et al. (2007). Aerosol penetration properties of an electret filter with submicron aerosols with various operating factors. Environmental Science and Health Part A 42, 51-57.

Zhou, Y.H. et al. (2011). New and advanced materials. Switzerland: Trans Tech Publications.

Zhao, X. et al. (2016). Slip-effect functional air filter for efficient purification of particulate matter 2.5. Scientific reports 6(35472). DOI: 10.1038/srep35472. 